\title{
ESPECTRÔMETRO DE MASSA POR TEMPO DE VÔO PARA ANÁLISE DE MACROMOLÉCULAS
}

Eduardo Luiz Augusto Macchione

SEI-IFUSP

305 MB 1072845

Orientador: Prof. Olacio Dietzsch
Tese de Doutoramento submetida ao Instituto de Física da Universidade de \$ắn Paulo

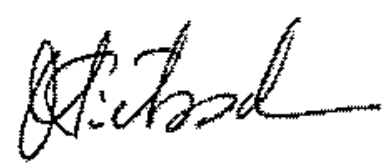

Banca examinadora:

Prof. Olacio Dietzsch Prof. Gerard Gerson Bezerra de Souza Prof. Manoel Tiago Freitas da Cruz Prof. Nison Dias Vieira Jr. Profa. Nobuko Ueta
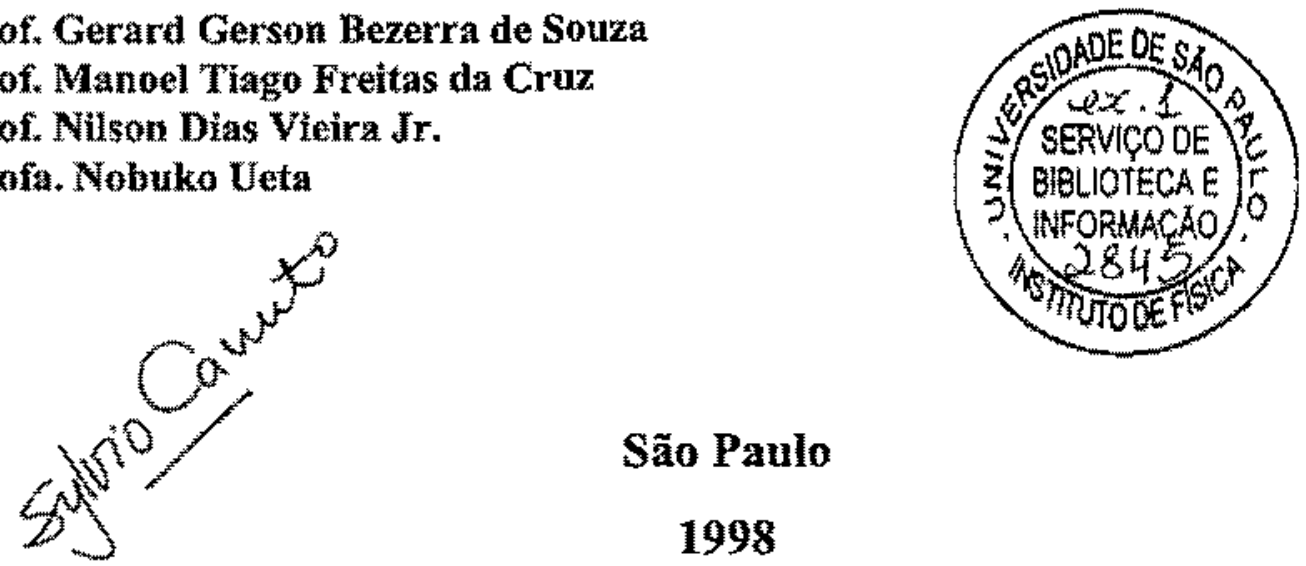

São Paulo 1998 


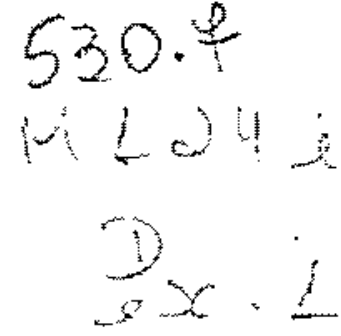

\section{FICHA CATALOGRÁFICA}

Preparada pelo Serviço de Biblioteca e Informação do Instituto de Física da Universidade de Säo Paulo

Macchione, Eduardo Luiz Augusto

Espectrómetro de Massa por Tempo de Vôo para Análise de Macromoléculas. São Paulo, 1998.

Tese (Doutoramento) Universidade de São Paulo. Instituto de Fisica - Departamento de Fisica Geral

Orientador: Prof. Dr. Olacio Dietzsch Area de Concentraçäo: Física Nuclear

Unitermos: 1. Espectrometria de Massa;

2. Tempo de Vôo; 3. Instrumentação; 4. Dessorçäo. 
aos mets pais e à Martinha 


\section{Agradecimentos}

Gostaria de expressar os meus agradecimentos a todas as pessoas que contribuiram para a realizaçâo deste trabalho, em particular,

ao Prof. Olacio Dietzsch, pela orientação e apoio durante as várias etapas deste trabalho,

ao Prof. Kiyomi Koide, pelas proveitosas e esclarecedoras discussöes, aos Profs. José Hiromi Hirata e Suzana Salem Vasconcelos, pelo apoio e participação,

a todos os funcionários do IFUSP, em especial ao Srs. Rubens Dismar Forcemo e Marcelino Alves, pelo suporte prestado,

à Marta Maria Cassiano, por sua extrema dedicaçâo e total envolvimento, aos amigos e colegas que, de alguma maneira, partíciparam e torceram para o sucesso deste projeto, e

ao PADCT/CNPq pelo apoio financeiro. 


\section{Resumo}

Um espectrômetro de massa por tempo de vôo foi projetado e construído. A técnica de Plasma Desorption e empregada para provocar a dessorção e ionização das moléculas da anrostra por colisöes com os produtos de fissão emitidos de uma fonte radioativa de ${ }^{252} \mathrm{Cf}$. O espectrổmetro encontra-se instalado no interior de uma câmara de våcuo, que permite a sua operaçăo a pressões da ordem de $10^{7}$ torr. Uma pré-têmara é utilizada para a manipulação e troca de até trểs amostras simultaneamente, sem a necessidade da abertura da cẳnara principal para a atmosfera, reduzindo o tempo de recuperação da pressão do sistema para inicio das análises. No tubo de vôo, que possui uma extensão de $111 \mathrm{~cm}$, encontra-se instalado um guia eletrostático de partículas, usado para aumentar a transmissäo dos ions secundarios até o sistema de deteç̧ão. Medidas foram feitas utilizando-se amostras-padrão para a caracterização do instrumento. Estudos também foram realizados sobre o comportamento da resolução e da eficiência de transmissão do aparelho em funçăo da tensão de acelerą̧ão dos íons secundários. Foi obtida uma resolução em massa de $m / \Delta m$ entre 1600 e 1800 para ions com massas em torno de 900 u.m.a. 


\begin{abstract}
A time-of-flight mass spectrometer was projected and constructex. The Plasma Desorpion technique is employed to desorb and ionize the molecules sample by collisions with fission fragments emitted from ${ }^{252} \mathrm{Cf}$ source. The spectrometer is placed inside a vacuum chamber, allowing operation at a pressure around of $10^{47}$ torr. A pre-chamber is used to insert three samples simultaneously into the mass spectrometar, without the need of opening the muin chamber to the atmosphere, reducing the recover time of the pressure system for the beginning of analyzes. Inside the flight tube (11 $\mathrm{cm}$ length) was installed an electrostatic particle guide, used to increase the secondary ton transmission to the detection system. Measurements using standard samples were done to characterize the apparatus performance. The instrument resolution and transmission efficiency were analyzed with respect to the secondary ion acceleration veltage. The mass resolution of $m / \Delta m$ from 1600 to 1800 for mass ions around 900 u.m. was obtained.
\end{abstract}




\section{INDICE}

1. Introdução ___ 6

2. Considerą̧ōes Iniciais _____ 8

2.1 Espectrometria de Massa

2.1.1 Fontes de lons _ _ _ _

2.1.2 Analisadores de Massa ___ _

2.2 Projeto do Espectrômetro de Massa por Tempo de Vồ 16

2.3 Dessorção Induzida por Lons Räpidos ___ 18

2.4 Fonte $d e^{252} \mathrm{Cf}$

3. Montagem do Espectrômetro de Massa por Tempo de Vồ ___ 24

3.) Sistema de Vácuo _ 24

3.2 Trocador de Anostras, Sigportes de Amostra e Fonte ${ }^{23} \mathrm{Cf}$

3.3 Tubo de Vô e Guia Eletrostático de Particulas __

3.4 Alinhamento do Sistema ___ 34

3.5 Sistema de Bombeamento ___ 35

4. Sistema de Aqquisição de Dados ___ 36

4.1 Eletrônica para Análise Temporal ___ 36

4.2. Ajuste da Eletrönica ....__ 39

4.3 Etetrônica para Análise de Amplitude de Pulsos ___

4.4 Sistema do Detecçäo de lons - Detectores Stop e \$tant___ 46

4.4,1 Detector de lons Secundários - Stop _ _ _ 49

4.4.2 Detector de Fragmentos de Fissãa - Stari__ 57

5. Caracterização do Espectrổmetro ___ 62

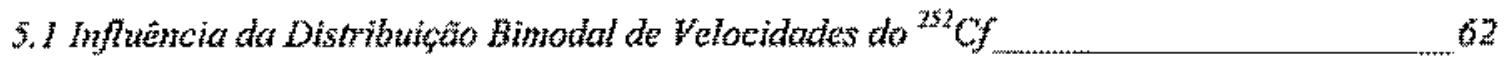

5.2 Equação de Tempo de Vào dos lons ___ 66

53 Calibraçäa em Massa __ _ 60

5.3.1 Amostra de Csi__....__

5.3 .2 Amostra de Fenilalarina____ 77

5.3.3. Amostras de Angiotesin I t L LHRH _ 82

5.4 Resolução do Espectrometro de Massa________ 85

5.4.1 Comportamento da Resoluçăo com a Tensão de Aceleraçăto ___ 87 
5.4.2 Resoluçaxio para regia do massas baixas a altas 92

5.5 Transmissäo e Guin Eletrostatico de Portïulas 97

\$.\$.1 Transmissão dos Ions Secundánios 97

5.5.2 Ouia Eletrostático de Particulas 103

6. Analise to Peptideo y-Giutamil-S-Metilcisteina 114

7. Conclusâes 118

8. Referências 121 


\section{INDICE DE FIGURAS}

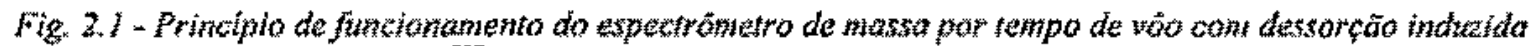

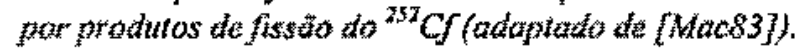

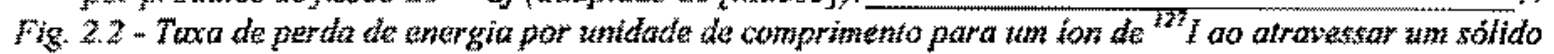

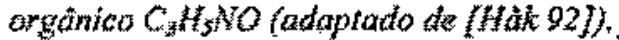

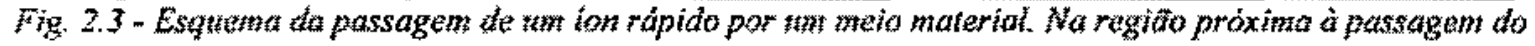

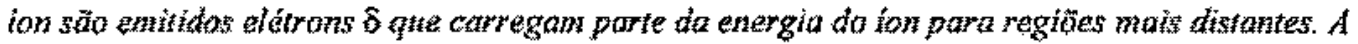

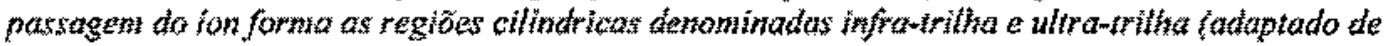
(HW

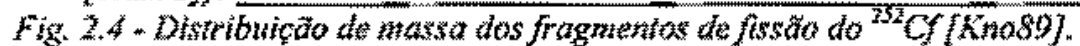

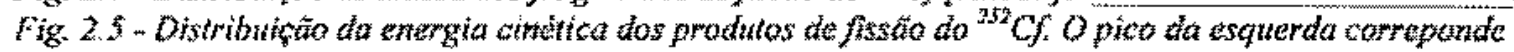
zas fragmentas pesados $e$ o da dirata aos leves [Knozyl.

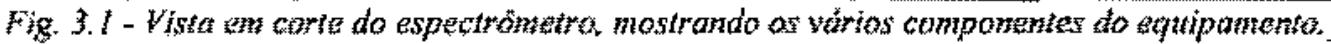

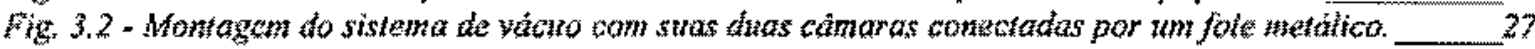

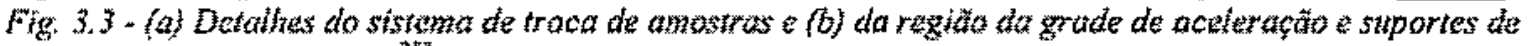

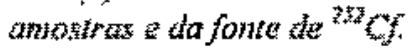

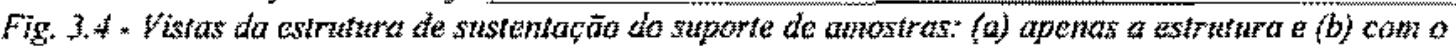
szonorte de amostros.

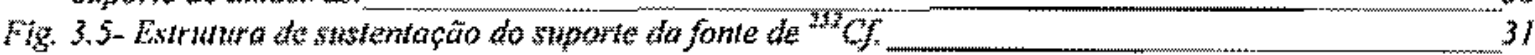

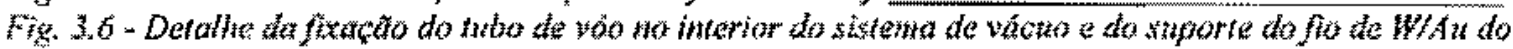
guin elurostatico de particulas.

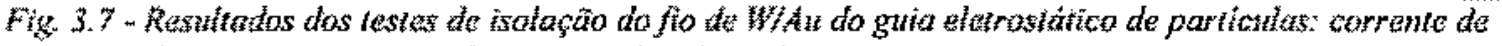

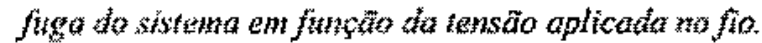

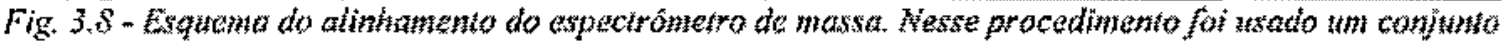
de aborturas circulares de $0,5 \mathrm{~mm}$ e dois aparethos de rotos loser de He-Ne.

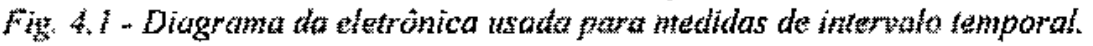

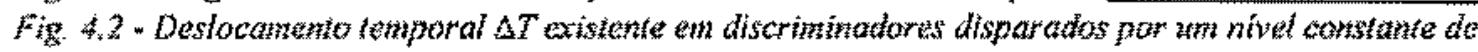

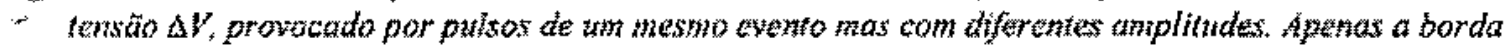

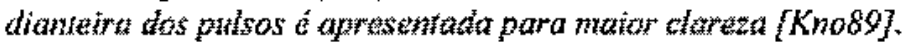

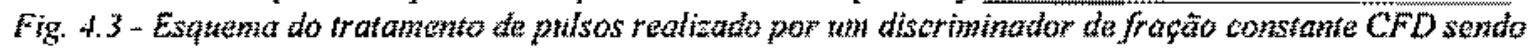

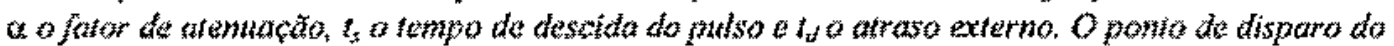

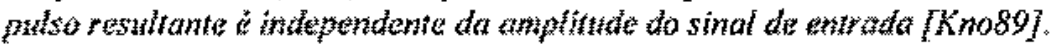

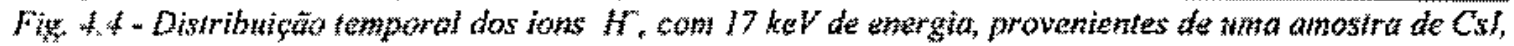

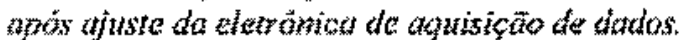

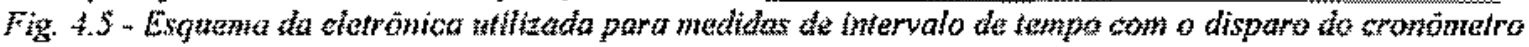

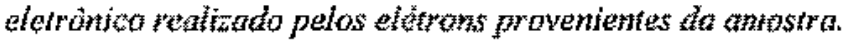

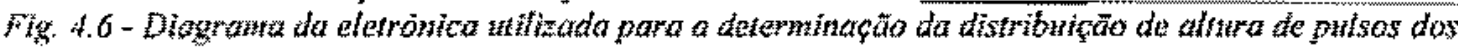
detector as Stam a Stop, en coincidencia com as pulsos rópidos selecionados com a nive de

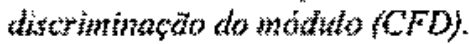

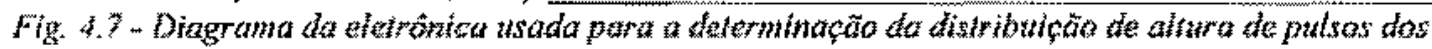

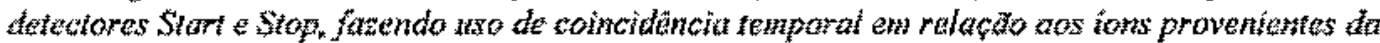
antasira.

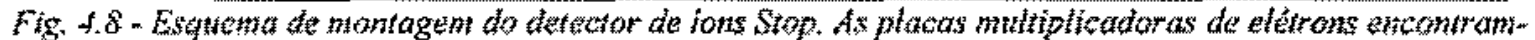
se montadas ent wha configutactat Chevrom.

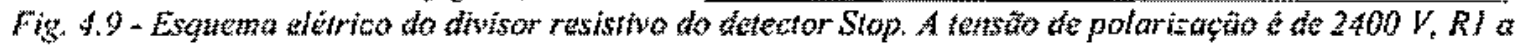

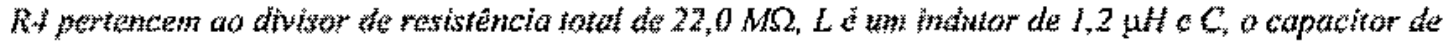

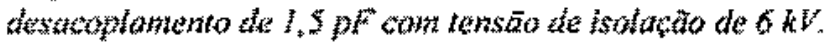

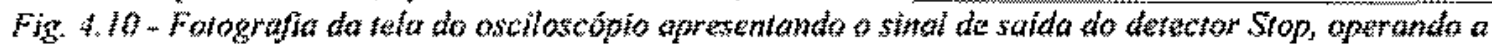

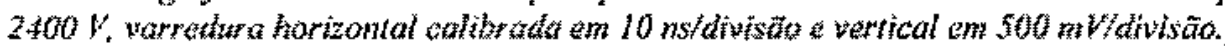

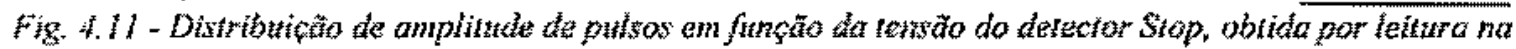

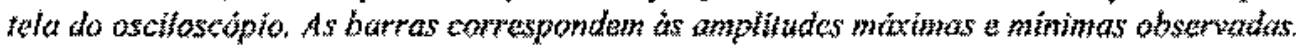




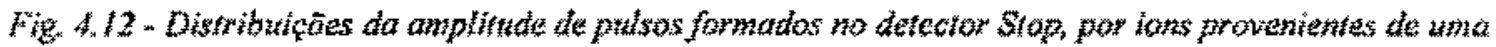
amostra de LiF a $+12 \mathrm{kV}$, para lenšbes de operaçäo de $2400 \mathrm{~V}$ a $2660 \mathrm{~V}$.

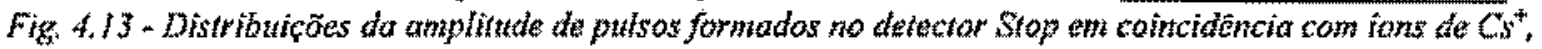
provententes de uma amostra de Cslat $12 \mathrm{kV}$, para tensües de operaçäo de $1950 \mathrm{~V} \mathrm{a} 2570 \mathrm{~V}$. De (a) para (b) as escalas horizontais foram atteradas para melhor visualização, sendo o ganho do sistema de amplificąăo o mesmo para todos as distribuiçöes.

Fig. 4.14 - Fostiçờes dos primeiros momentos des distribuiçäes de amplitudies de pulsos em funçäo da tensäo the operaça do dotector Siop. Os putsas a

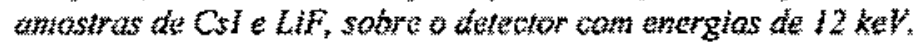

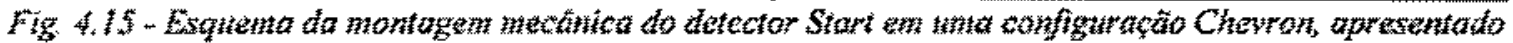
em vista frontal e em corte latatat.

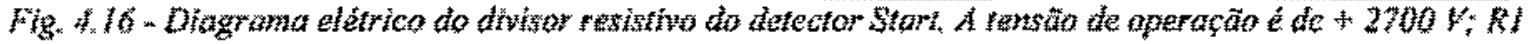

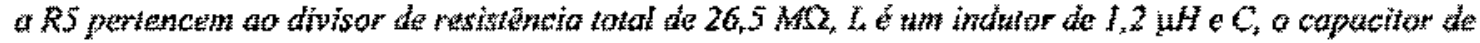
desatoplantento de $1,5 \mathrm{pF}$ com tansữo de isolaçẫo de $6 \mathrm{kV}$.

Fig. 4.17. Fotografia da tela do osciloscobio apresentando o sinal do detector Start, operando a $2700 \mathrm{~V}$. varredura horizontal calibrada em 5 ns/divisão e vertical am 200 mVtutivistä.

Fig. 4.18. Distribuição da amplitude de pulsos do detector \$tart em funçäo de sua tensäo, obtida por leitura nut tala to ordiloscópio. As barras correspondem as amplitudes máximas e minimas observadas.

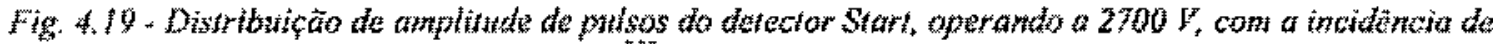

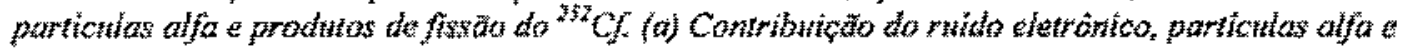

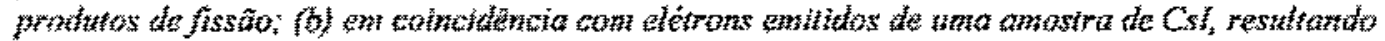

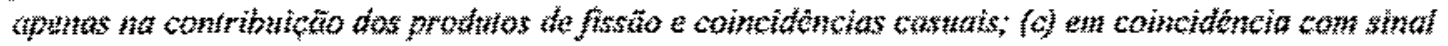

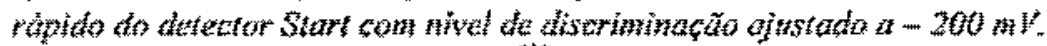

Fig.

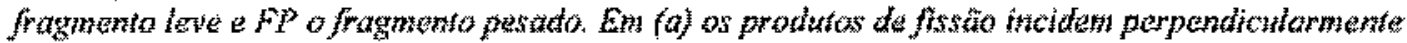
sobre a amosira e o detector Start, am (b) na regiño mais distamte posswel de seus centros. Em ambos os casos a fonic está colocada à mesma distância da amostra a do detector.

Fig 5.2 - Influência da distribuigăo de velocidades dos produtos de fissüo do ${ }^{252} \mathrm{Cf}$ na distribuiçäo temport the alatrons de $18 \mathrm{keV}$ provenuantes de ama anostra de Csl. O pito à esquerda corresponde a eventos onde a fragmento pesado incide subre o detector Start e a da diritu ofragmento leve. A origem do

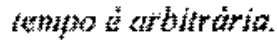

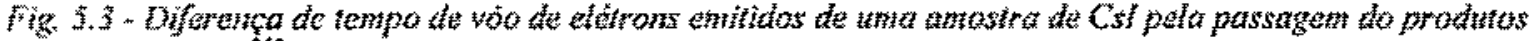

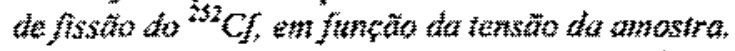

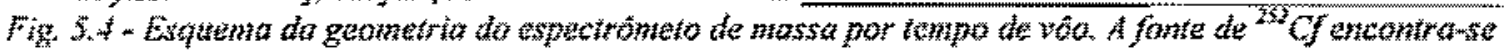

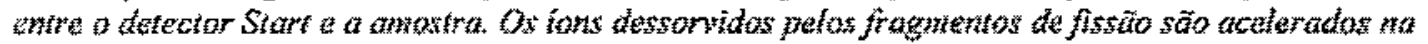

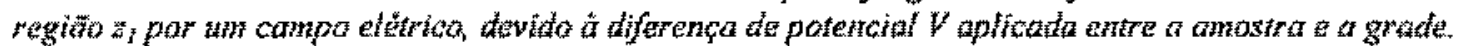

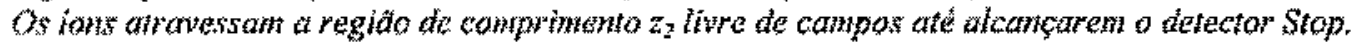

Fig. $\$ .5$. Representação da valocidade inical de emissão $v_{0}$ do ion; 6 é o ängulo entre a normal da stiperficie da amostra e a direcäo da velocidade do ion.

Fig. 5.6. Espectros de massa de uma anostra de Csl depositata a vácuo sobre tom substrato de Kimfol

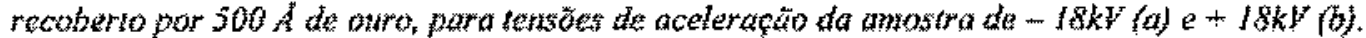

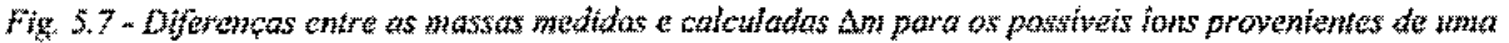
tam

Fig.

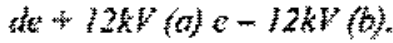

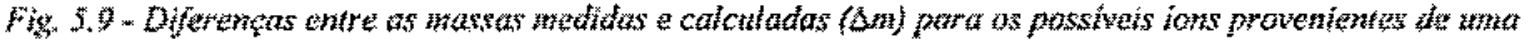
amostra te fonilafanina a $+12 \mathrm{kl}$ (a) $\mathrm{a}-12 \mathrm{kV}$ (b). Os pontos axperimenas (A) rapresentam as fons

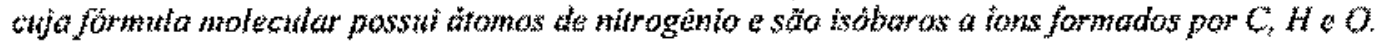

Fig. 3.10 . Espectros de massa do Angiotensin $\mathrm{l} a+12 \mathrm{kV}$ (a) e a $-12 \mathrm{kV}$ (b) e do LHRH a $+12 \mathrm{kV}$ (o) Ao lado săo mostrados detalhes dos picos dos ions quasi-molaculares.

Fig. 5.11 . Comparação entra os rasultatos experimentais e catchlados para a resohuçấo em massa do expecirometro para ions $H$, com o sistena de aquisiçâa disparado por elétrons. (a) Curvas calculadas

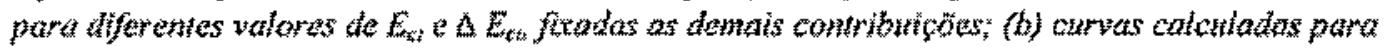

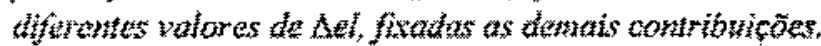




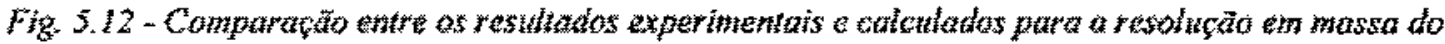

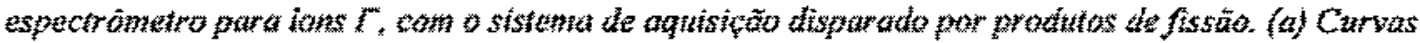

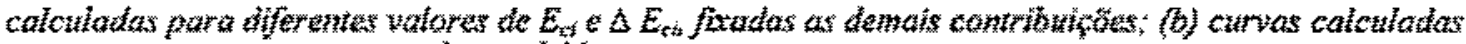

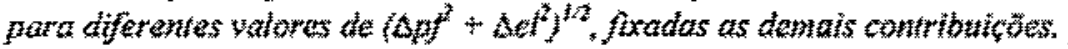

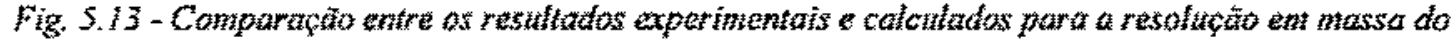

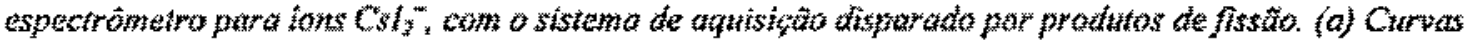

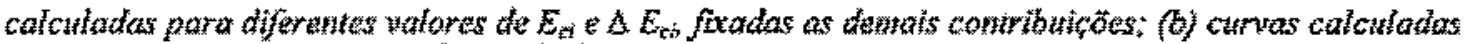

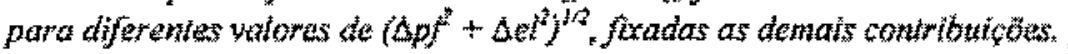

Fig. 5.I4 - Resoluçắo do espactrôntetro na região de pequenas massas. Em (a) picos formados pelos ions At e $\mathrm{C}_{2} \mathrm{H}_{3}{ }_{3}$, provenientes te una antostra de mylar aluminizado e separados por dn $=0,041$ u.m.a.; em (b) a amostra, recoberta por sacarose $\left(\mathrm{C}_{12} \mathrm{H}_{22} \mathrm{O}_{11}\right)$. teve o pico de $\mathrm{Al}$ eliminato.

Fig. 5.15 - Ressoluçấo do espeströmetro na regiäo de pequenas massas. Em (a) picas formados por ions $\mathrm{K}^{+}$e por ions $\mathrm{C}_{2} H \mathrm{H}^{+}$a $\mathrm{C}_{3} \mathrm{H}_{3}^{+}$, provenientes de uma amostra de valina sobre nitroctulose estäo separados por $\Delta m=0,05$ un.a; $\mathrm{cm}(\mathrm{t})$ a amostra, tavada com agua destituda tave o pito de $\mathrm{K}^{+}$praticamente

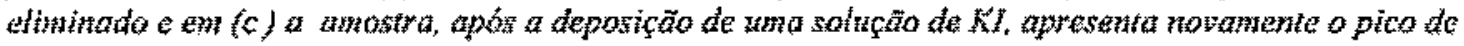
$K^{+}$

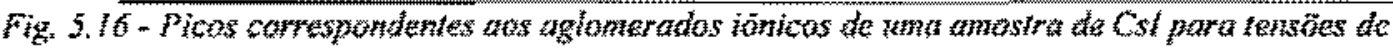

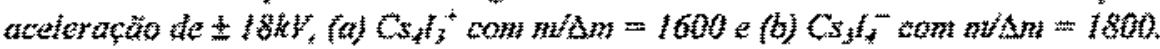

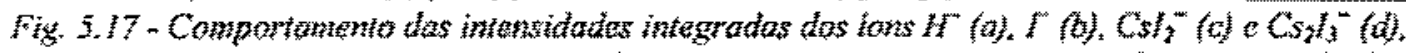

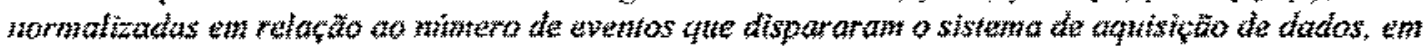

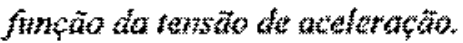

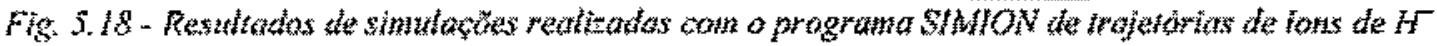

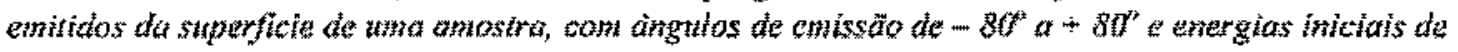

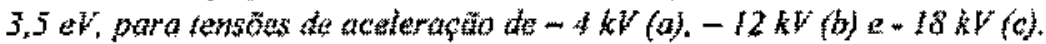

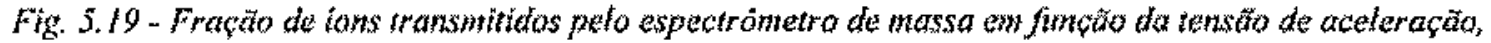
sujeitos a influetroias da geometria do sistema e das energias iniciais, obtidas por simutacöes computacionais.

Fig. 5.20 - Geometria do guia elturastático de particulas. Em um instante qualquer, o ion cncontra-se a uma distäncia $r$ do fio, posstindo velocidade v e fazendo un angulo $\theta$ com a nomat ao plano xy $e$ ф com o plano yz (atoplado de lowat)].

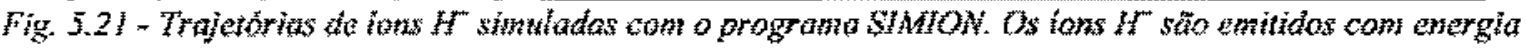

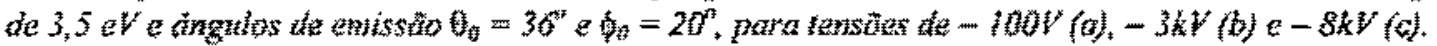

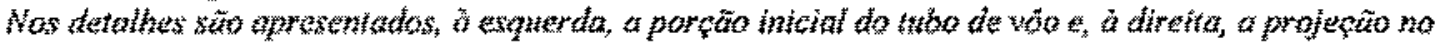

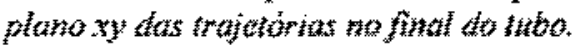

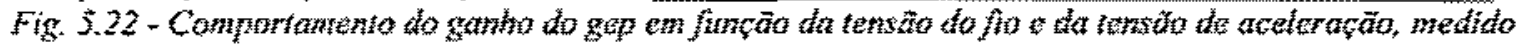

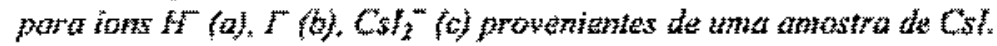

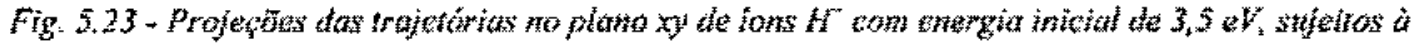
infuéncia do gutia afetrostatico de particalas colocado a $+20 \mathrm{~V}$. As trajubriats sâo oblidas por

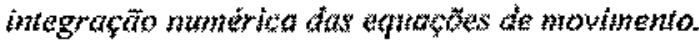

Fig. 5.24 - Comparaçäo dos restiltados experintentais do ganho do gep con as obtidos por simulaçöes (curvas continuas). para os ions $h^{T}(a)$ e $\Gamma$ (b).

Fig. 5.25 - Detalhe da porçäo inicial do tubo de vố mostrando as deformaçóes nas equipotenciais devido a efeitos de borda do gap de timensäo finita.

Fig. 6.1- fa) Espectros de masssa da uma omostra de $\gamma-G$-Gi-Cys (S-Me) thepositoda sobre um substrato de

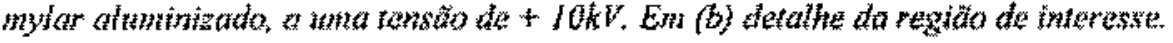

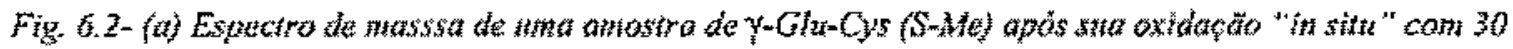

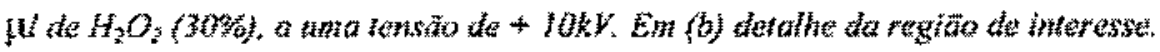




\section{Introduçäo}

A espectrometria de massa tem aplicaçöes em vários setores de interesse cientîfico e tecnológico, sendo uma importante ferramenta na caracterizaçă de substâncias em pesquisa basica e no controle de qualidade em processos industriais. Sua utilização adequada na área da bioquímica em indústrias famacológicas, onde e de extrema importância a verificação da integridade estrutural e pureza das substảncia deteção e identificação de produtos secundários formados durante o processo de sintese. A técnica também é adequada para analise de derivados de petróleo polimeros. Nas áreas ligadas ao estudo do meio ambiente, a espectrometria de massa possibilita a determinaţăo de contaminantes do solo ou em mananciais, tais como pesticidas subståncias organometálicas, prejudiciais ao ccossistema.

O objetivo deste trabalho consiste no desenvolvimento e construçăo de um espectrômetro de massa por tempo de vôo que utiliza a técnica de Plasma Desorption, onde a emissão e ionização de moléculas de uma amostra é feita pelo bombardeio com ions rápidos provenientes de uma fonte radioativa de ${ }^{252} \mathrm{Cf}$. Um sistema de vácuo, usado para o acondicionamento do espectrômetro, sistemas de manipulação e trocas de amostra e detectores de fons também foram desenvolvidos especialmente para esse equipamento.

No capitulo 2 é apresentada una revisão de algumas tênenicas usadas na volatilização e produção de fons de moléculas orgänteas e de alguns sistemas analisadores de massa. Nos demais itens desse capitulo sâo apresentadas as caracteristicas do espectrốmetro de tempo de vô desenvolvido, consideraçôs sobre a produçăo de íons secuntátros pela incidência de lons rápidos en uma amostra e caracteristicas da fonte de ions primánios utilizada.

No capitulo 3 são apresentados as caracteristicas mexhnous a montagem do espectrönetro, seu sistema de vácuo, o trocador de amostra e gula eletrostático de particulas.

No capitulo 4 são apresentados 0 sisterma de deteçâno e aquisiçäo de dados. Alguns cuidados para o ajuste do sistema etetrônico sẫo também discutidos neste capítulo. 
No capitulo 5 são apresentados os restiltados da caracterizaçä́o do espectrômetro relativos aos seguintes aspectos: $(b)$ a influência da fonte de ions primários sobre a distribuiçăo temporal dos ions analisados, (ii) os procedimentos de calibração do espectro de massa e a precisão obtida na determinação de massas de molëculas, (iii) testes da resoluçäo do espectrômetro e (iv) o eféto do guia eletrostâtico de partículas usado para aumentar a transmissão dos ions atraves do equipamento.

No capítulo 6 é apresentata, como exemplo de aplicaçăo do instrumento, a análise do peptideo 7 Glutamil-S-Metilcisteina.

No capitulo 7 são feitas as consideraçôes finais do trabalho, sendo discutidas as alteraçôes e implementaçôes que seräo realizadas no equipamento para ampliar suas possibilidades de aplicação. 


\section{Consideraçōes Iniciais}

\subsection{Espectrometria de Massa}

A espectrometria de massa e utra técnica na qual moléculas lonizadas são separadas por meio da utilizaçấo de campos elétricos ou magnéticos de acordo com suas razões de massa sobre a carga elétrica ( $m$ L) [Waig3].

Um espectro de massa consiste na distributçäo das razôs mă em funçăo da intensidade. Dependendo do processo de ionização utilizado, as molétulas da amostra podem sofrer fragmentaçōes, produzindo um padrö̌o de ions relacionado com a estrutura do material analisado. Pela interpretação do espectro é possivel obter informações sobre a massa da substäncia que compöe a amostra e, eventualmente, sua estrutura. Por ser uma

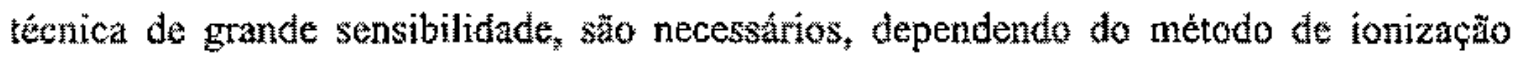
usado, apenas alguns picomoles ou nanomoles do material.

Um espectrômetro de massa é constituido por fô um sistema de produção de fons, (in) un analisador de massa, (in) um sistema de deteção de lons e (iv) um sistema de armazenamento de dados. As diferenças entre as várias técnícas de espectrometria de naassa estão relacionadas a variaçōes de partes do equipamento, sendo que a escolha de um determinado sistema depende dos seguintes fatores [Fen91]: fáixa de massa a ser analisada, resolução, precisăo, sensibilidade, rapidez na analise c custo do equipamento. Na maioria dos casos, as caracteristicas fisico-quimicas das amostras constituem un dos principais fatores para a escolha da técnica empregada. 


\subsubsection{Fontes de Lons}

Para materiais que se encontram em fase gasosa ou que são facilmente volatilizados é usual o emprego do processo de ionizaçäo por bombardeamento de elétrons [Har90], Neste processo, um filamento aquecido é utilizado para a produçăo dos elêtrons, que são acelerados para o interior de uma célula, onde o material a ser ionizado se encontra. Após as colisões, os tons positivos formados são extraidos por campos eletrostáticos e enviados para o interior do sistema analisador. Este tipo de fonte também provoca a fragmentaçăo dos ions moleculares, podendo causar, em alguns casos, a compleka destruiçäo da amostra.

Outro processo utllizado, que permite a sobrevivência de algumas fornas de fons, que seriam destruidas com a utilização da técnica anterior, a lonização química [Mun66]. Neste caso, os lons săo produzidos por colisôt das moléculas, em estato gasoso, com íons primários presentes na fonte. Estas colisôts ocorrem em uma célula, onde dois gases são introduzidos: o gás reagente (por exemplo, o $\mathrm{CH}_{4}$ e o isobutano) e as moléculas da amostra, sendo a pressăo local mantida em condiçốes que permitam frequientes colisões.

Para a análise por espectrometria de massa de materiais argânicos sólidos temicamente instáveis, como peptideos e proteinas, várias técnicas de produção de ions foram desenvolvidas. Com a utilização dessas tentcas, que serăo discutidas em seguida, as moléculas sâo fonizadas de maneira branda, sen que haju uma significante transferência de energia para modos internos da molécula, o que poderia provocar a sua dissociação.

Um grande avanço foi conseguido em 1968, com o surgimento da técnica de dessorção por campo desenvolvida por Beckey et al. [Bec69]. Nesta técnica a amostra é depositada sobre um filamento de tungstenio recoberto por micro-agulhas de carbono. Com o aquecimento do filamento, o material depositado escome ate as pontas das microm agulhas e um intenso campo elatrico $\left(10^{8} \mathrm{~V} / \mathrm{m}\right)$ existente entre of flamento e um oletrodo provoca a emissẩo das moleculas lonizadas. Esta técnica pernitiu a analise de materiats como aminoácidos, esteróis, drogas e pesticidas. 
Em 1974 foi introduzida a tếenica de aquecimento rápido [Beu74], onde a amostra, colocada na extremidade de uma agulha de Teflon, é rapidamente aquecida e volatilizada. O emprego do Tefon permite uma dimimuiçä̃o da intensidade das forças de aderência cntre a superficie da agulha e a amostra, favorecendo o processo de

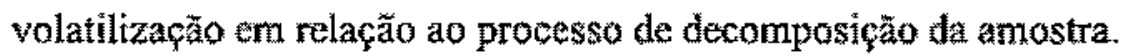

Neste mesmo ano, Macfariane et al. [Tor74, Mac76] descobriram o efeito de dessorçắo de moléculas termicamente instáveis e não-volảteis induzidas por colisöes com ions rapidos (1 MeV/nueleon). Esse efeito possibilitou o desenvolvimento da técnica conhecida como Plasma Desomption Mass Spectromety - PDMS, que utiliza os produtos de fissäo de uma fonte de ${ }^{252} \mathrm{C}$ como íns primários para provocar a dessorçẫo de moléculas de superficies sólidas. Logo nas primeiras aplicações, a técnica mostrou seu potencial, permitindo a análise de zmostras orgânicas que nunca tinham sido analisadas com sucesso com técnicas de espectrometria de massa existentes na epoca [Tor74]. Outros fatores que favoreceram o emprego da técnica PDMS foram: a facilidade no preparo da amostra, a técnica ser nễo-destrutiva e factlidade na determinaçẩo da masșa do material analisado, decorrente da produção intensa de íons quasimmoleculares. As primeiras aplicaçōes da técnica de PDMS foram nos campos da bioquímica e química orgânica molecular, sendo empregatia na caracterizaçăo de estruturas de peptideos a proteinas. Biomoléculas com peso molecular de at 45000 u.m.a. agregados de moléculas com até I00000 u.ma. foram medidos com sucesso [Jon89, Pau91]. Além de permitir a determinação da massa da molécula analisada, informaçôes referentes à estrutura tambóm podem ser obtidas com o emprego do padrâo de fons de fragmentos da molécula, obtidos por procedimentos especiais em combinaçă丶 com o PDMS [Cha86].

Em 1976 Benninghoven et al. [Ben76] introduziram a utilizaçăo da técnica Secondary lons Mass Spectrometry - SIMS na caracterização de biomoléculas termicamente insthveis. Como na técnica $P D M S$, um feixe de particulas ionizadas colide com uma amostra sólida, provocando sua dessorçăo. Nesse caso, a energin dos íns primários ta ordem de $\mathrm{keV}$. Embora os espectros de massa produzidos tenhatn se mostrado similares aos obtidos com $P D M S$, a efuciencia de produção de tons secundários quasi-moleculares é menor no caso do SIMS. 
0 uso de pulsos de laser de ultravioleta para análise de biomoléculas foi introduzido por Posthumus el al. em 1978 [Pos78]. Substâncias como oligossacarideos, glicosídios e nucleotideos foram analisadas e os espectros de massa apresentaram, alêm dos pices quasi-moleculares, picos de fragmentos, que permitiram a obtenção de informaçōes estruturais.

Em 1981 Barber et al. introduziram a técnisa Fast Atom Bombardement - FAB [Bar81]. Essa técnica é similar à SIMS, mas utiliza um feixe de partículas neutras para bombardear a amostra, com energia da ortem de keV. Outra diferença estáx relacionada ano preparo da amostra, que, nesse caso, é produzida na forma líquida, dissolvida em uma matriz de glicerol. Os espectros obtidos podem, no entanto, ser de dificil interpretação devido à interferência da matriz. Com esta técnica, amostras de polipetídeos e proteinas foram analisadas.

A técnica denominata MALDI - Mntrix Assisted Laser Desorption lonization, desenvolvida por Hillenkamp et al. em 1988 [Hil88], utiliza uma fina camada formada pela mistura do material a ser analisado com uma matriz composta por pectuenas noléculas orgânicass, que apresentam forte absorçăo no comprimento de onda de um laser (UV) utilizado para arrancar o material do substrato. A excitaçăo eletrônica das moléculas da matriz pelo pulso do laser provoca a dessorçăo e ionizaçăo das moléculas da amostra. Como matrizes säo utilizados os ácidos sinapinitico on nicotinico. Esta técnica permite a produçẵo de fons moleculares de massas extremamente elevadas, da ordem de centenas de milhares de u.m.a. En 1990, este mesmo grupo relatou a possibilidade de dessorção de moléculas por fotons tra faixa do infravermelho [Ove90].

Em 1988 Fenn al. [Yam88] apresentaram resultados do uso da técnica de Eletrosputzy para a volatilização e ionização de grandes proteinas. Uma soluçầo díluida da amostra passa por um tubo capilar, com um fluxo extremamente baxo (1 a 10 t $1 / \mathrm{min}$ ). Um campo elëtrico intenso é criado pela aplicaçăo de uma diferença de potencial de $3 \mathrm{kV}$ a $6 \mathrm{kV}$ entre o tubo capilar e um elefrodo, separados por uma distância de $3 \mathrm{~mm}$ a $20 \mathrm{~mm}$. O campo elétrico induz cargas no liquido, provocando a formação de uma superficie cônica, de cuja extremidade são expelidas gotículas altamente carregadas. A evaporaçă do solvente na goticula provoca sua fragmentaçăo devido ao efeito de forças elétricas, 
mais intensas que ats forças de coesão da goticula. Säo formadas entầo gotas ainda menores, que sofrem novas framentações, produzindo um ếteito em cadeia, até que as forças elétricas fiquem tầo intensas que causem emissầo de tons da amostra. $O$ interessante nessa técnica é a produçăo de íons moleculares com grande quantidade de cargas, o que pernite a utilização de sistemas analisadores como quadrupolos eletrostáticos, que operam numa faixa de razão $\mathrm{m} / \mathrm{q}$ de 1000 u.m.a. a 2000 u.m.a.

\subsubsection{Analisadores de Massa}

Existem varios analisadores que podem ser empregados em espectrometria de massa, entretanto, a escolha de um deles depende do problema a ser investigado e das características da fonte de lons utilizada [Wai93]. Por exemplo, no caso das técnicas PDMS e MALDI a maioria tos sistemas utiliza analisadores por tempo de vô, uma vez que existe um evento temporal bem definido relacionado ao efeito de emissäo dos íons da amostra [Mac76, Hil88]. No caso do eletrospray podem ser empregados analisadores do tipo quadrupolo, setores eletrostáticos e magnéticos, ja que nesta técnica os lons são produzidos de forma continua [Hof96].

Em um espectrômetro de massa que utiliza um setor magnetico [Wai93], um ion de carga a massa na ao entrar em uma região onde existe um campo magnético de intensidade $B$, perpenticular à sua velocidade $v$, sofre a aço de uma força de intensidade $q u B$, que o faz percomer uma trajetoria em arco, de naio $p$

$$
\rho=\frac{m v}{q B}
$$

ou seja, um setor magnetico efm analisador de momento, separando os tons de acordo com o produto da massa pela sua velocidade. Neste tipo de analisador importante que os jons de mesma massa possum praticamente a mesma energia, caso contratio eles serão focalizados em pontos ligeiramente diferentes, causando perdas nat resoluçăo. Para 
corrigir esse efeito são usados analisadores eletrostáticos em conjunto com os magnéticos, formando os chamados analisadores de duplo-foco [Wais3].

O setor sletrostático formado por duas placts curvas, sujeitas a uma diferenca de potencial, que produz um campo eletrico $E$ entre elas. Quando um íon de carga $q$ e massa $m$ penetra nessa região, percorre uma trajetória em arco de raio $R$ :

$$
R=\frac{2\left(m v^{2} / 2\right)}{q E}
$$

ou seja, tons com mesma carga energia cinética, penetrando na mesma regiăo do setor eletrostático, percorrerão a mesma trajetória, sendo focalizados em um mesmo ponto. Fendas localizadas na saida do setor eletrostático minimizam a dispersäo de energia dos lons que seräo enviados para o setor magnético.

Os equipamentos podem ser encontrados nas configuraçồ de geometria dianteira, onde o setor eletrostático antecede o setor magnético, ou na geonetria reversa, onde o setor magnético está colocado à frente do eletrostático. A resoluçăo em massa, definida como a razão $m / \Delta m$, e muito alta para este tipo de analisador, podendo thegar a 100000. Porem, isso é consegutido com uma drástica diminuição da transmistsăo dos íns, uma vez que as aberturas das fendas do instrumento devem ser reduzidas. Com esse tipo de espectrômetro é possível analisar moléculas com massas da orđem de até 15000 u.m.a., sendo a intensidade do campo magnético utilizado o maior fator de limitaça [Hof96]. Un espectro de massa é conseguido por meio de uma varredura no valor dn intensidade do campo magnético, causando a passagem seqüencial de ions com diferentes massas no ponto focal do setor magnético, onde se cncontra un detector.

Um analisador de massa por quadrupolo elétrico é formado por quatro barras metálicas de seção reta circular ou hiperbólica, paralelas e eqüidistantes entre si [Bru87]. Nas barras săo aplicadas diferenças de potencial $V(t)=V+U \cos (\omega t)$ sendo $V$ e $U$ amplitudes das componentes continuta e de radiofrequência, respectivamente. $\mathrm{O}$ efeito desses potenciais é o de produzir um movimento oscilatóno nas trajetórias dos sons que atravessam o analisador. Quando $V, U$ e a freqứência de oscilaçăo $\omega$ são escollhidas 
adequadamente, apenas íons com um particular valor de razão $m / q$ conseguem atravessar o quadrupolo e alcançar o sistema de detecção. Os ions restantes entram em trajetórias instáveis e se perdem no interior do aparelho. Um espectro de massa pode ser obtido variando-se as amplitudes das tensões aplicadas $V$ e $U$, com a imposição de que a razão de $V / U$ se mantenha constante. Isto faz com que o quadrupolo faça uma varredura em uma faixa de valores de $m / q$. A faixa de massas e a resolução dos quadrupolos são inferiores às dos setores magnéticos de duplo-foco, sendo o limite de massa mensurável da ordem de 4000 u.m.a., com resolução entre 2000 e 4000 . A transmissão desse dispositivo é alta, uma vez que o uso de fendas para colimação é desnecessário.

Em sistemas analisadores que utilizam a técnica de tempo de vôo, os íons, após serem acelerados por uma diferença de potencial $V$, atravessam uma região de comprimento $L$ livre de campos [Wai93]. Se todos os ions formados em um mesmo evento penetrarem nessa região com a mesma energia cinética, as suas massas podem ser determinadas a partir da medida de seus tempos de vôo, isto é:

$$
\begin{gathered}
\frac{m v^{2}}{2}=q V \Rightarrow v=\left(\frac{2 q V}{m}\right)^{V / 2} \\
t=\frac{L}{v}=\left(\frac{L^{2} m}{2 q V}\right)^{1 / 2}
\end{gathered}
$$

No entanto, a resolução em massa obtida com esses analisadores sofre limitações devido às flutuações na energia dos íons. Esse efeito pode ser corrigido com o uso de espelhos eletrostáticos [Mam73], onde ions de mesma massa mas possuindo energias ligeiramente diferentes têm seus tempos de vôo corrigidos por meio de campos eletrostáticos, que focalizam os ions no tempo e espaço. Sistemas empregando esse dispositivo têm apresentado resoluções de até 10000 [Jen90, Pri90]. A transmissão desse analisador é independente da massa, o que possibilita, em princípio, a análise de uma região ilimitada de massas, e a não utilização de fendas para colimação faz com que 
possua uma maior transmissão quando comparado, por exemplo, com sistemas magnéticos de duplo-foco [Hof96].

Em um sistema analisador que utiliza uma célula de ressonânciáa ciclotrônica por transformada de Fourier (Fourier Transform Ion Cyclotron Ressonance) ions, aprísionados no interior de uma célula e sujeitos a um intenso campo magnético, descrevem trajetórias circulares na direçäo perpendicular à do campo aplicado [Hof96]. A frequîtencia de cyelofmon do movimento dos ions é dada por:

$$
\omega_{5}=\frac{q B}{m}
$$

Urn detector capta a corrente induzida pelo movimento circular dos íons, gerando um sinal que é analisado por técnicas de transformada de Fourier para a determinaçăo do espectro de freqüências. $O$ espectro de massa é obtido pela correspondencia entre frequência e razẫo $m / q$. A resoluçâo do instrumento depende do intervalo de tempo do sinal induzido, sendo este limitado pelo tempo de vida do fon aprisionado no interior da célula. Na prática, valores de $\mathrm{m} / q$ da ordem de 2000 u.m.a. podem ser analisados. 


\subsection{Prö̈to do Espectrômetro de Massa gor Tempa de Vồ}

Objetivo deste trabalho é o desenvolvimento de um espectrômetro de massa por tempo de vớ, que utiliza a tê้cnica PDMS (Plasma Desomption Mass Spectrometry), onde a dessorçăo e ionizaçăo das moléculas da amostra provocada pelo seu bombardeamento por íons rápidos provenientes de uma fonte radioativa de ${ }^{252} \mathrm{Cf}$. A Fig. 2.1 apresenta um esquema ilustrando o princípio de funcionamento do espectrômetro, com a fonte de ${ }^{252} \mathrm{Cf}$ e a amostra montadas na geometria de transmissão. Un núcleo do ${ }^{252} \mathrm{Cf}$, ao sofrer fissäo, emite dots fragmentos na mesma direçăo mas em sentidos opestos. Um dos fragmentos

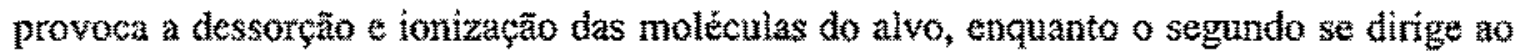
detector de frugmentos de fissão, posicionado atrảs da tonte radioativa $O$ s ions secundáríos emithdos da amostra são acelendos em uma pequena região, penetram em um tubo de vôo livre de campos elétricos e são detectados em um outro sistema colocado no final do tubo. Para a determinação do tempo de vôo dos fons é usado um cronômetro eletrônico de grande precisäo, com resolução temporal de sub-nanossegundos, que é acionado pelo produto de fissão correlacionado com aquele que provocou a emissäo te ions da amostra.

Neste projeto foram utilizados conhecimentos e resultados anteriomente adquiridos na construçào de um espectrômetro de massa compacto, que possui um tubo

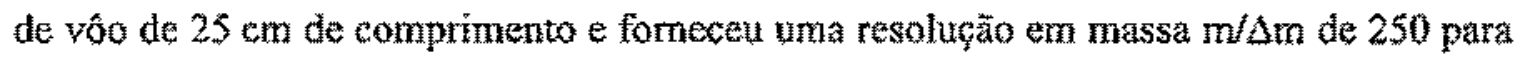
ions corn massa de 650 u.m.a. [Koi91, Mac94]. No intuito de se ter um equipamento com melhor resoluçẫo e com características mais flexiveis quanto à sua operação, surgiu a proposta da construçã̃o de um espectrômetro com um tubo de yồo de maior comprimento (111 cm) e possuindo un sistema de troca de amostras, que permite a manipulação de até trếs amostras simultaneamente, sem a introduçầ de ar no sistema principal, o que ocorria no espectrômetro anterior. Devido a maior extenstäo do tubo de vô, o sistema projetado utiliza um guia eletrostatico de particulas (gep) para aumontar a transmissão dos lons.

O espectrốmetro precisa ser oparado em văcuo, para que os ions secundários da amostra não sejam perdidos por colisōes com moleculas do gás residual durante a sua 
trajetóna até o sistema de deteç̧ăo. Deste.modo, um sistema de vácuo foi projetado e construido totalmente em aço inoxidável, provido de flanges com guanições metálicas qute permitem operat o espectrômetro de massa em pressões muito baixas.

Fazen tamberm parte desse projeto o desenvolvimento e os testes dos sistemas de deteçẫo ustados no espectrômetro de massa, que utilizam placas multiplicadoras de eletrons de microcanais (nicrockamel plates).

Para a caracterização do espectrômetro foram utilizadas amostras padrōes como 0 sal de CsI e algumas amostras biologicas (fenilalanina, Angiotesin I e o LHRH), cujos espectros possibilitaram estudar a precisão na determinę̧ão das massas, a resolução a 0 comportamento da transmissäo de ions pelo sistema.

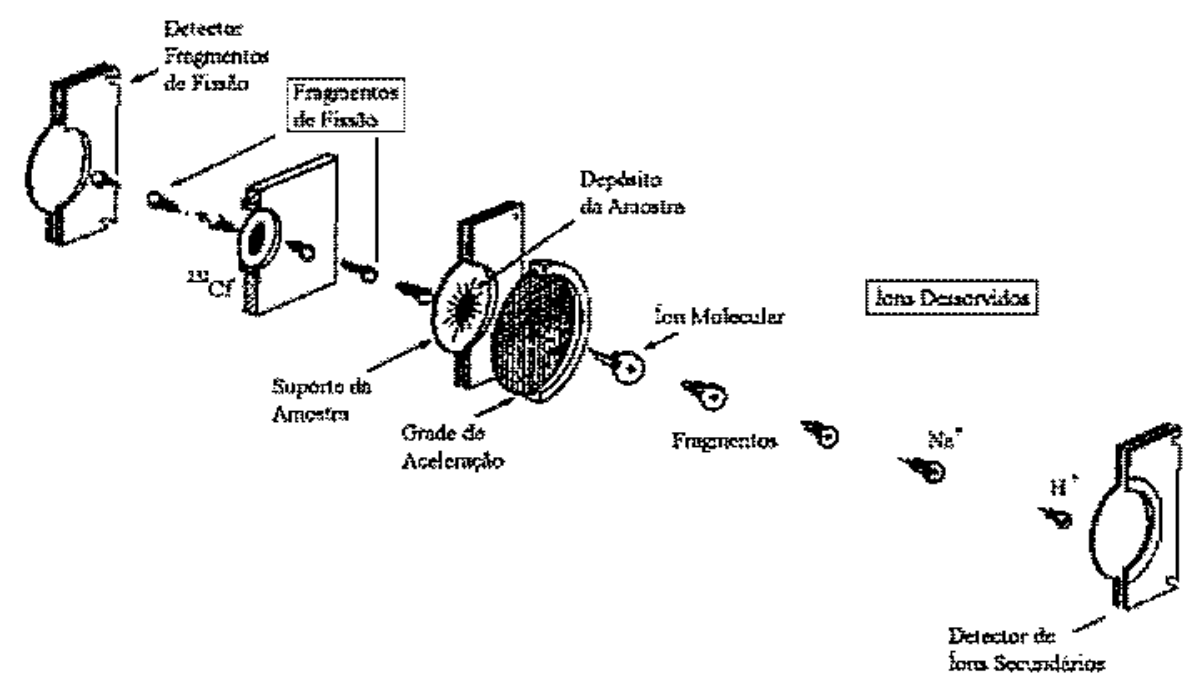

Fig. 2.1 - Principio de funcionamento do espectrômetro de massa por tempo de vô com dessorção induzida por produtos de fissão do ${ }^{252} \mathrm{Cf}$ (adaptado de (Mac83]). 


\subsection{Dessorçäa Induzíă por lons Rápidos}

Um lon, penetrando em um meio material, perde gradativamente sua energia. A transferência de energia do lon para o meio pode provocar a emissäo de fótons, átomos, fragmentos de moleculas e aglomerados de partículas, eletricamente carregados ou não 0 tipo de interaçăo que o ́n primário tem com o material define o comportamento de sua taxa de perda de energia por unidade de comprimento $(d E / d x)$, que pode ser expressa como [Bet94].

$$
\frac{d E}{d x}=\left(\frac{d E}{d x}\right)+\left(\frac{d E}{d x}\right)
$$

onde $(d E / d x)_{n}$ representa a perda de energia por colisones mucleares ou elasticas e $(d E z d x)_{*}$ a perđạ por colisỏes eletrónicas ou inelásticas.

A predominânciá de um dos processos de perda de energia é dependente da velocidade $v$ do ion incidente. A velocidade de Bohr $v_{B}$, definida como a velocidade do elétron ao redor do átomo de hidrogênio no modelo semiclássico $\left(y_{B}=0.22 \mathrm{~cm} / \mathrm{ns}\right)$, है usada como parâmetro para definir um limite entre os dois regimes de perda de energia: se $v<v_{B}$ predomina o termo $(d E / d x)_{n}$ e se $v>v_{B}$ o termo $(d E / d x)_{e}$ [Bet94].

A Fig. 2.2 apresenta como exemplo os valores calculados para as perdas de energia nuclear e eletrônica em função da energia de uma particula pesada $\left(^{127} \mathrm{n}\right.$ ) atravessando um sólido orgânico $\left(\mathrm{C}_{3} \mathrm{H}_{5} \mathrm{NO}\right)$, com densidade de $1 \mathrm{~g} / \mathrm{cm}^{3}$ [Sun91].

A emissão de partículas é também govemada pelas características físicas do meio material. Por exemplo, mesmo em casos em que a velocidade do íon é alta $(v>v)$, pode ser que a emissão ocorra preferencialmente por processos colisionais nucleares, como no caso de condutores. Niesses materiais, o tempo de relaxação eletrônica é extremamente rápido $\left(-10^{15} s\right)$ o que impede a transferência da energia dos elétrons livres gerados no 
processo colisional para o movimento dos atomos do meio. Nos isolantes esse tempo e mais longo $\left(\sim 10^{-13} \mathrm{~s}\right)$, possibilitando esta forma ce transferêneia [Joh82, \$ung1].

A emissão de moléculas intactas da superficie de um material isolante pelo bombardeamento por ions rápidos esta relacionada com a formaçäo de uma regizo altamente energizada em tomo da trilha formada pelo lon. A Fig. 2.3 mostra uma representação dos efeitos de um fragmento de fissẫo do ${ }^{25} \mathrm{Cf}$ (1MeV/nucleon) ao atravessar um meio material. Este fragmento atravessa $1 \mathrm{~A}$ do material em $10^{47} \mathrm{~s}$ formando uma regia cilindrica densamente ionizada exeitada ao redor da trilha, devido

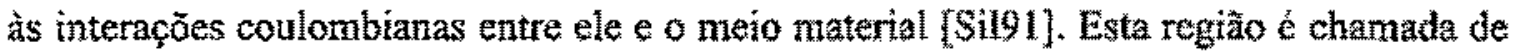
infra-trilha e seu raio $r_{i}$ é proporcional à raiz quadrada da energia cinética $E_{c}$ do íon primário [Hàk92]:

$$
r_{i \mathrm{r}}=6,7\left(\frac{E_{t}}{m}\right)^{2 / 2}
$$

sendo $r_{i t}$ dado em $\AA, E_{c}$ em MeV e $m$, a massa do íon, em u.m.a.

A interação direta entre o ion primário e os elétrons do alvo produz elétrons secundários de alta energia ( $\sim \mathrm{kev}$ ), chamados de elétrons $\delta$, cuja interação com o meio material provoca a produçăo de novos elêtrons secundários. Uma nova régiäo cilindrica ao redor da infra-trilha, chamada de ultra-trilha, ${ }^{6}$ cormada em um intervalo de tempo da orden de $10^{-15}$ s após a passagem do fragmento de fissăo. O raio $r_{z}$ dessa regiẫo é determinado pela projeção do alcance dos elétrons $\delta$ no meío material, sendo aproximadamente [Hak92]:

$$
F_{w}=830\left(\frac{E_{i}}{\rho m}\right)
$$

sendo $r_{t t}$ dado em $A$ e $p$, a densidacte do material, $\mathrm{cm}_{\mathrm{g}} \mathrm{cm}^{3}$. 
No caso dos produtos de fissäo provententes do ${ }^{252} \mathrm{Cf}$, cujas massas e energias sầ da ordem de 100 a.m.a. e $100 \mathrm{MeV}$, os raios da infra- e uitra-trilha formados são de $5 \mathrm{~A}$ e $500 \mathrm{~A}$, respectivamente. $\mathrm{A}$ densidade de energia depositada pelo fon no meio material fecresce, em relaçấ ao centro da tritha, aproxinadamente com a distância ao quadrado [1]सk92].

Os detalhes dos mecanismos básicos que levam à emissão de particulas são complexos e continuam em estudo, não existindo um modelo que consiga explicar completamente todos os resultados experimentais observados [Joh87, Reig2, Pin93]. Vários tipos de medidas säo usados para a caracterizaçăo da interaçăo de ions rápidos com meios materiais sólicos, como por exemplo, medidas da eficiência de produçăo dos ions secundários em funçäo da energia do íon incidente, distribuições de velocidades radial e axial das partículas emitidas, bem como distribuiçoes angulares de emissä̀ [Bet94].

Alguns modelos supöem que a emissão de partículas de um sôtiđo ocorra devido a uma alta densidade local de energia em sua superficie, por meio de processos térmicos, que provocam a evaporaçäo ou sublimaçäo do material do alvo [Joh87, Luc87].

Medidas da distribuiçäo angular de emissăo de íons secundários fornecem subsídios para um entendimento dos mecanismos de emissão de partículas [Ens89, Mos89, Dem91, Eri96]. Nessas medidas, ions formados de material orgânico apresentam uma distribuiçăo angular näo-uniforme, direcionada para ângulos distantes da nomal à superficie da amostra, sendo estas distribuiçôes também dependentes do ângulo de incidencia do ton primário. Esse efeito pode ser atribuido, segundo modelos propostos por Johnson (pressure pulse modeh) [Joh89] e Bittensky (shock wave modef) [Bit87], à transferência de momento devido ao processo de expansão da região central da trilha en sua direçäo radial, provocando a emíssaco de moléculas em regiöes próximas à superficie do alvo.

Maiores detalhes sobre os vários modelos propostos podem ser encontrados em trabalhos de revisuro de Johnson [Joh87], Reimann[Reig2], Pinho [Ping3] Wien [Bet94]. 


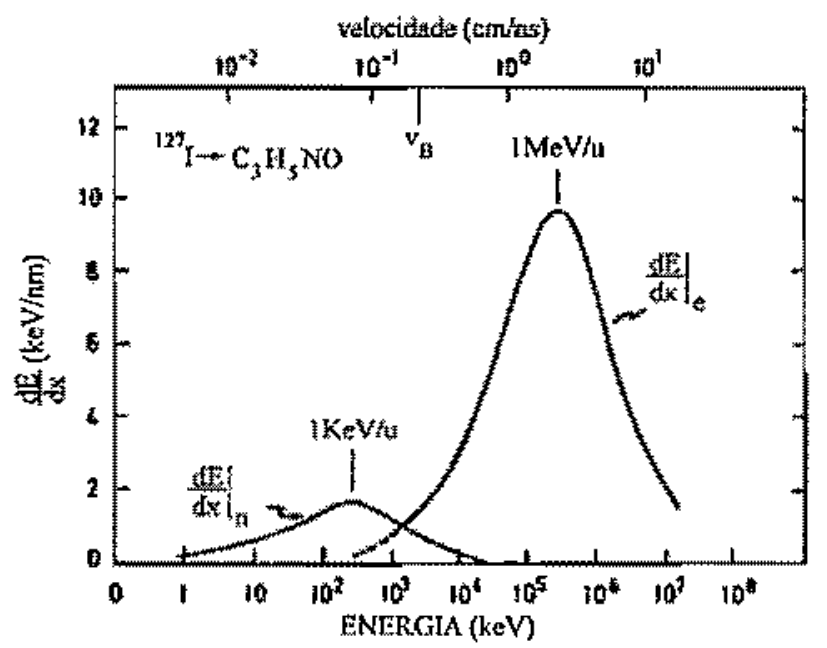

Fig. 2.2 - Taxa de perda de energia por undade de comprimento para un ion de ${ }^{127}$ I ao

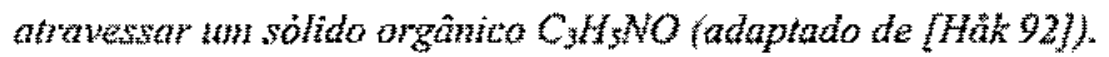

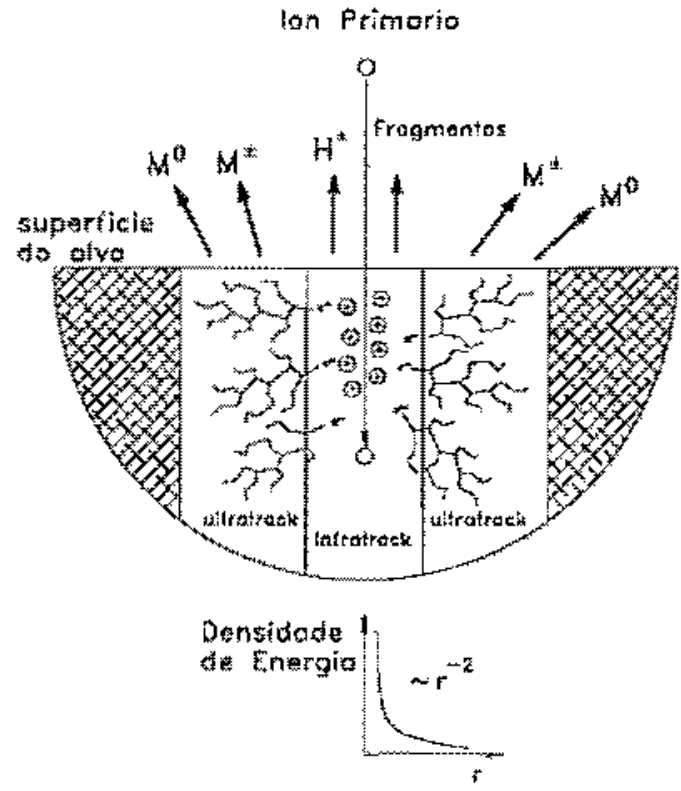

Fig. 2.3 - Esquema da pasagen de um ton rópido por um neto material. Na regiäo proxina à passagem do ton são emitidos etêtrons ô que carregan parte da energia do ion para regiöes mais distantes. A passagem do ion forma as regiöes cilindricas danominadas infra-trilha e ultra-trilha (adaptado de [Hak92]). 


\subsection{Fonte de ${ }^{252} \mathrm{Cf}$}

$\mathrm{O}^{252} \mathrm{Cf}$ e um elemento artificial produzido em reatores nucleares, com alto fluxo de neutrons, a partir do ${ }^{239} \mathrm{P} u$ em sucessivas reações onde ocorrem absorção de neutrons. Sendo um núcleo instável, sua desexcitação ocore por dois processos: (i) a emissăo te particulas alfa, com energia de 6,12 MeV e meia vida de 2,73 anos numa proporcăo de $97 \%$ dos eventos, ou (in) a fissân nuclear, de meia vida de 85,5 anos, ocorrendo em $3 \%$ dos casos. Dessa forma, a mela vida efetiva do ${ }^{252} \mathrm{Cf}$ e de 2,65 anos. No processo de fissão săo tambếm tmítido neutrons rápidos com energia media de $2,35 \mathrm{MeV}$, numa tazão de 3,76 neutrons por fissẫo [AN34].

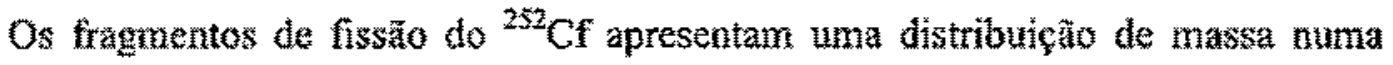

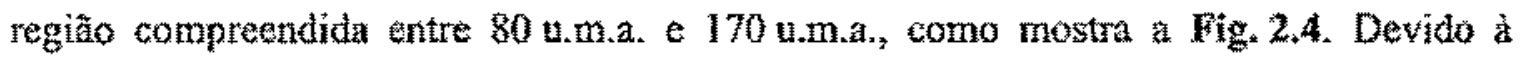
quebra assimétrica do nủcleo, a dístribuição em massa encontra-se dividida em um grupo leve e outro pesado ao redor das massas do ${ }^{106} \mathrm{Tc}_{\mathrm{A} 3}$ e ${ }^{142}$ Bast [Mac76]. Como a distribuiçăo de massa, a distribuiçẫo de energia também é assimétrica, sendo que os fragmentos leves sũo os que recebem a maior fração da energia total (Fig. 2.5). A energta média dos dois grupos é de $104 \mathrm{MeV}$ e $79 \mathrm{MeV}$, respectivamente. Cada fïssão produz um par de fragmentos que, por conservação de momento, são enithidos na mesma direçăo mas em sentidos opostos.

Uim espectrómetro de massa por tempo de vôo que opere com ${ }^{252} \mathrm{C}$ necessita de uma fonte extremamente fina para permitir a transmissäo dos pares de fragmentos produzidos na fassato por ambos os lados da fonte e com uma montagem que impecti a contaminaça do sistema de vácuo pelo efeito de auto-transporte [Cha81]. Na fonte utilizada neste trabalhot, o ${ }^{252}$ C encontra-se colocado entre dus folhas de Ni de 1,1 um de espessura ( $\left(\mathrm{mg}^{2} \mathrm{~cm}^{2}\right)$, estando o material radioativo eletrodepositado sobre uma delas. As follas de Ni possuem em seu exterior uma fina camada de Au de 518 A $\left(100 \mu \mathrm{H}^{2} \mathrm{~cm}^{2}\right)$ usada como proteçăo contra a oxidaçào. Dois anéis de aço inoxidável de $10 \mathrm{~mm}$ de diâmetro externo $5 \mathrm{~mm}$ de diâmetro interno servem de molduras para suporte das folhas

1 Isotope Products Laboratories, Burbank, CA,EUA - aferida pelo fabricante em $15 / 06 / 96$. 
de Ni. Todo o conjunto encontra-se fixado por soldas a ponto feitas ao redor dos anéis de aço. A fonte usada neste equipamento possui uma área útil de $7 \mathrm{~mm}^{2}$ e atividade inicial de $25 \mu \mathrm{Ci}$, o que significa a ocorrência de $2,7 \times 10^{4}$ fissões por segundo.

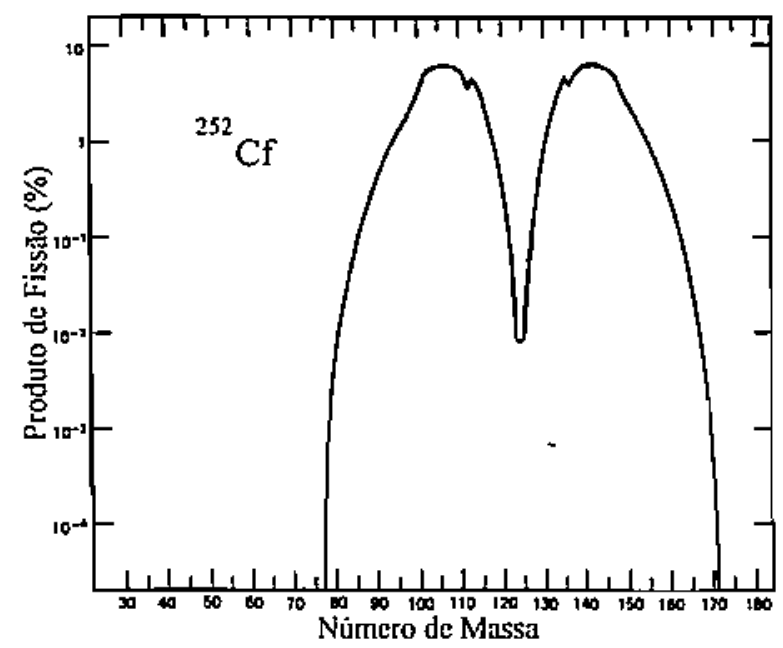

Fig. 2.4 - Distribuição de massa dos fragmentos de fissão do ${ }^{252} \mathrm{Cf}$ [Kno89].

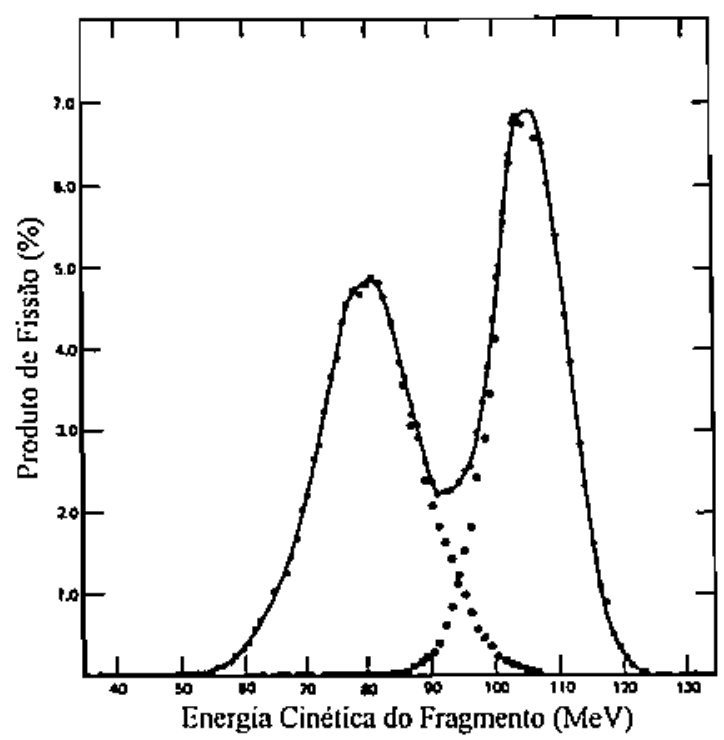

Fig. 2.5 - Distribuição da energia cinética dos produtos de fissão do ${ }^{252} \mathrm{Cf}$. O pico da esquerda correponde aos fragmentos pesados e o da direita aos leves [Kno89]. 


\section{Montagem do Espectrômetro de Massa por Tempo de Vốo}

\section{3.) Sistema de Vúcuo}

A Fig. 3.1 apresenta uma vista em corte do projeto do espectrồmetro de massa por tempo de vôo com indicą̧ōes dos vários componentes do sistema e a Fig. 3.2 mostra uma foto da montagem do ststema de vácuo, construtdo nas oficinas do Instituto de Fisica da USP, usado para o acondicionamento do espectrometro.

O sistema de vacuo, todo ele feito de aço inoxidàel padrão 304 , constituido por duas câmaras conectadas por um fole metálico. $O$ aço 304 apresenta propriedades adequadas para utilizaç̧̃o em ultra alto vácuo, como a sua baixa tała de degaseificação, e fornece excelentes resultados quanto à soldagem pela técnica de arco de Argônio ${ }^{2}$ [Gey76], Todas as soldas foram realizadas na parte interna da câmara, evitando o aparecimento de yazamentos virtuais. Apôs as soldagens dos componentes, foram realizados testes com um detector de vazamentos, que emprega o gás Helio para a verificação de microfissuras ou falbas de soldagem.

As vedações usadas nas flanges do sistema de vácuo são todas metálicas, permitindo operaçoess a pressốt da ordem de $10^{7}$ tor. A maioria das vedaçōes utiliza o padrâo CONFLAT ${ }^{3}$, onde um anel de cobre, com sectäo retangular de 2 mm de espessura, é esmagado entre duas facas de formatos cônicos existentes nas flanges. A escolha desse padrão deveu-se às suas excelentes características de vedaçâo a à possibilidade de aquecimento do sistema temperaturas da ordem de $250^{\circ} \mathrm{C}$, permitindo a eliminação de gastes adsorvidos em suas partedes. Além disso, esse tipo de vedaçāo êdotado em empresas que trabalham com tecnologia de vảcuo, o que garante a padronizaçấo do sisterna.

No projeto foi levado em consideraçă̌n a possibilidade de futuras implementaçôes no equipamento, com instalaçäo de novos dispositivos e acessórios. Dessa forma, o

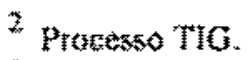

3. Marca nesistrada da cmuresa Varian, Palo Alo, USA.
} 
sistema de vácuo foi construído possuindo um total de 22 entradas, con flanges metálicas de vărias dimensöes.

A câmara 1 (Fig. 3.1), de formato cilindrico, possui um diâmetro externo de $219 \mathrm{~mm}$ e altura de $200 \mathrm{~mm}$. Nela encontram-se instalados o sistema de troca de amostras, os suportes de amostras e da fonte de ${ }^{252} \mathrm{Cf}$ e seus manipuladores, a parte inicial do tubo de vỗo com a grade de aceleração e conectores elétricos usados na transmissão de sinais e alimentaçăo das tensōes do detector de fragmentos de fissăo (Start) e da amostra.

A cấmara 2 possui un corpo támbén cilindrico, con diấmetro externo de $138 \mathrm{~mm} \mathrm{e}$ altura de $150 \mathrm{~mm}$. Perpendicularmente à sua parede estão soldados dois tubos alinhados entre si, de comprimentos de $200 \mathrm{~mm}$ e $400 \mathrm{~mm}$ e diâmetro de $89 \mathrm{~mm}$. Nesta câmara encontra-se grande parte do tubo de vô, o detector de ions secundários (STop) e o acoplamento com o sistema de bombeamento.

O comprimento total do equipamento é de $135 \mathrm{~cm}$ e as câmaras encontram-se montadas sobre bancadas feitas em estruturas metálicas. $O$ alinhamento entre as cămaras $t$ possivel com o emprego de apoios que permitem a movimentaçâo das câmaras. 


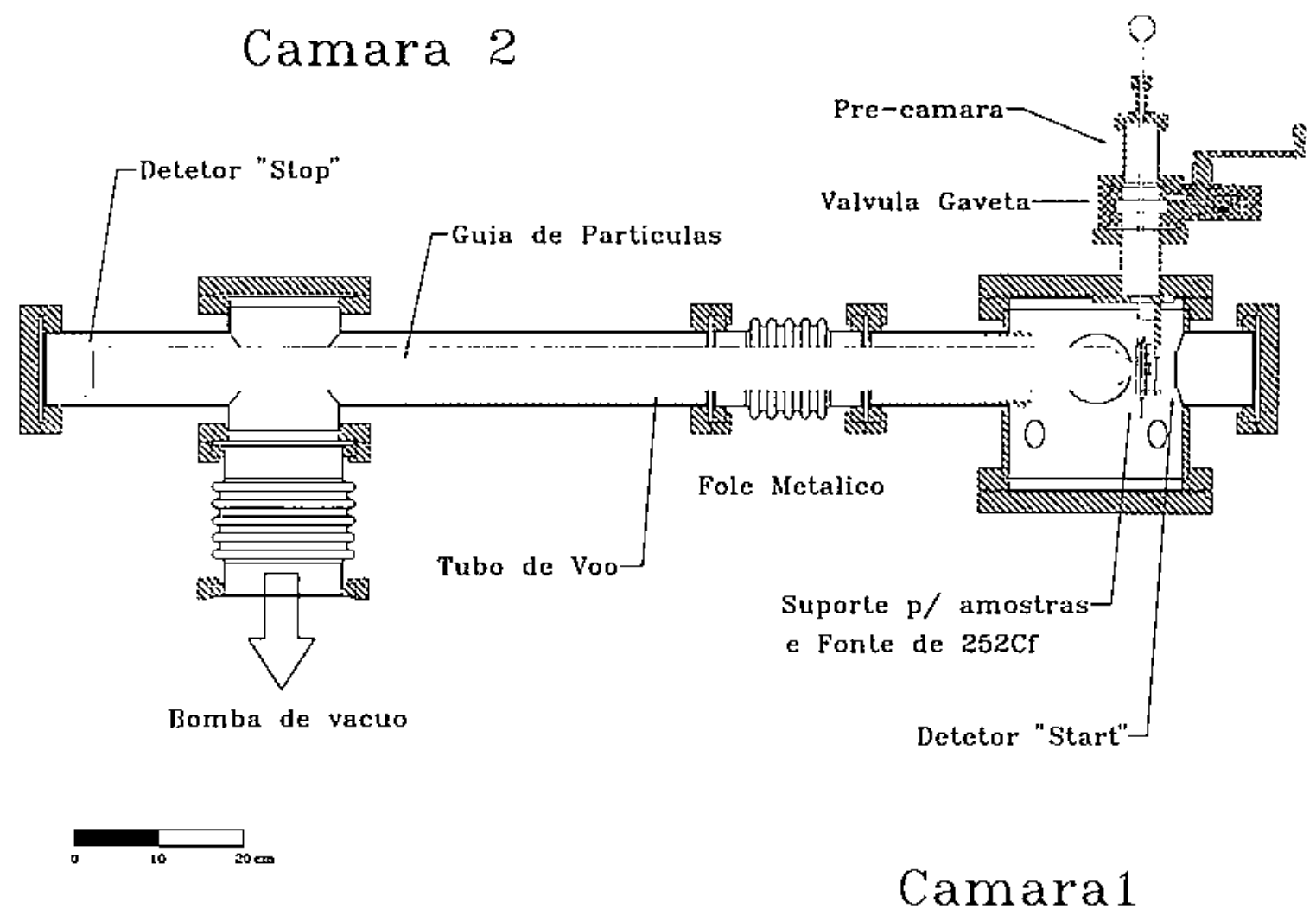

Fig. 3.1 - Vista em corte do espectrômetro, mostrando os vários componentes do equipamento. 


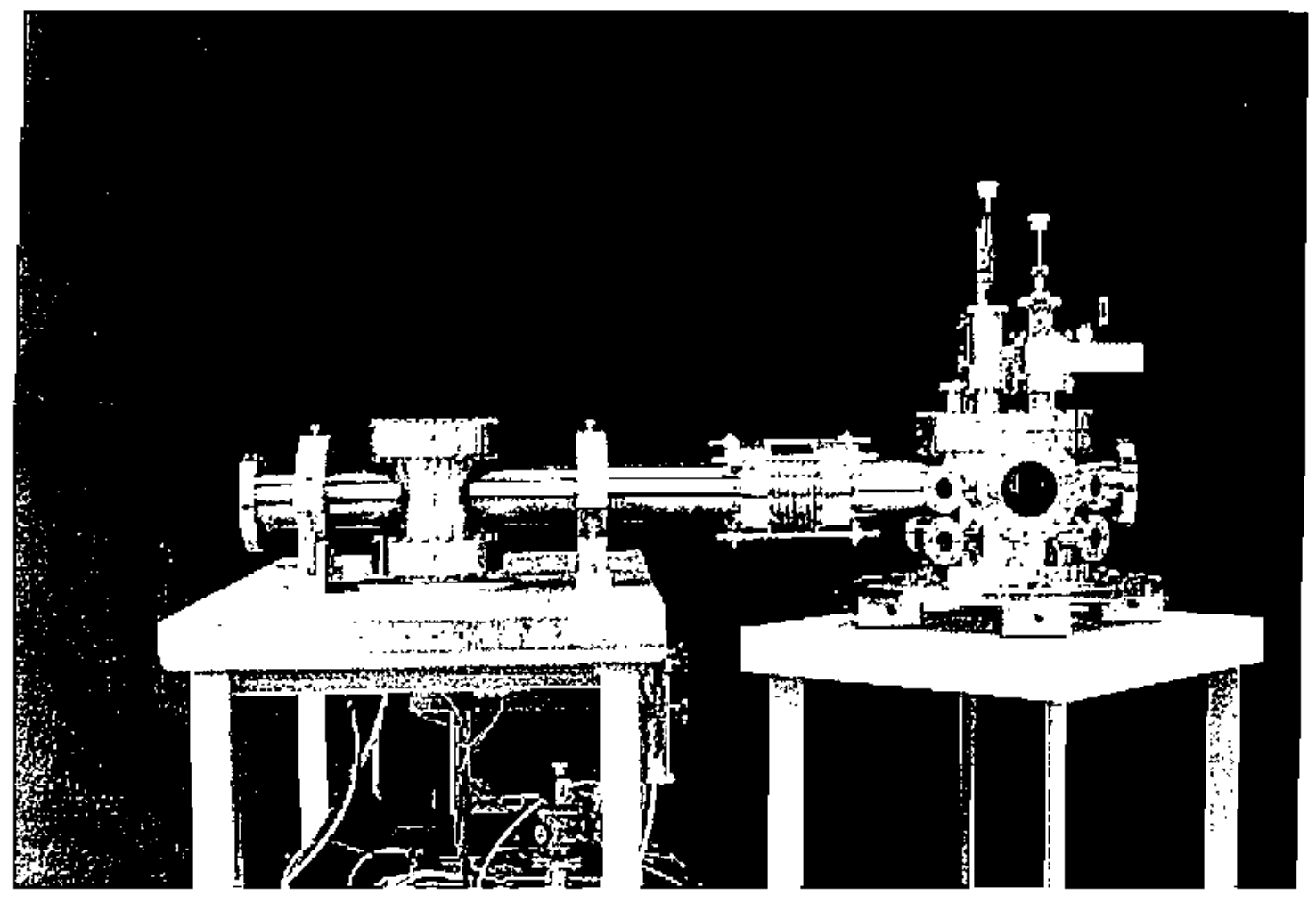

Fig. 3.2 - Montagem do sistema de vácuo com suas duas câmaras conectadas por um fole metálico. 


\subsection{Trocador de Amostras, Suportes de Amostra e Fonte ${ }^{252} \mathrm{Cf}$}

O sistema de troca de amostras está instalado na câmara 1, em sua tampa superior. Este sistema pemite a introduçăo de até três amostras simultaneamente, sem a necessidade da abertura da câmara principal para a pressão atmosférica, minimizando o tempo de espera para o início das análises. A Fig. 3.3 (a) apresenta o trocador de amostras constituido por uma prềcç̂mara, uma válvula gaveta e uma haste metảlica de translação. A movimentação do portam-amostras no interior do sistema de vacuo s acionada exteriomente por meio de hastes e alayancas metálicas. Dessa forma, as três amostras podem ser posicionadas ì frente da grade de aceleração no momento de suas medidas.

Na Fig. 3.3 (b) é apresentado um esquema da montagem dos suportes de amostras, da grade de aceleraçăo e da fonte de ${ }^{252} \mathrm{Cf}$ A fonte esta posicionada entre o detector de fragmentos de fissão e amostra, a uma distancia de 13 mm de suas superficies.

A fonte de ${ }^{252}$ Cf pode ser movimentada para o seu armazenamento no tuterior de uma estrutura de proteção durante os procedimentos de troca de amostra e mudança de tensâo de aceleração, sendo esta uma forma de garantir sua integridade física e ímpedir eventuais contaminações das partes internas do sistema de vácuo. A movintentaçăo da fonte também feitu com o uso de hastes a alavancas metalieas, que podem ser acionadas exteriormente sem a quebra de väcuo.

Os suportes de amostras e da fonte de ${ }^{252} \mathrm{Cf}$ estão montados em uma placa de vidro temperado, usado para isolação elétricica dos mesmos. As hastes metálicas de movimentaçăo estão isoladas dos suportes por conexöes de Delrin. Este conjunto mostrou ser capaz de suportar tensōes de até $118 \mathrm{kV}$. Acima destas tensöes ocorrem faiscamentos entre o suporte e as partes metaltoas adjacentes. $O$ detector de fragmentos de fissão tamberm encontra-se montado nesta placa de vidro, mas esta isolado eletricamente dos suportes de amostra e da fonte radioativa.

A sequência de fotos da fig. 3.4 e Fig. 3.5 apresenta as estruturas de sustentação dos suportes de amostras e da fonte de ${ }^{252} \mathrm{Cf}$, respectivamente. 


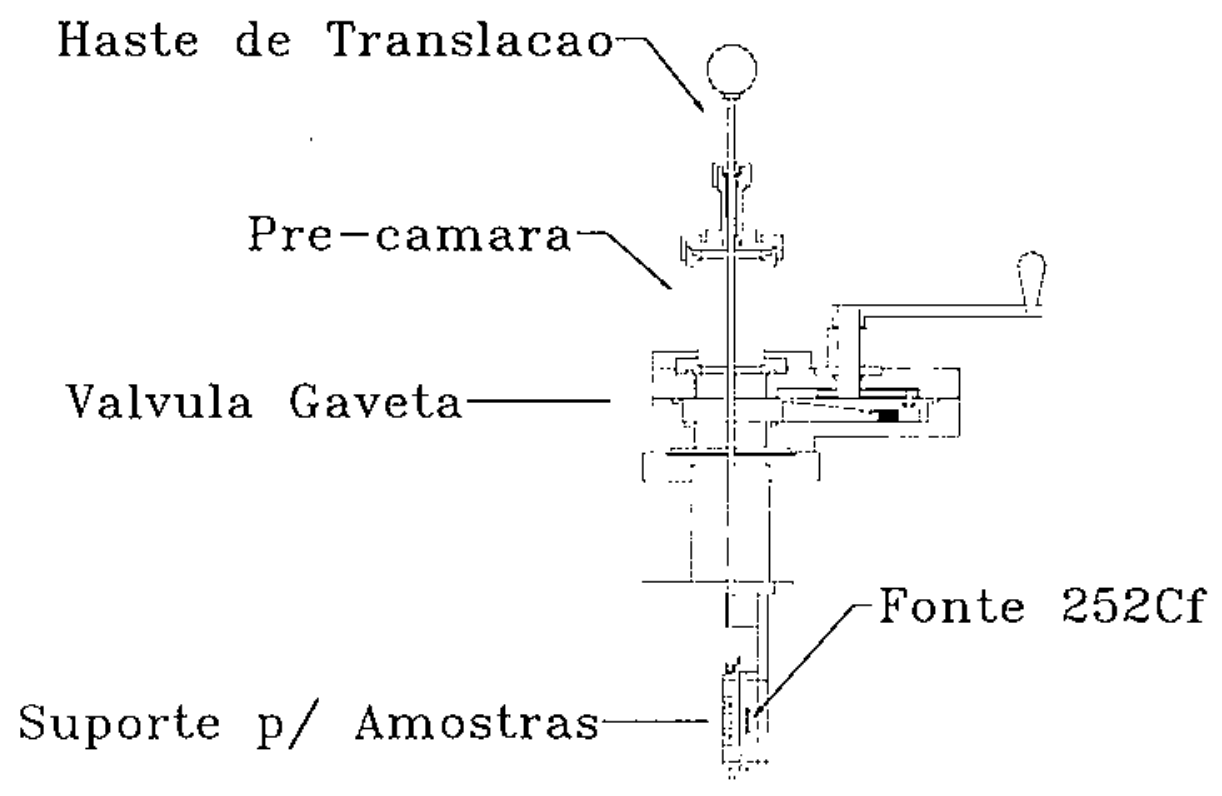

(a)

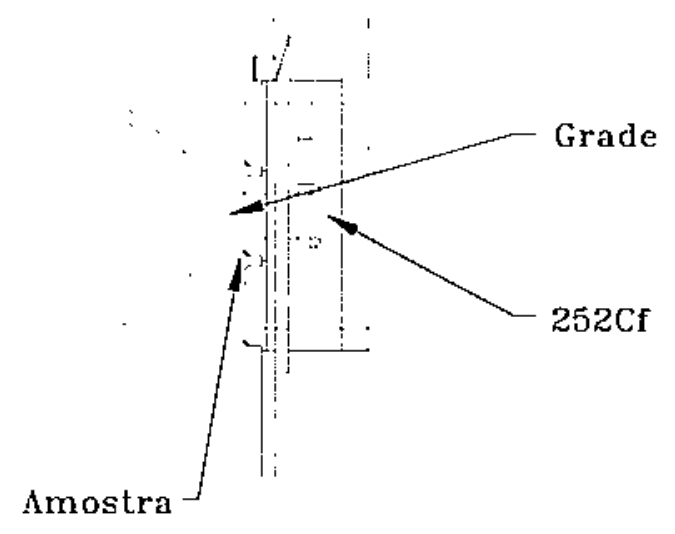

(b)

Fig. 3.3 - (a) Detalhes do sistema de troca de amostras e (b) da região da grade de aceleração e suportes de amostras e da fonte de ${ }^{252} \mathrm{Cf}$. 


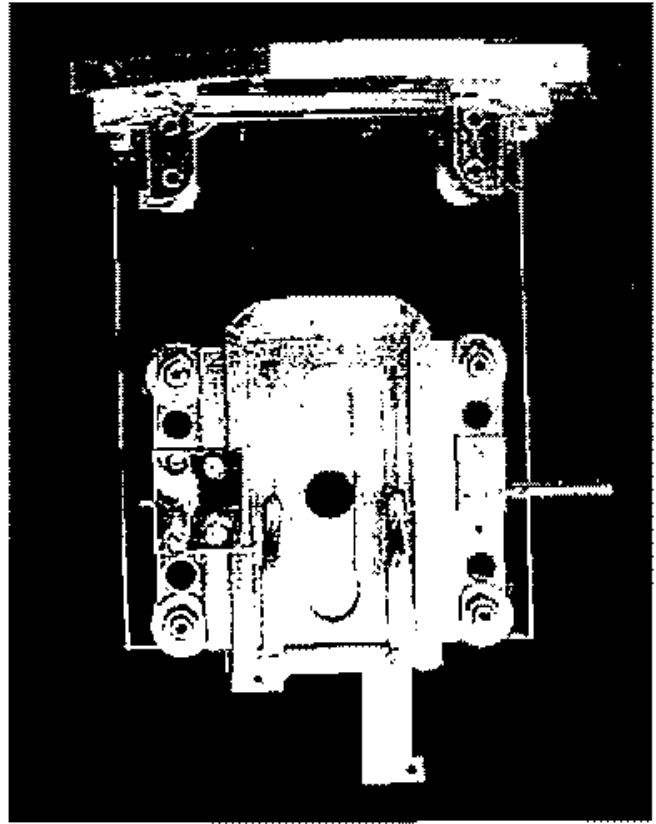

(a)

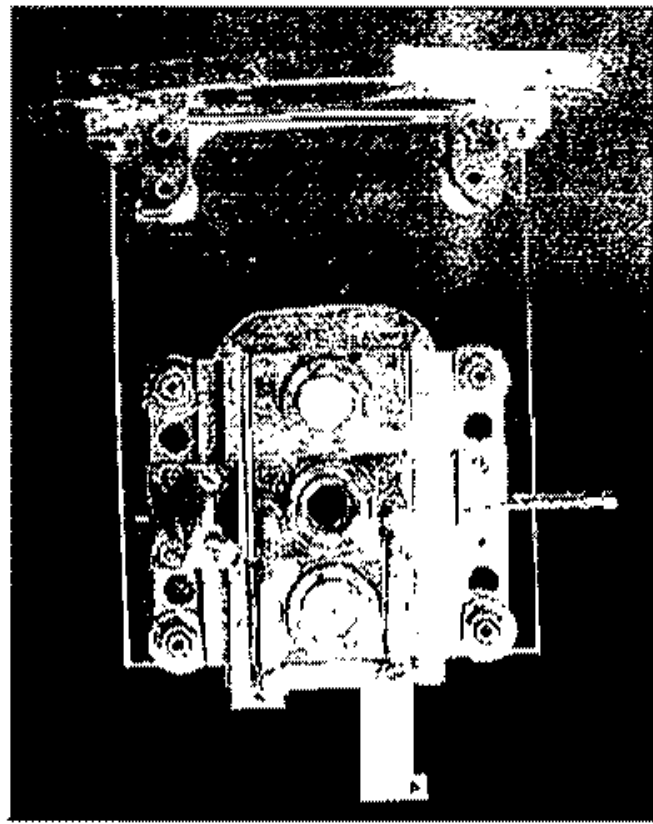

(b)

Fìg. 3,4 - Vistos da eshutura de sustentaça do suporte de amostras: (a) apenas a estrutura e (b) com o suporte de amostras. 


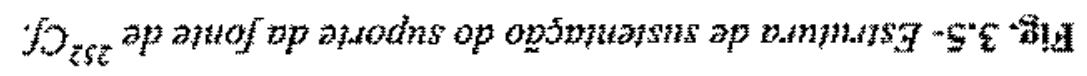

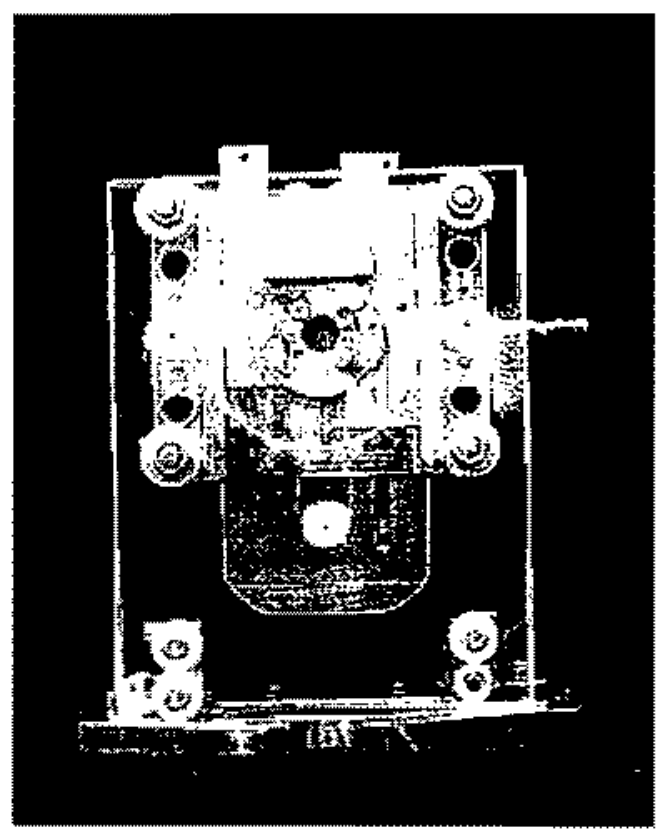




\subsection{Tubo de Vồ e Guia Eletrostático de Particulas}

No interior do sistamu de vácuo encontra-se montado um tubo de vồ de $111 \mathrm{~cm}$ de comprimento e $50 \mathrm{~mm}$ de diâmetro, feito de aço inoxidával (Fig. 3,6). A fixaçăo do tubo de vôo no interior da câmara de vácuo é feita por dois suportes que possuem tambèm o papel de permitir o ajuste da posiçäo do tubo no interior da câmara para a sua centralização em relaça a conjunto formado pelo porta-amostras e pela fonte de ${ }^{252} \mathrm{Cf}$.

Em um dos extremos do tubo extá instalado o detector de lons secundútios (Stop) e no outro extremo, um suporte cônico, onde a grade de aceleraçấo está montada. $\mathrm{A}$ grade, de $90 \%$ de transmissão ${ }^{4}$, permite a entrada dos ions secundarios para o interior do tubo de vôo após a etapa de aceleraçäo. Seu uso minimiza as inomogeneidades do campo elétrico na regiâo de aceleração, responsảveis pelas alterações das trajetớtas dos ions secundários, que podem prejudicar a resoluçato do instrumento. A grade encontra-se fixada em um anel de aço de $10 \mathrm{~mm}$ de diâmetro, estando a $5 \mathrm{~mm}$ da superficie da amostra. Nesta regităo, onde ocorre a aceleraçäo de íons secundários, a intensidade do campo elétrico pode chegar a um valor de $3600 \mathrm{~V} / \mathrm{mm}$ (para uma diferença de potencial de $18 \mathrm{kV}$ ).

Ao longo do centro do tubo de vốo está instalado um guia eletrostático de partículas, formado por um fio de Tungstenio com diametro de $150 \mathrm{\mu m}$, recoberto por uma fina camada de Ouro. Sua funçã̃o a de aumentar a transmissão de lons secundários provenientes da superficie da amostra até o detector Stop. Seu comprimento total é de $102 \mathrm{~cm}$ e encontra-se a uma distância de $52 \mathrm{~mm}$ da grade de aceleração e a $35 \mathrm{~mm}$ da face frontal do detector Stop. O fio está suspenso nos seus extremos por dois tubos de aço de I mm de diametro. O fio de W/Au encontra-se isolado eletricamente, sendo possivel aplicar diferenças de potencial entre o fio e o tubo de vô de at $\pm 1500 \mathrm{~V}$. Para tensỏes fora deste intervalo, ebservado o aparecimento de faiscas entre o fino de W/Au o os tubos usados para sta sustentação. A Fig. 3.7 apresenta os resultados dos testes de isolamento, mostrando a corrente de fuga do sistema em função da tensão aplicada no fio.

${ }^{4}$ Buck Bee Mears, USA 


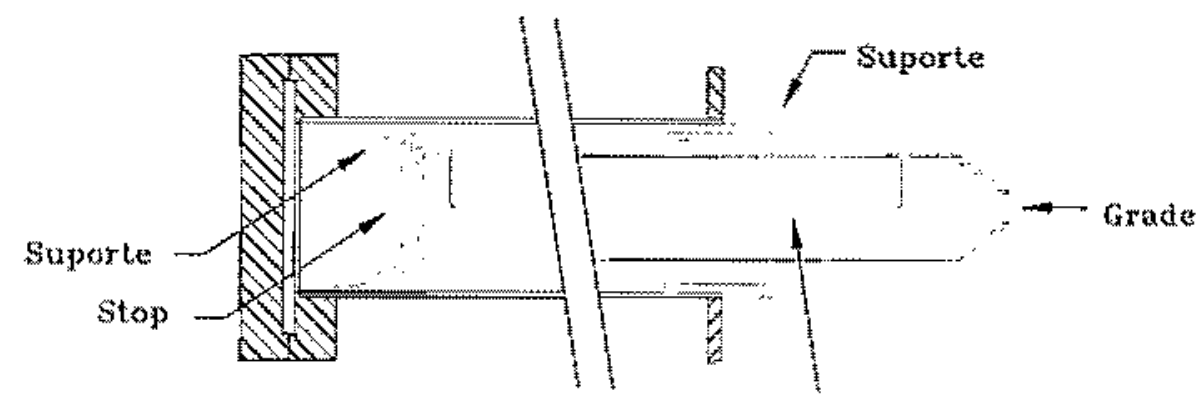

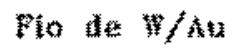

Fig. 3.6 - Detalhe da fixaçäo do tubo de vôo no interior do sistema de vácuo e do suporte do fo de Wha do guia eletrostatico de particulas.

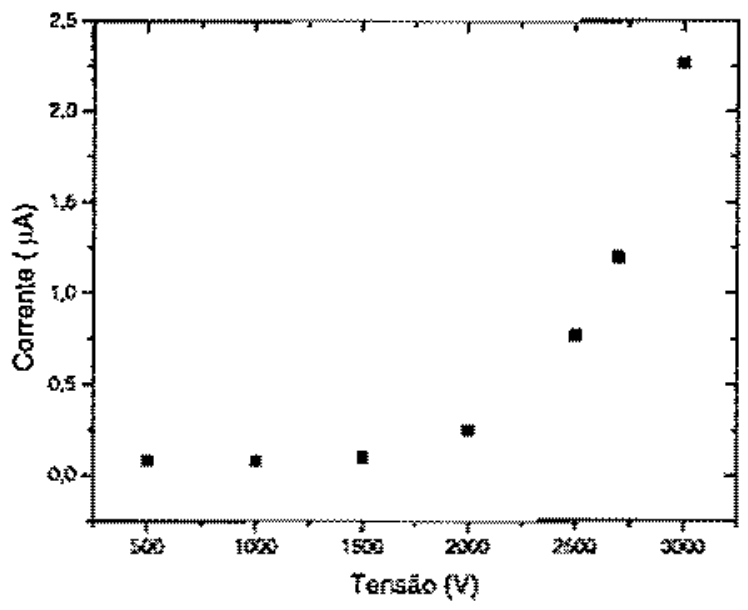

Fig. 3.7 - Resultados dos testes de isolação do fio de W/Au do guia eletrostático de particulas: corrente de fuga do sistema en função dä tensäo aplicada no fio. 


\subsection{Alinhamento do Sistema}

Inicialmente foi feito um alîhamento das câmaras de vácuo, sendo necessário movimenta-las aas direçôes vertical e horizontal usando-se, para isso, parafusos do sistema te sustentaço das cầmaras projetados para esta funalidade.

$O$ alinhamento dos componentes intenos do spectrômetro de massa foi realizado com o auxilio de aberturas circulares de $0,5 \mathrm{~mm}$ de diâmetro e de dois aparelhos de raios laser de He-Ne, conforme a montagem esquematizada na Fig. 3,8. A utilizaçấo dos dois laseres cyitou a perda do refereneial de alinhamento, mesmo quando um dos feixes era

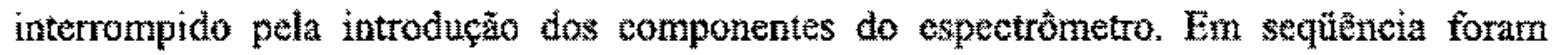
instalados o tubo de vô, com o seu guia eletrostático de particulas, os suportes de amostras e da fonte radioativa e os sistemas de deteção. A precisão obtida para o alinhamento é de $\pm 0,25 \mathrm{~mm}$, sendo esta limitaçuấo devida ao conjunto de fendas utilizado.

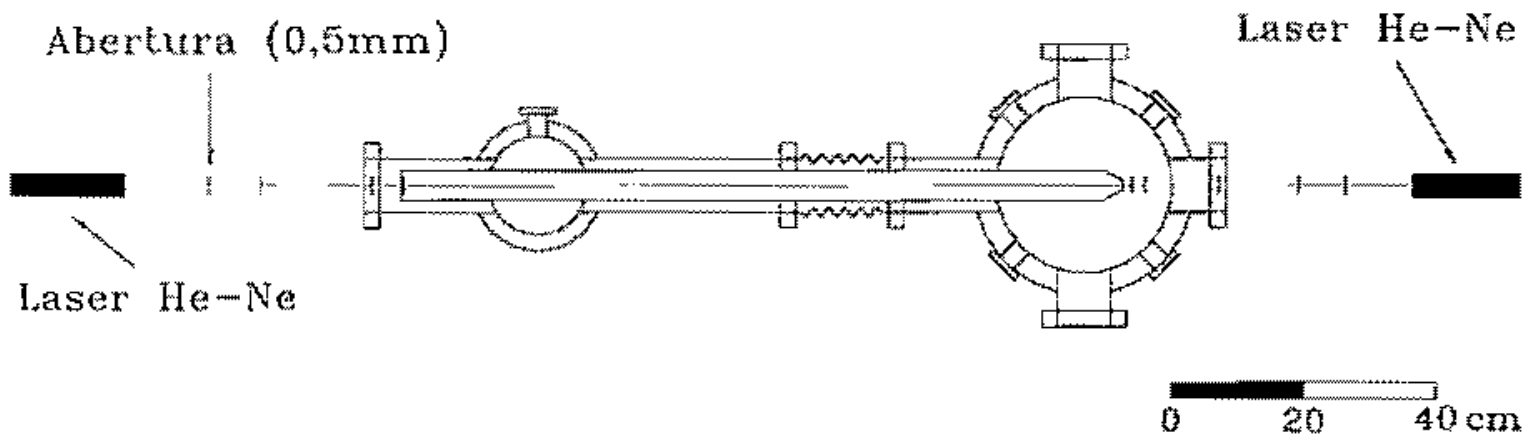

Fig. 3.8 - Esquema do alinhantento do espectrometro de massa. Nesse procedimento for usado um conjumto de aberturas circulares de $0.5 \mathrm{~mm}$ e dois aparelhos de raios laser de $\mathrm{He}-\mathrm{Ne}$ 


\subsection{Sistema ate Bombeamento}

O sistema de vácuo do espectrômetro de massa utiliza um conjunto formado por uma bomba turbomolecular uma bomba mecanica de duplo estagio. A bomba turbomolecular encontra-se instalada na cẩmara 2 . Com este tipo de bombeamento há uma menor taxa de contaminação por compostos orgânicos no sistema de vácuo. Uma bomba turbomolecular retira os gases do sistema pela colisão das moléculas do gás com as palhetas to rotor, que giram a 30000 mpm. A bomba turbomolecular usada tem velocidade de bombeamento de $600 \mathrm{~m}^{3} / \mathrm{h}$ para a faxa de pressócs de $10^{-3}$ tor a $10^{-16}$ torr e trabalha associada a uma bomba mecânica com velocidade de bombeamento de $16 \mathrm{~m}^{3} / \mathrm{h}$ para a faixa de pressöes de $10^{-3}$ torr a 760 torr.

A pressâo interna do sistema e da ordem de $10^{-7}$ torr. As medidas de pressäo para esta faixa säo ftitas com medidores de ionização Penning. Para pressôes acima de $10^{-3}$ tom o sistema utiliza medidores termopar ${ }^{*}$.

$O$ sistema de troca de amostras possuí uma bomba mecânica auxiliar, acionada apenas durante os procedimentos de substituição dos alvos. A válvula gaveta, instalada entre a prể-câmara e o sistema de análise, deve ser aberta para a introduçăo das amostras quando a pressẫo da pré-cămara alcança um valor de $10^{2}$ torr. Para evitar a contaminação da superficie da amostra por vapores organicos provenientes da bomba mecantea é utilizada uma armadilha de nitrogênio liquido conectada entre a bomba e a pré-câmara.

\footnotetext{
5 Modelo Tru 170 da Balzers.

- Modelo DUO 016B da Balzers.

7 Modelo Varian Multi-Gauge com transdutor UHV-24, EUA.

${ }^{3}$ Modelo Varian Mutti-Gauge com transdutor 531, EUA.
} 


\section{Sistema de Aquisiộẫo de Dados}

O sistema de aquisiçăo de dados do espectrồmetro de massa faz uso de eletrônica modular padrão NM (Nuclear Instrtments Modules) [Kno89]. São utilitzados módulos para tratamento de sinais rápidos lentos em medidas de intervalos de tempo de altura de putsos dos detectores.

\section{I Eletrônúca para Análise Tomporal}

Pata a medida da distribuiçä́o temporal dos fons secundarios provenientes da amostra, é utilizada a montagem eletrônica apresentada na Fig. 4.1. Um produto de fissão a alcançar o detector Start gera um pulso que dispara o cronómetro eletrónico. Os fons secundánios emitidos da amostra pelo produto de fissăo correlacionado com aquele aue dispan o cronômetro interrompern a contagem de tempo com pulsos gerados no detector Stop. Os sinais provenientes dos detectores Start e Stop săto tratados inicialmente por prê-anplificadorts rápidos. Conectados às saidas dos pré-amplificadores estão discriminadores de fraçuto constante (constant fraction discriminator - CFD). Esses módulos säo ajustados para serem disparados por sinais cujas amplitudes estejam acima de um nivel de tertsto prérdefinido.

Um dos módulos de medida temporal é um conversor tempo-amplitude (time to amplitude comverter - TAC), que envia um sinal analogico com amplitude proporcional ao intervalo de tempo medido para un analisador multicanal que armatena a informaça. $O$ disparo desse crônometro por outro sinal de Stan é novamente realizado somente após um periodo de tempo prêprogramado, que pode ser ajustado entre $50 \mathrm{~ns}$ e $80 \mu \mathrm{us}$ A resoluçäo temporal desse instrumento é meror ou igual a $0,01 \%$ da escala de tempo selecionada mais $25 \mathrm{ps}$.

Outro cronômetro empregado um conversor tempo-digital time to digitat convertey - TDC), onde o intervalo de tempo medido representado por uma palava 
digital. Esse módulo possui a característica de medir sucessivos intervalos de tempo relacionados a um mesmo evento que dispara o processo de contagem. No caso do espectrómetro de massa o uso desse tipo de cronômetro permite o registro de uma sequiência de intervalos temporais relativos a ions formados em um mesmo evento de dessorção. Un novo sinal de Staft é aceito somente após decorrido um periodo de tempo pré-programado entre $80 \mathrm{~ns}$ e 163,84 us. A resoluçäo temporal do TDC é de $0,1 \mathrm{ppm}$ da escala de tempo mais $25 \mathrm{ps}$. 


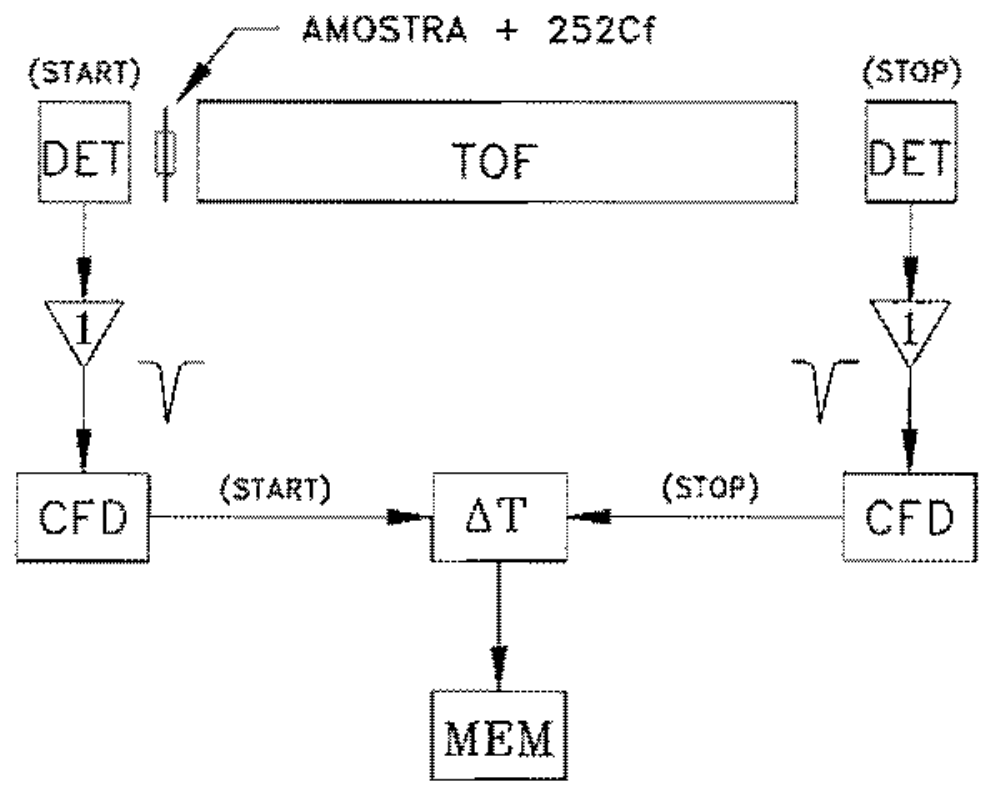

TOF - Tubo de tempo de vôo (Time of Flight)

DET - Detectores multiplicadores de elétrons

1. Pré-amplificador rápido

CFD - Discriminador de fraçã̃o constante (Constant Fraction Discriminator) ${ }^{\text {11 }}$

$\Delta \mathrm{T}$ - Cronometro detrônico: conversor tempo-amplitude (Time to Amplitude Converter - $A C)^{n}$ ou conversor tempo-digital (The to Digital Corverter $\operatorname{TDCl}^{12}$

MEM - Memória de amozazenamento

Fig. 4.1 - Diagrama da eletrónica usada para medidas de intervalo temporal.

Prétamplificador modelo YT110 da EO\&G Oriec, Oak Ridge, EUA.

10 Discriminador de frafío consiante modelo $\$ 53$ da EG\&G Oriec, Oak Ridge, DLA.

11 Conversor tempo-amplitude modelo 467 da EG\&G Ortec, Oak Rìnge, EUA.

12 Conversor tempo-digital modelo PTA 9308 da EG\&G Ortec, Oak Ridge, EUA. 


\subsection{Ajuste dî Eletrônica}

A natureza estatística do processo de multiplicaçẫo eletrônica nas placas multiplicadoras de elétrons de microcanais (microchannel plates - MCP), usadas nos detectores Start e Stop, provoca grandes flutuações na amplitude de seus pulsos [Wiz79]. Deste modo, desaconselhado o emprego de discriminadores de tempo gut utilizeri simplesmente um nivel constante de tensăo para seleçẵo do ponto de disparo de seus circuitos. Diferentes amplindes geram deslocamentos temporais no ponto de dispato desses discriminadores (amplitude time walk), causando perdas na resolução temporal (Fig, 4.2). Nesse caso o discriminador de fraçäo constante CFD pode ser usado na eletrönica associada ao espectrôntro de massa por tempo de voo, deste que alguns cuidados sejam tomados.

O principio de functonamento do CFD baseiam na manipulagâa dos pulsos provenientes dos detectores, de forma a gerar um ponto de disparo no discriminador independente da amplitude dos pulsos (Fig. 4.3) [Kno 89]. Em uma primeira etapa o sinal é dividido enviado a dois circuitos, sendo em um deles atenuado a uma fração de $10 \%$ a $20 \%$ da amplitude do sinal orginal e no outro invertido e atrasado por um intervalo de tempo $i_{z_{3}}$ da ordem do tempo de subida do pulso. Em seguida os dois pulsos sáto somados, resultando em um pulso bipolar, 0 ponto de cruzamento do pulso bipolar com a linha de base é utilizado para disparar o discriminador; sendo este ponto independente das amplitudes dos sinais, desde que os pulsos na entrada do modulo possuam a mesma forma. Com este tratamento de sinais é possivel minimizar a perda da resolução teroporal provocada pelas variaçôs de amplitude.

Entretanto, os CFD is existentes foram desenvolvidos para trabalhar com pulsos formados por fotomultiplicadoras, mais lentos (tempo de subida da ordem de 1 a 2 ns) e de maior amplitude que os pulsos provenientes dos MCP's. Cova et al. [Cov90, Cov91, Cov93], sugerem procedimentos que permitem contornar esta limitação, tornando a utilizaçä̀ de CFD's também adequadia para o uso com os MCP's, sem a necessidade de alteraçôs dos circuitos deste módulo. Uma sugestão é ntilizar préramplificadores com pequena largura de banda (tempo de subida da ordem de 1 ns) e que, apos uma 
pré-filtragem, forneçam pulsos com larguras entre 2 ns e 3 ns, dentro da faixa de operação do $C F D$. Estes pré-amplificadores também deven fornecer ganhos que possam compensar a diferença existente entre as amplitudes dos pulsos dos $M C P$ 's e das fotomultiplicadoras.

Seguindo essas sugestoes, neste trabalho foram usados com os $M C^{p}$ 's pré-amplificadores rápidos com largura de banda de 10 a $350 \mathrm{MHz}$ e ganho de 200 vezes.

A Fig. 4.4 apresenta a distribuiçăo temporal de ions de $\mathrm{H}^{*}$, com $17 \mathrm{keV}$ de energia, provenientes de uma amostra de $\mathrm{CsI}$, com largura à meia altura de $(240 \pm 20)$ ps, medida com o sisterna de aquisiçẫo após o ajuste da eletrônica. Nos ajustes dos CFD's usados no sistema de aquisição de dados foi empregada a eletroñnica esquematizada na Fig.4.5. Neste caso o disparo do cronômetro eletrônico foi feito por elétrons provenientes da amostra, utilizados para eliminar a contribuição devida à distribuiçăo bimodal das velocidades dos fragmentos de fissão. 


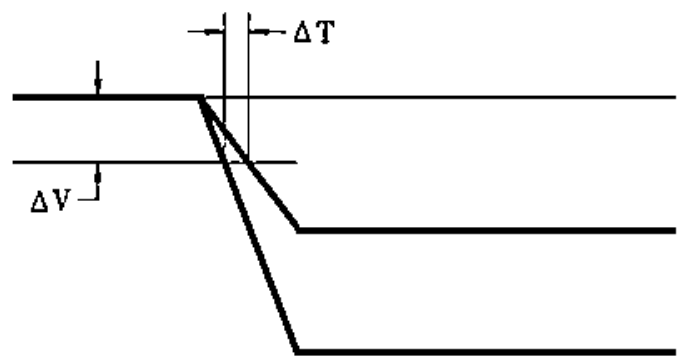

Fig. 4.2 - Deslocamento temporal $\Delta T$ existente em discriminadores disparados por um nivel constante de tensão $\Delta V$, provocado por pulsos de um mesmo evento mas com diferentes amplitudes. Apenas a borda dianteira dos pulsos é apresentada para maior clareza [Kno89].

(a)

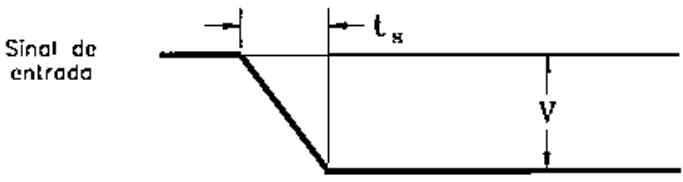

(b)

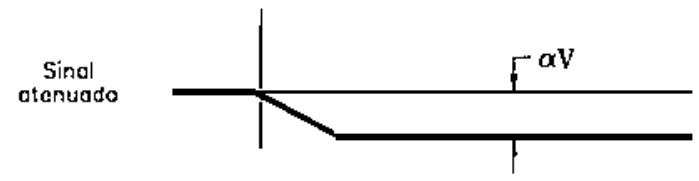

(c)

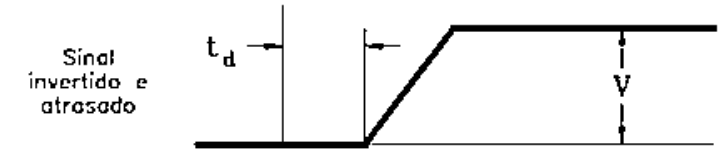

(d)

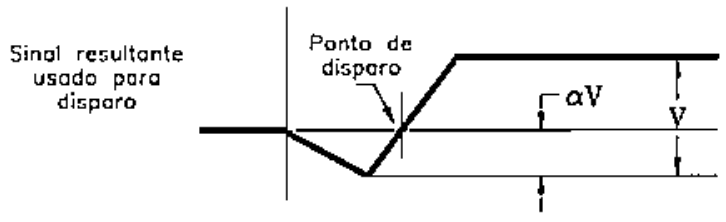

Fig. 4.3 - Esquema do tratamento de pulsos realizado por um discriminador de fração constante CFD sendo $\alpha$ o fator de atenuação, $t_{s}$ o tempo de descida do pulso e $t_{d}$ o atraso externo. O ponto de disparo do pulso resultante é independente da amplitude do sinal de entrada [Kno89]. 


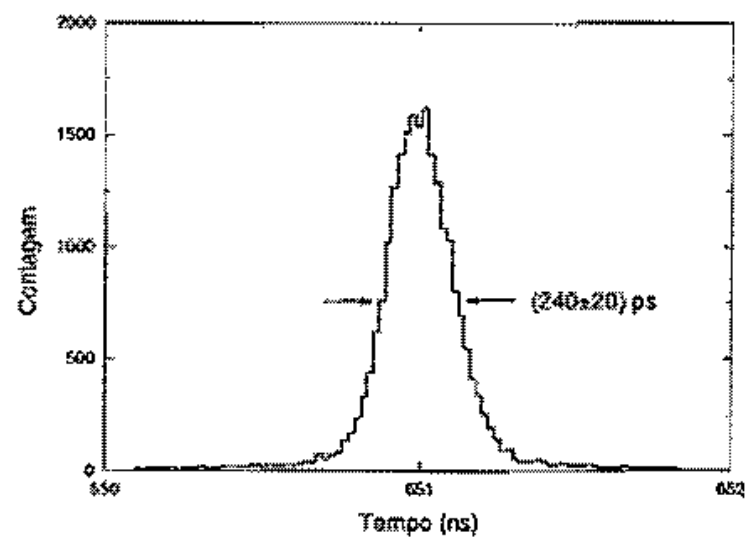

Fig, 4,4 - Distribucăo temporal dos lons $H^{H}$, com $17 \mathrm{keV}$ de energia, provenientes de uma amostra de CsI após ajuste da eletrônica to aquisiçäo de dados.

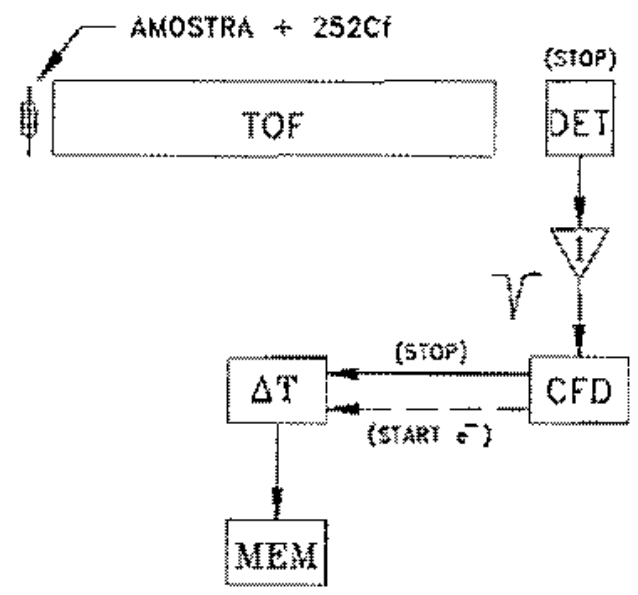

TOF. Tubo de tempo de vô (Time of Flight)

DET - Detectores multiplicadores de eletrons

1. Pré-amplificador rápido

CFD - Discriminador de fração constante (Constant Fraction Discriminator)

AT - Cronômetro eletrônico: conversor tamponamplitude (Time to Amplitude Converter - TAC) ou conversor tempo-digital (Time to Digital Converter TOO

MEM - Memória de ammazenamento

Hig. 4.5 - Esquema da eletrônica milizada para medidas de intervalo de tempo com o asparo do cronônetro eletrônto realizado pelos elétrons provententes da amostra. 


\subsection{Eletrônica para Análise de Amplitude de Pulsos}

O sistema de aquisiçăo de dados usado nas medidas de amplinte de pulsos dos detectores Start Etop é apresentado na Fig. 4.6. Nesse sistema fe feita uma coincidencia entre pulsos do detector enviados para os ramos da eletrônica rápida e lenta O CFD, usado como um analisador monocanal, faz com que apenas pulsos acima de um determinado valor de tensto possam ser medidos. Para o amazenamento dos dados é usado um analisador multicanal.

No caso em que as distribuiçôes de amplitude dos detectores devan estar correlacionados com o tempo de vôo de algum íon secundário proveniente da amostra é usada a eletrônica esquematizada na Fig. 4.7. O TAC é usado para gerar um sinal de coincitencia, utilizando uma janela para selecionar o tempo de vô do íon de interesse, obtida com os controles do analisador monocanal incorporados neste módulo. Assin, esse módulo fornece um sinal logico (GATE) que é enviado para disparar a etapa subseqüente da eletrônica, o módulo $L G S$, em coincidência com o tempo de vồ do ion de interesse. 


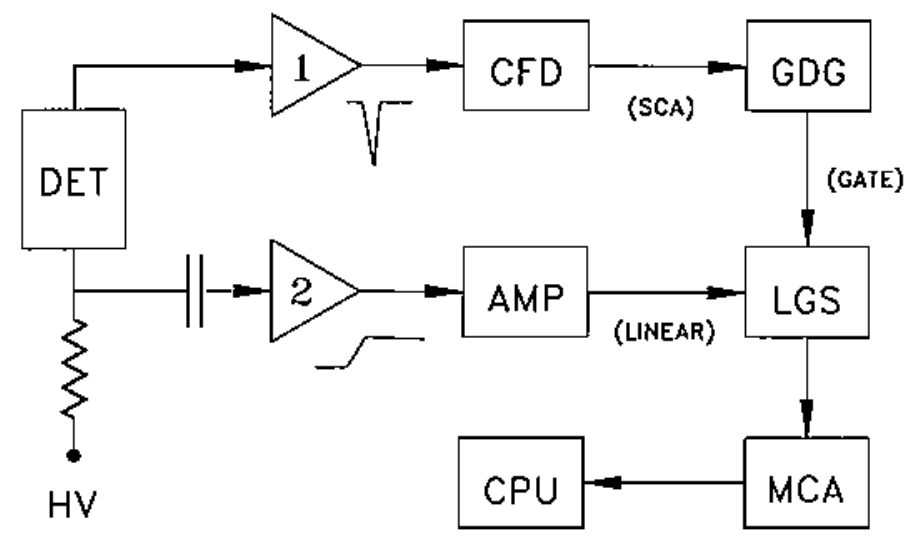

DET - Detector

1 - Pré-amplificador rápido

2 - Pré-amplificador de carga ${ }^{13}$

CFD - Discriminador de fração constante (Constant Fraction Discriminator)

AMP - Amplificador ${ }^{14}$

GDG - Gerador de atraso temporal e sinal para lógica de coincidência (Gate \& Delay Generator) ${ }^{15}$

LGS - Detector de máxima amplitude e módulo de coincidência (Linear Gate \& Stretcher) ${ }^{16}$

MCA - Analisador multicanal (Multichannel Analizer) ${ }^{17}$

CPU - Computador

Fig. 4.6 - Diagrama da eletrônica utilizada para a determinação da distribuição de altura de pulsos dos detectores Start e Stop, em coincidência com os pulsos rápidos selecionados com o nivel de discriminação do módulo (CFD).

13 Pré-amplificador modelo 124 da EG\&G Ortec, Oak Ridge, EUA.

14 Amplificador modelo 572 da EG\&G Ortec, Oak Ridge, EUA.

${ }^{15}$ Módulo 416A da EG\&G Ortec, Oak Ridge, EUA.

${ }_{17}$ Módulo 542 da EG\&G Ortec, Oak Ridge, EUA.

17 Analisador multicanal modelo Spectrum 88 da Nucleus, EUA. 


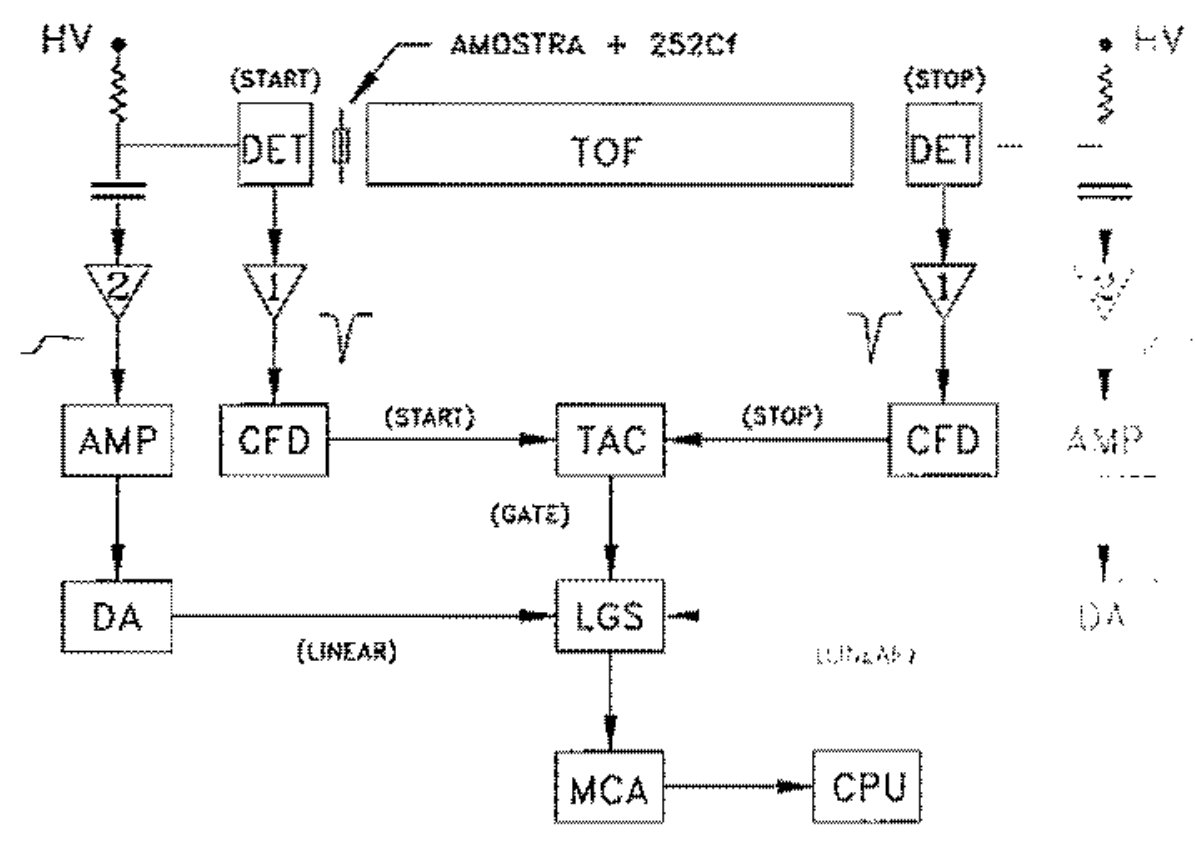

DET - Detector

1 - Pré-amplificador rápido

2 - Pré-amplificador de carga

CFD - Discriminador de fracão constante (Constant Fraction Discriminator)

AMP - Amplificador

TAC - Conversor tempo-amplitude (Time to Amplitude Converter)

LGS - Detector de máxima amplitude e módulo de coincistência (Lînear Gate \& Stretcher)

DA - Amplificador atrasador (Delay Ampliner)

MCA - Analisador multicanal (Mulichannel Anatyzer)

CPU - Computador

Fig. 4.7 - Diaghama da eletronica ksada para a detaminaçäo da distribuicăo de altura de

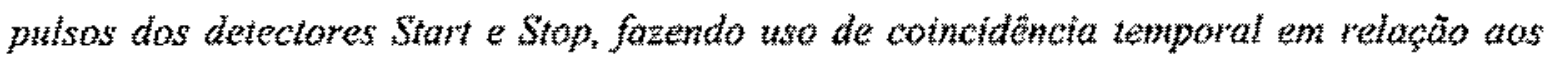
ians provenientes da amostra. 


\subsection{Sistema de Deteç̧äo de Íons - Detectores Stop e Start}

O espectrômetro de massa utiliza um sistema de detecção para produtos de fissão provenientes da fonte de ${ }^{252} \mathrm{Cf}$ (detector Start) e um para ions secundários emitidos no processo de dessorção da amostra (detector Stop).

Ambos os detectores são construídos com placas multiplicadoras de elétrons de microcanais (microchannel plates - MCP). Os $M C P$ 's, por serem sensíveis a partículas carregadas e formarem pulsos extremamente rápidos, são comumente empregados em sistemas de deteç̧ão de espectrômetros de massa por tempo de vôo que utilizam a técnica PDMS [Wiz79, Hed87]. Essas placas são formadas pela fusão de um feixe de microtubos de vidro-chumbo com diâmetros internos da ordem de $12 \mu \mathrm{m}$, possuindo paredes semicondutoras, adequadas para a produção de elétrons secundários sob a incidência de elétrons, ions, fótons de ultravioleta e raios X. O ganho nesse dispositivo é obtido pela emissão em cadeia de elétrons secundários à medida que os mesmos colidem com as paredes e são arrastados para o interior do microtubo, devido à presença de um campo elétrico formado pela diferença de potencial aplicada entre as faces do $M C P$. Ganhos de $10^{3}$ a $10^{4}$ podem ser alcançados por placa multiplicadora. Para que ganhos maiores possam ser obtidos, os detectores são montados com duas placas em uma configuração Chevron, proporcionando ganhos da ordem de $10^{6}$ a $10^{7}$. Nesse tipo de montagem é minimizada a corrente inversa de íons positivos formadas no interior dos microcanais, responsável pela limitação do ganho do dispositivo [Wiz79].

O detector Stop tem a função de fornecer os sinais usados para a interrupção do sistema de análise do tempo de vôo dos íons secundários. Para que isso ocorra, o detector deve ser sensivel a ions com energia da ordem de $\mathrm{keV}$.

Para um mesmo tipo de íon, a intensidade de elétrons secundários emitidos pela superficie do detector é descrita por uma distribuição de Poisson [Beu77] e a probabilidade de um íon ser detectado é dada por [Gen89]: 


$$
P=1-e^{-r \gamma}
$$

onde $y$ é o número médio de elétrons secundărios amitidos.

O numero médio de elétrons secundarios emitióos $y$ depende de varios fatores relacionados com as interaçōes dos tons com a superficie do MCP, do tipo de material tmpregado na construção do detector das condiçoes superficiais fontaminaçăo rugosidude).

Valores de $\gamma<1$ foram encontrados em medikas com lons de biomoléculas na fáxa de energia de keV [Hed87, Gen89]. Geno et al. [Gen89], usando ions formados por aminoácidos e peptídeos, com velocidades entre $15000 \mathrm{~m} / \mathrm{s}$ e $32000 \mathrm{~m} / \mathrm{s}$ e massas entre 86 u.m.a. e 1059 u.m.a., verificaram que $\gamma$ e proporcional à massa $m$ do ion e possui dependência exponencial com sua velocidade v [Gen88], isto é:

$$
y=A m e^{B y}
$$

Sendo A e $B$ constantes relacionadas as condiçoes experimentais.

O detector Start, usado na deteç̧⿸丆口 de particulas com energia de MeV, utiliza uma folha conversora de elétrons que permite aumentar a sua área de deteçăo, uma vez que apenas aproximadamente $50 \%$ da área total do $M C P$ é sensivel à radiação [Wiz79, Lam93]. As particulas, ao atravessarem o conversor, arrancam elétrons que são acelerados por uma diferença de potencial ate a superficie da placa do $M C P$. Devido a dispersào das trajetónias destes elétrons existe a possibilidade de ocorrer a excitaçầo de vários microcanais, 0 uso da folha conversora tambetm possibilita a discriminação entre as amplitudes dos pulsos formados por diferentes particulas incidentes. Como visto anteriomente, a fonte de ${ }^{253} \mathrm{Cf}$, em seu processo de decaimento, emite produtos de fissio e uma grande quantidade de particulas alfa. Entretanto, os produtos de fissão, ao passarem pelo conversor, produzem um maior nủmero de eletrons secundários (10 $0^{2}$ elétrons) que as 
particulas alfa (10 elétrons) [Cle73]. Cada conjunto de elétrons, ao ser arrastado até primeira placa, multiplicado, formando um pulso no anodo, sendo de maior amplitude nqueles relatrvos aos dos produtos de fissäo. Apesur da não-linearidade na resposta dos

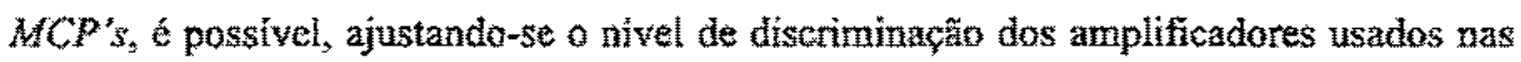
atapas subseqüentes de tratamento de sinais, distinguir entre os pulsos das particulas alta e aqueles relativos aos produtos de fissão.

No processo de fabricaçăo dos MCP's pode ocorrer a formação de tensōes internas no material que, com o passar do tempo, devido a variaçōes de temperatura ou umidade do ar, provocam rachaduras no componente. No momento da montagem dos detectores do espectrômetro, as placas disponiveis encontravam-se danificadas e, para que a montagem não fosse interrompida, optou-se pala utilizaçãa de fragmentos de $M C P^{\prime} s$ que possutam regtôes intactas grandes o suficiente para a montagem.

Os fragmentos foram retirados de $M C P$ 's possuindo $5 \mathrm{~cm}$ de diametro, espessura de $1 \mathrm{~mm}$, microcanais com diàmetro de 12 um e um OAR (Open Area Rate) de $50 \%$ \% ganho por placa é de $4 \times 10^{3}$ para uma tensẫo de $1000 \mathrm{~V}$. Os microcanais fazem um ângulo de $8^{\circ} \mathrm{em}$ relação à normal da superficiè da placa (bias angle).

Inicialmente, com a ajuda de uma lupa, foi feita uma inspeção para determinar regiōes dos $M C P^{\prime} s$ em melhores condiçỏes para fornecer fragmentos de maior área. Uma vez escolhida a area de interesse, o fragmento foi separado cuidadosamente para se evitar novas quebras. Em seguida, a limpeza do fragmento foi feita em um aparelho de ultrassom com álcool isopropilico. Procedimentos de limpeza mais drásticos, fazendo uso de meios ácidos a quente, podem ser encontrados na literatura [Gib94], mas devido à quantidade limitada de $M C P^{\prime}{ }_{3}$, optou-se por uma limpeza mais branda.

Com esse procedimento foram dotidos fragmentos de tamanho adequado para as montagens dos detectores Start e Stop.

18 Fabricados pela Galileo Electro-Optics Corporation (USA). 


\subsubsection{Detector de Ions Secundários - Stop}

Um esquema da montagem mecânica do detector Stop utillizada no espectrômetro é apresentado na Fig. $4.8 . O$ detector Stop possui uma área útil de $314 \mathrm{~mm}^{2}(\mathrm{R}=10 \mathrm{~mm})$. As placas nultiplicadoras de elétrons encontram-se montadas em uma configuração Chevron, estando separadas por anéis confeccionados por placas de circuito impresso de $1,7 \mathrm{~mm}$ de espessura, fettas de resina epoxy a fibra de vidro, com contatos elétricos feitos por pistas de cobre. A espessura do conjunto e de $7,5 \mathrm{~mm}$. $\mathrm{O}$ detector encontra-se posicionado no final to tubo de vô, a $111 \mathrm{~cm}$ da superficie do alvo.

A Fig. 4.9 apresenta um esquema do divisor resistivo usado para a distribuição de tensöes dos varios estagios do detextor. Este divisor, com resistência total de $22,0 \mathrm{M} \Omega$, encontra-se montado na mesma placa onde está a anodo plano usado para coletar os elêtrons. A face da primeira placa multiplicadona encontra-se no mesmo potencial que a grade de aceleraçà do tubo de vô, evitando-se assim que campos elétricos espúrios alterem as velocidades dos lons secundários durante o percurso até o detector Siop. A tensão de polarizaça so sploada ao anodo por meio de um indutor de $1,2 \mu \mathrm{H}$, usado para filtrar eventuaid nidos provenientes da fonte de alta tensăo.

O sinal do detector Stop extraido do anodo utilizando-se um capacitor de descoplamento de $1,5 \mathrm{pF}$ com tensäo de isolacão de $6 \mathrm{kV}$. Entre o capacitor e a linha de aterramento está colocada uma resistêncila de $4,7 \mathrm{k} \Omega$, usada para proteger a eletrônica associada ao detector.

As distorçotes e reflexöes presentes nos pulsos dos detectores do equipamento mostram-se de pequena ordem, como pode ser apreciado na foto do pulso na saida do detector, apresentada na Fig. 4.10, tirada diretamente da tela do osciloscópio ${ }^{19}$, com uma câmara digitalizadora do tipo CCD (charge coupling device $)^{20}$, sem amplificações ou tratamentos eletrönicos adicionais. Devido à freqüëncia de corte de $400 \mathrm{MHz}$ do osciloscópio, o tempo de descida apresentado, da ordem de 2 ns, não corresponde ao do

\footnotetext{
19 Tektronix modelo $2465 \mathrm{BCT}$.

20 Tektronix modelo DCSOL.
} 
pulso do detector, tipicamente da ordem de $500 \mathrm{ps}$ a $600 \mathrm{ps}$ [Wiz79]. Os pulsos foram produzidos pela incidência de particulas alfa e produtos de fissăno provenientes da fonte de ${ }^{232} \mathrm{Cf}$, colocada próxima a este detector para os testes.

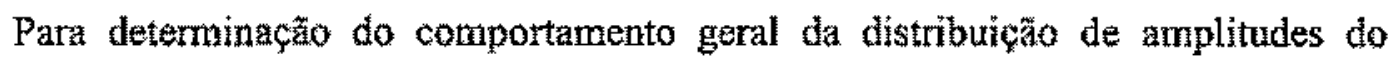
detector Stop em função da tensăo de operação, uma série de medidas foi feita com o uso do osciloscópio. Os resultados obtidos são apresentados na Fig.4.11. Os pontos observados são os valores médios das amplitudes máximas e minimas dos pulsos, representadas no gráfico pelas barras que envolvem os valores médios. Nesse gráfico pode-se observar uma regiầ com um comportamento aproximadamente exponencial da amplitude do sinal em funçăo da tensão aplicada ao MCP o início do processo de saturaçã̃o do ganho [W]79].

A distribuiçâno de amplitudes dos pulsos tambem foi teterminada com o uso de sistemas de aquisiçăgo descritos no item 4.3. A Fig. 4.12 apresenta as distribuições de amplitude de pulsos, para várias tensōes de operaçăo do detector Stop, de ions provenientes de uma amostra de LiF, colocada a uma tensã̃o de aceleração de $+12 \mathrm{kV}$. É possivel observar o deslocamento da distribuição e seu alargamento com a tensão e a crescente separaçẵo do nutdo eletrônico.

Outro composto utilizado neste estudo fol o CsL A Fig. 4.13 apresenta os resultados obtidos para vătias tensfes do detector, estando a amostru colocada também a uma tensäo de $+12 \mathrm{kV}$. Neste caso, as medidas foram feitas em coincidencia temporal com os lons de $\mathrm{C}$, tutilizando o sistema de aquisição descrito no item 4.3. As distribuiçōes de amplitudes para este material se mostraram mais largas que as do LiF. A queda de intensidade na regiăo de pequenas amplítudes é decorrente da utilizaçăo de um limite de tensäo usado para o disparo dos discriminadores ( $C F D$ 's), permitindo eliminando o ruido eletrônico.

A Fig, 4.14 apresenta os valores dos primeiros momentos das distribuições de amplitude de pulsos obtidas para o LiF e o CsI em funçăo da tensão de operação do detector Siop. Como pode ser visto, a saturação do ganho nẫo foi alcançada até a tensão de $2700 \mathrm{~V}$. A tensäro de $2400 \mathrm{~V}$ foi escolhida para a operaçăo do detector. Com esta 
tensẫo o primeiro MCP do detector Stop opera a 980 V e o segundo a $1000 \mathrm{~V}$, nos demais intervalos as tensões são da ordem de $210 \mathrm{~V}$. Estas tensōes seguem as especificaçōes do fabricante dos MCP's, que recomenda tensôes ao redor de $1000 \mathrm{~V}$ por placa multiplicadora. $O$ uso de tensões acima da recomendada provoca a redução do tempo de vidu dos MCP's devido ao intenso bombardeto de eletrons nas paredes dos microcanais. Este efeito provoca a destruição da cobertura semicondutora das paredes, reduzindo gradativamente a sua capacidade de produçâa de elétrons secundảios e, dessa forma. reduzindo o fator de multiplicação do MCP [Wiz79]. Na tensão de trabalho escolhida a amplitude dos pulsos é suficiente para as aplicaçốt com o espectrômetro de massa. 

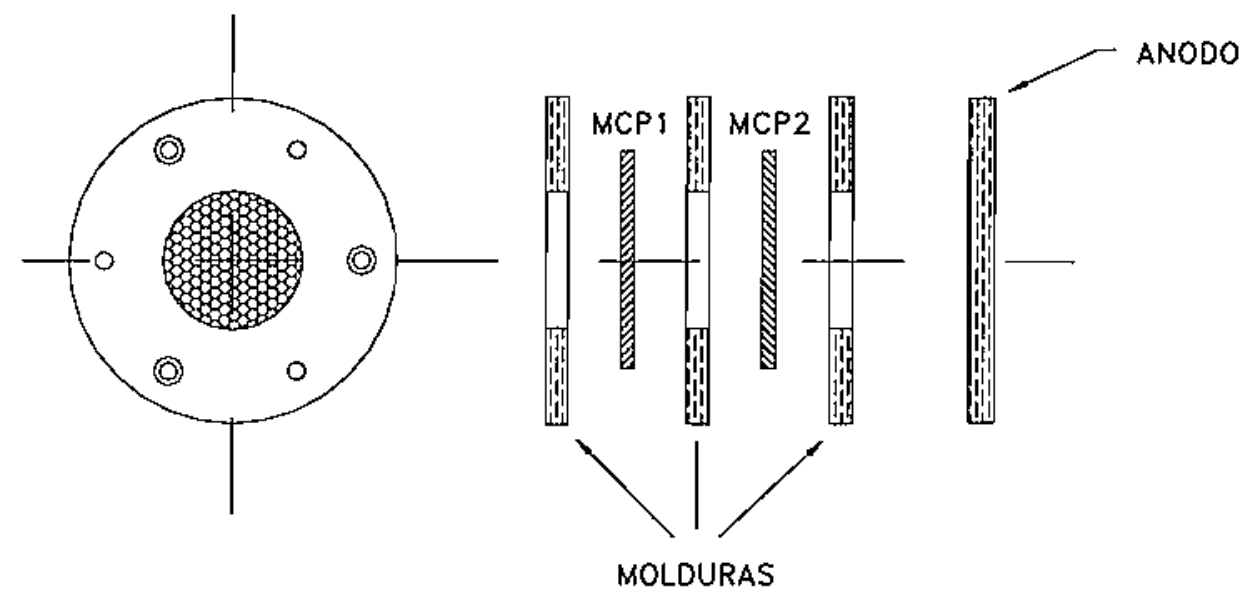

Fig. 4.8 - Esquema de montagem do detector de ions Stop. As placas multiplicadoras de elétrons encontram-se montadas em uma configuração Chevron.

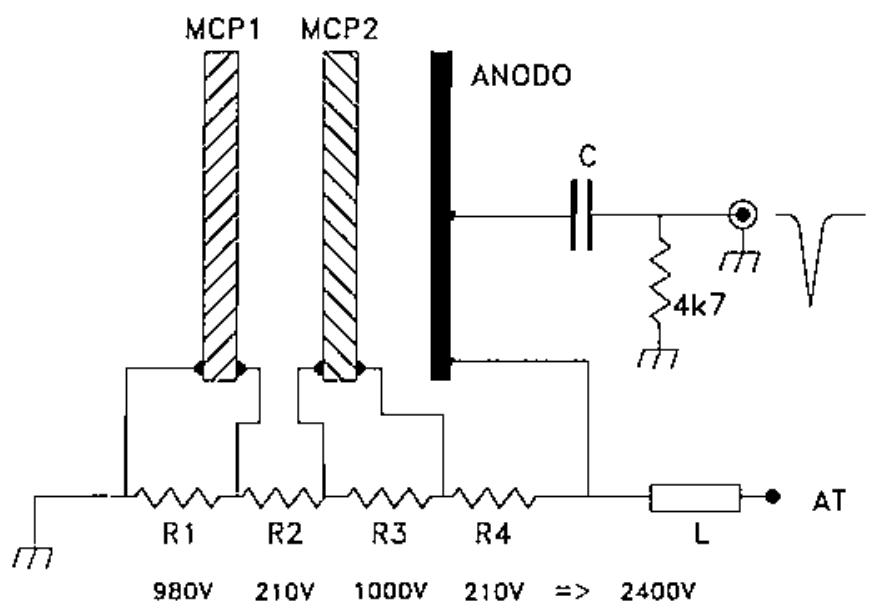

Fig. 4.9 - Esquema elétrico do divisor resistivo do detector Stop. A tensão de polarização $\dot{e}$ de $2400 \mathrm{~V}, \mathrm{Rl}$ a $\mathrm{R} 4$ pertencem ao divisor de resistência total de $22,0 \mathrm{M} \Omega, \mathrm{L} \dot{e}$ um indutor de 1,2 $\mu \mathrm{H}$ e C o capacitor de desacoplamento de $1,5 \mathrm{pF}$ com tensão de isolação de $6 \mathrm{kV}$. 


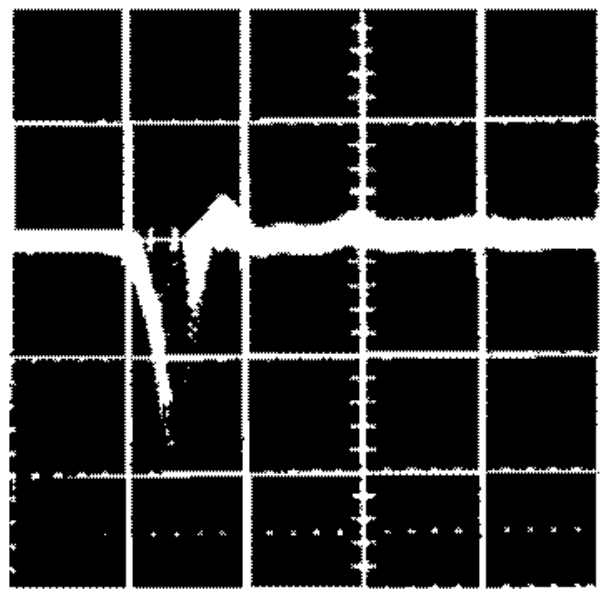

Fig. 4.10 - Fotografia da tela do osciloscopio apresentando o sinal de saida do detecior Stop, operando a $2400 \mathrm{~V}$, varredura horizontal calibrada em 10 ns/divis a e vertical em 500 m Vidivisân.

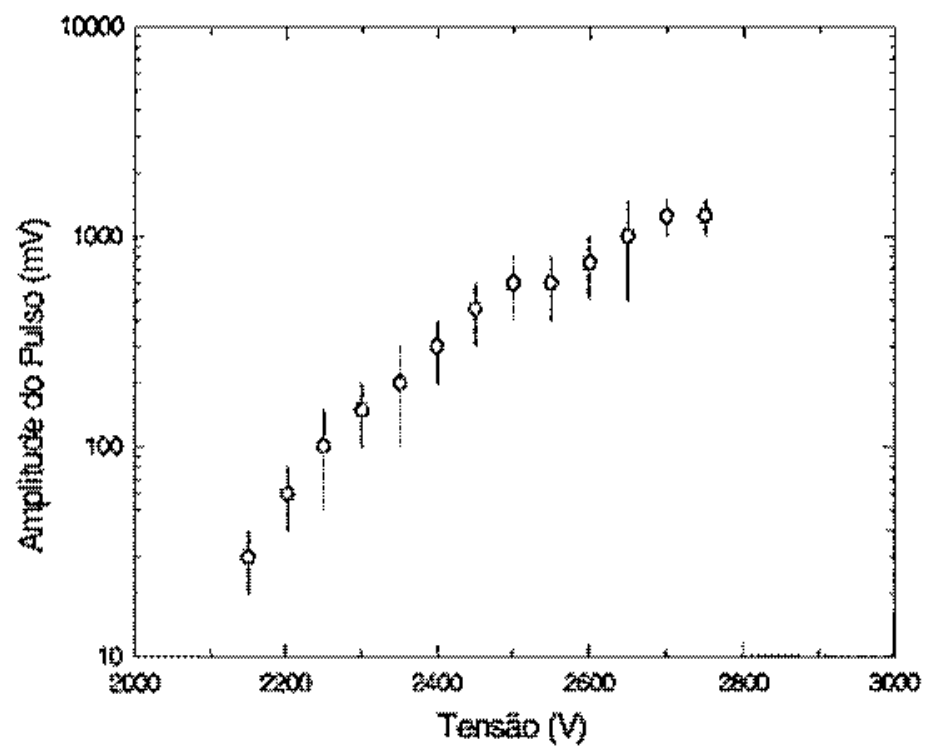

Fig: 4.11 - Distribuçäo de ampltude de pulsos en funcüo da tensäo do detector Stop, obtida por lettura na tela do osciloscopio. As barras corresponden is anplitudes maximas a mimimas obsentadus. 


\section{$\mathrm{LiF}(12 \mathrm{kV})$}
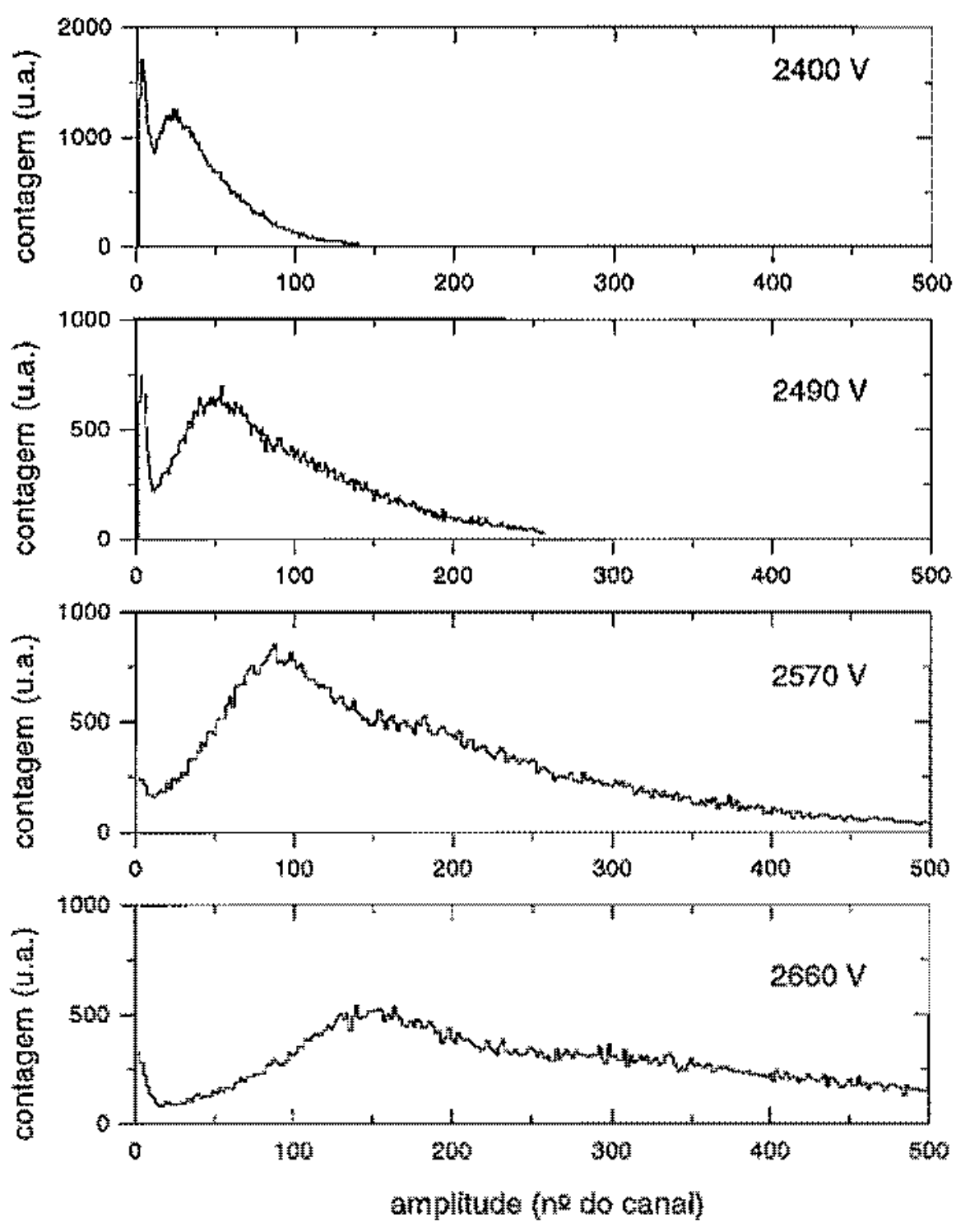

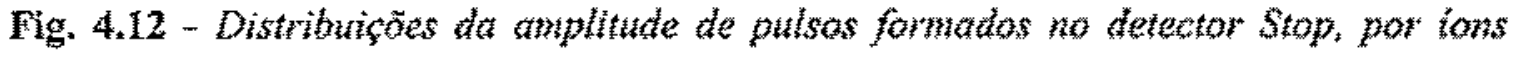

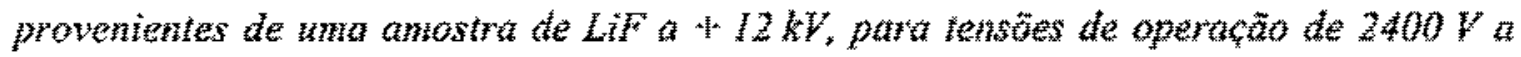
$2660 \%$ 


\section{Csl (12kV)}
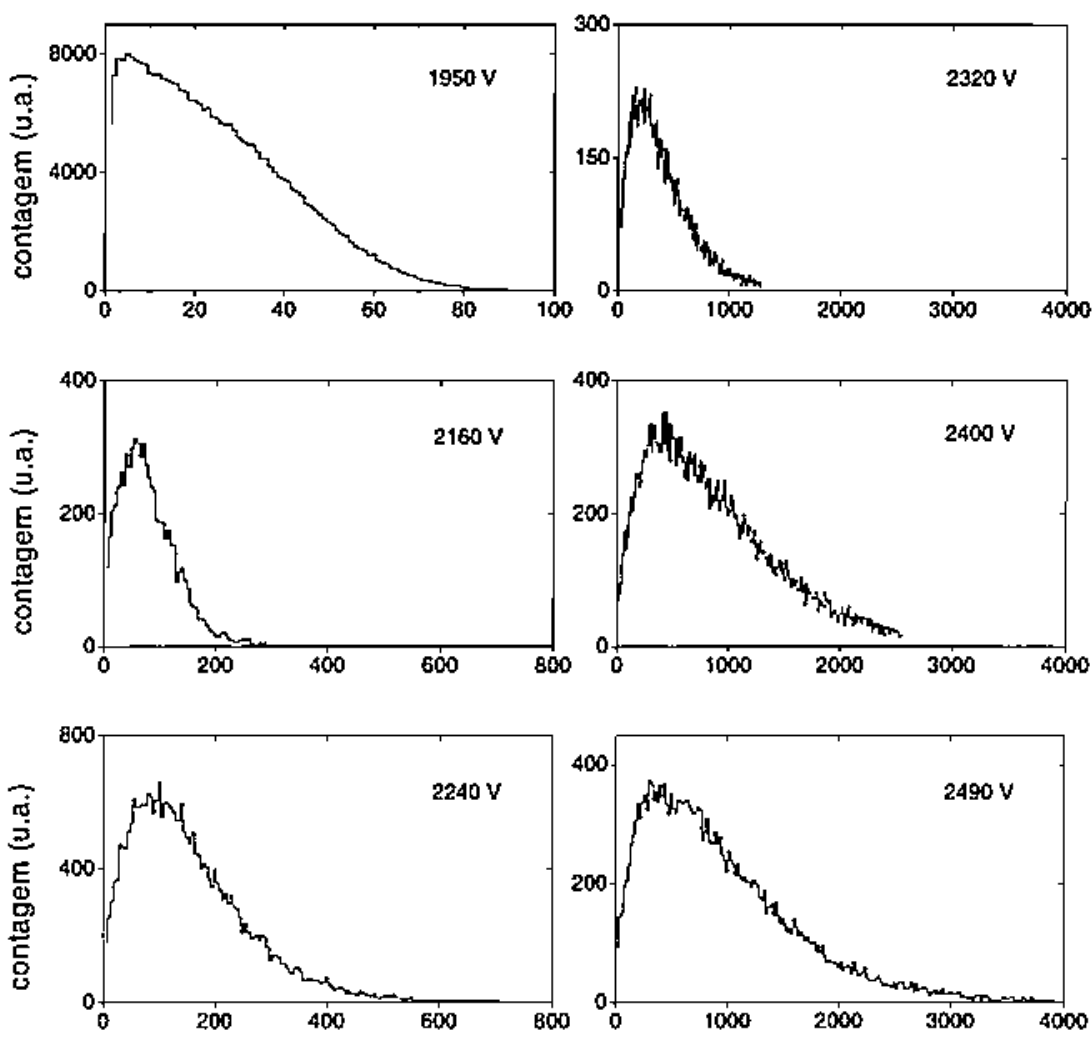

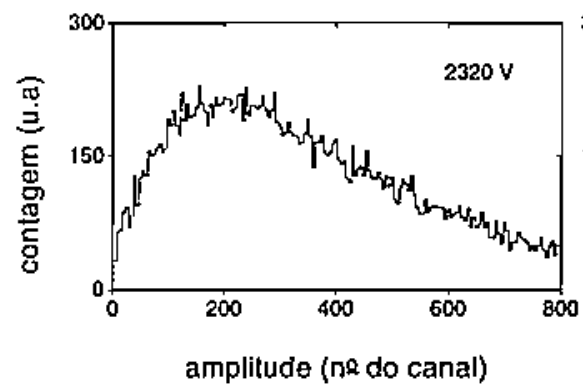

(a)

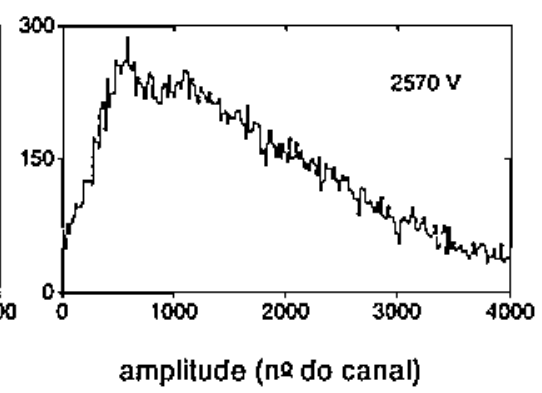

(b)

Fig. 4.13 - Distribuições da amplitude de pulsos formados no detector Stop em coincidencia com ions de $\mathrm{Cs}^{+}$, provenientes de uma amostra de CsI a $+12 \mathrm{kV}$, para tensões de operação de 1950 V a $2570 \mathrm{~V}$. De (a) para (b) as escalas horizontais foram alteradas para melhor visualização, sendo o ganho do sistema de amplificação o mesmo para todos as distribuições. 


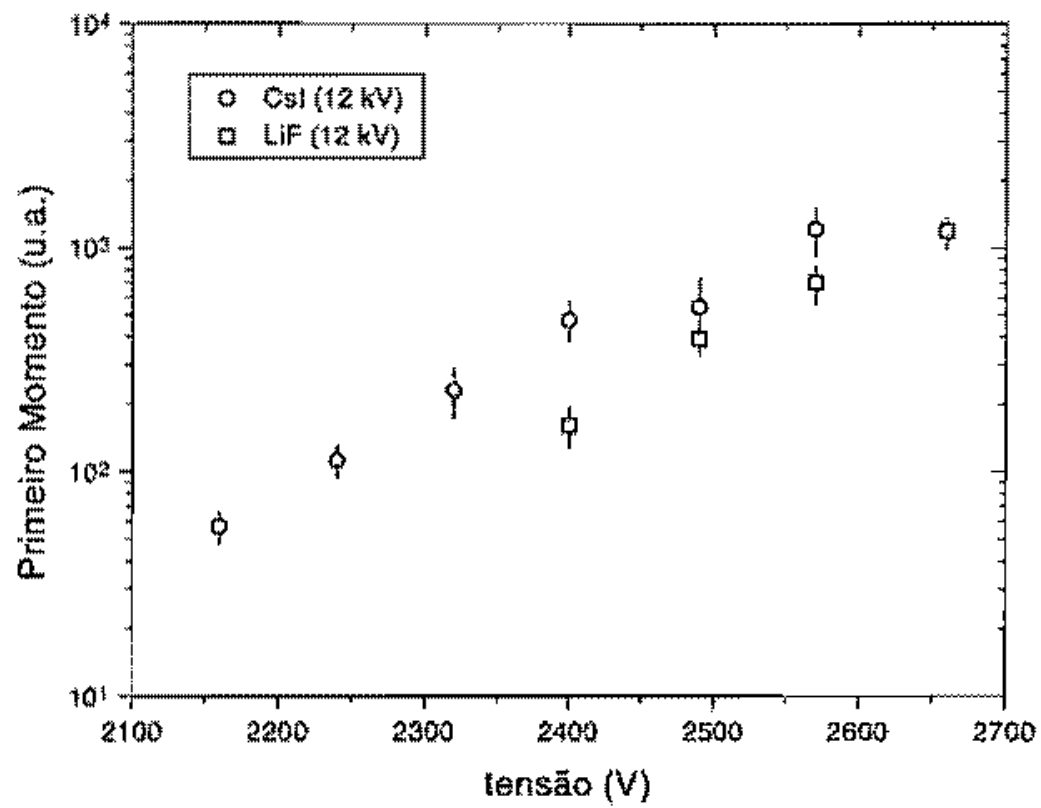

Fig. 4.14-Posicôes dos prineiros monentos das distribuções de amplitudes de pulsos

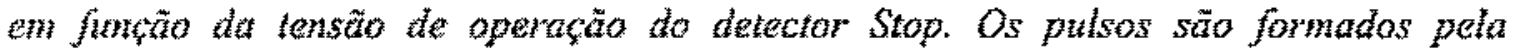
incidencia de lons positivas provenientes de amostras de CsI e LiF, sobre o detector com

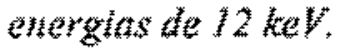




\subsubsection{Detector de Fragmentos de Fissäo - Start}

O detector Stani apresenta, essencialmente, a mesma construçăo do detector Stop, com excefato de uma folha de Myla ${ }^{2}$ aluminizada, de 1,5 um de espessura, usada como conversor de elétrons, instalada a $1,7 \mathrm{~mm}$ da face do primeiro MCP (Tig. 4.15). A folha conversora encontra-se a uma distância de $13 \mathrm{~mm}$ da fonte de ${ }^{25 / 2} \mathrm{Cf}$. Os clêtrons emitidos do conversor, pela radiação incidente, são acelerados por uma diferença de potencial de $+400 \mathrm{~V}$ sobre a face do primeiro $M C P$, disparando o processo de multiplicação de elétrons.

A folha conversora estă presa a uma moldura de aço inoxidavel. Como a superficie onde esta depositado o aluminio encontrawse voltada para a face do primeiro MCP, foi feita uma deposiçăo a vatou de uma camada de ouro de aproximadamente 500 A sobre a superficie de Mylat para garantir o seu contato elétrico com o anel de inox. Esta precauçäo foi tomada para evitar a formação de cargas estáticas sobre a face de Myla; que poderiam ocasionar faiscamentos entre o suporte de amostra e o detector Start. A fina camada condutora de ouro não impede a passagem dos produtos de fissăo.

A montagem do detector Start possui a área útil de $78,5 \mathrm{~mm}^{2}(\mathrm{R}=5 \mathrm{~mm})$. A espessura do conjunto a de $8,5 \mathrm{~mm}$, estando o seu divisor resistivo montado na mesma placa onde se encontra 0 anodo. A Fig. 4.16 apresenta o diagrama elétrico de montagem do detector com seu divisor resistivo, cuja resistencia total ê de $26.5 \mathrm{M \Omega}$. $\mathrm{O}$ detector opera a uma tensão de $+2700 \mathrm{~V}$, aplicada em seu anodo por um indutor de $1,6 \mu H$, usado para filtar eventuais nuidos da fonte de alta tensão. Com esta tensão cada placa multiplicadora fica sujeita a uma tensão de polarização da ordem de $1000 \mathrm{~V}$, como recomenda o fabricante.

Fazendo uso de um osciloscópio, uma fotografia do pulso do detector Start foi obtida (Fig. 4.17). A mesma ressalva feita para a imagem do pulso do detector Stop vale para este caso em relaçắo ao tempo de stibida do pulso, que b maís rápído do que o apresentado. Usando tambem o osciloscopio e a fonte de ${ }^{252} \mathrm{Cf}$ foi feito o levantamento da distritribuição de amplitude te pulsos em funçăo da tensà̃o do detector Stat. O resultado

it Mylar - nome comercial para o poltetelleno tereftalato dado pela DuPount. 
pode ser apreciado na Fig. 4.18 , onde as baras em tomo dos pontos medios representam os valores maxximos e mínimos observados,

Para verificar as condições operacionais do detector Start tentar determinar o nivel de discriminaçắo mais adequado para o corte das contribuiçóes do ruido eletrônico $\mathrm{e}$ das particulas alfa, medidas da distribuiçäo de amplifude de pulsos foram realizadas, utilizando o sistema de aquisição de dados descrito no item 4.3. Numa primeira medida, o detector Start foi exposto à fonte de ${ }^{252}$ Cf e a distribuição, apresentada na Fig. 4.19 (a), foi obtida tendo como contribuições o ruido eletrônico, as particulas alfa e os fragmentos de nisstio.

Na Fig 4.19 (b) é aprosentada a distribuiçäo de amplitude de pulsos do detector Statt, tendo sido fata uma coincidencia com os elétrons emitidos de uma amostra de Csl, apos a pasagem do produto de fissão. Como pode ser visto, houve um árástico corte no ruido detrônico na contribuição das partículas alfin, testando os aventos produzidos pelos produtos de fissão eventos casuais. Por este resultado, nota-se que a distribuição de amplitude de pulsos devido aos fragmentos de fissão ta larga, estando sobreposta à distribuiçâo das particulas alfa. Deșa forma, o nivel de discriminaçăo da eletrônica deve ser ajustado com cautela para que não ocorra um corte drástico na contribuiçăo dos fragmentos de fissão. A Fig. 4.19 (c) apresenta a distribuição de amplitude de pulsos obtida en coincidencia com o próprio sinal rápido do detector Stant, mas com o circuito de coincidência ajustado para tm nivel de discriminação de $-200 \mathrm{mV}$. Neste caso, o raido e parte da contribuiçăo das particulas alfa foram eliminados, mas é possivel notar a sobreposiçẫo de parte da distribuição das particulas alfa com a dos produtos de fissäo. 

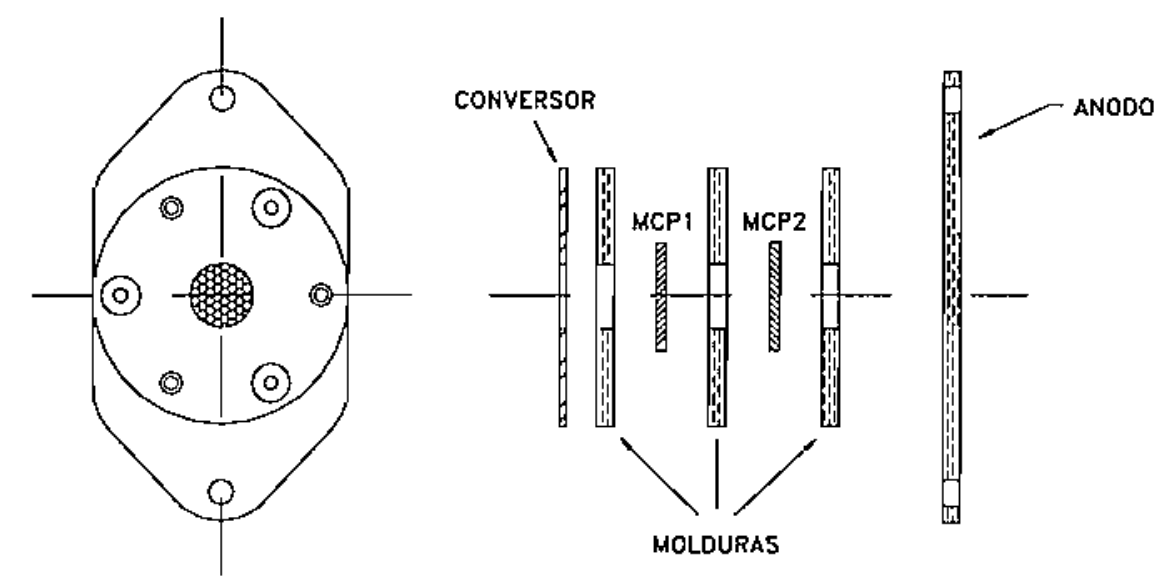

Fig. 4.15 - Esquema da montagem mecânica do detector Start em uma configuração Chevron, apresentado em vista frontal e em corte lateral.

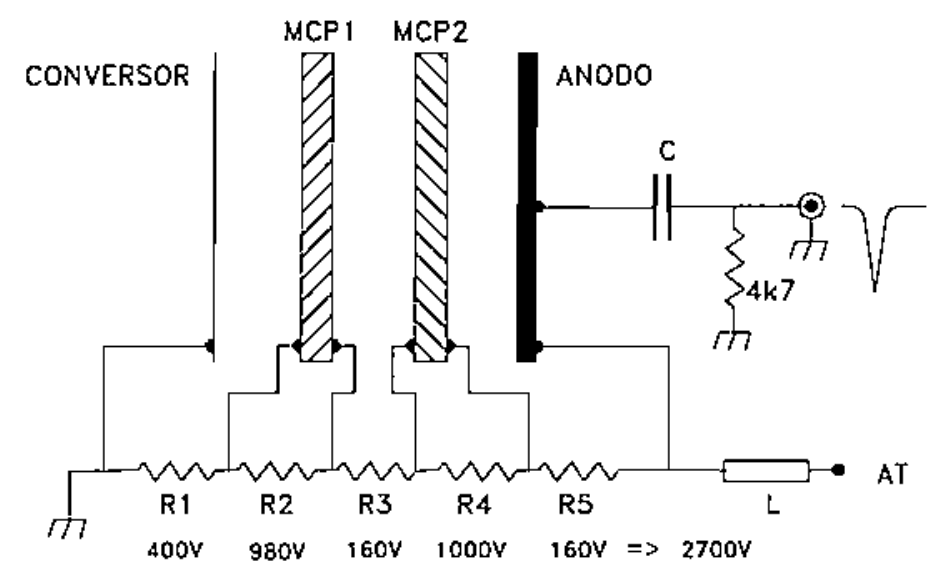

Fig. 4.16 - Diagrama elétrico do divisor resistivo do detector Start. A tensão de operação $\dot{e}$ de $+2700 \mathrm{~V} ; \mathrm{Rl}$ a R5 pertencem ao divisor de resistencia total de $26,5 \mathrm{M} \Omega, L \dot{e}$ um indutor de 1.2 $\mu \mathrm{H}$ e $\mathrm{C}$, o capacitor de desacoplamento de 1,5 pF com tensão de isolação de $6 \mathrm{kV}$. 


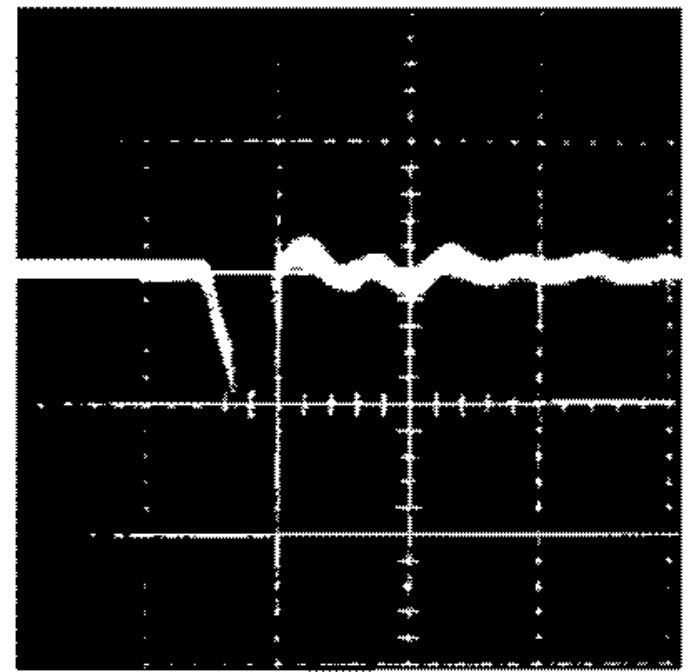

Fig. 4.17 - Fotografia da tela do osciloscópio apresentando o winal do defector Start, operando a $2700 \mathrm{~V}$, varredura horzontal callbrada em 5 ns/divisão e vertical an 200 mVldivisão.

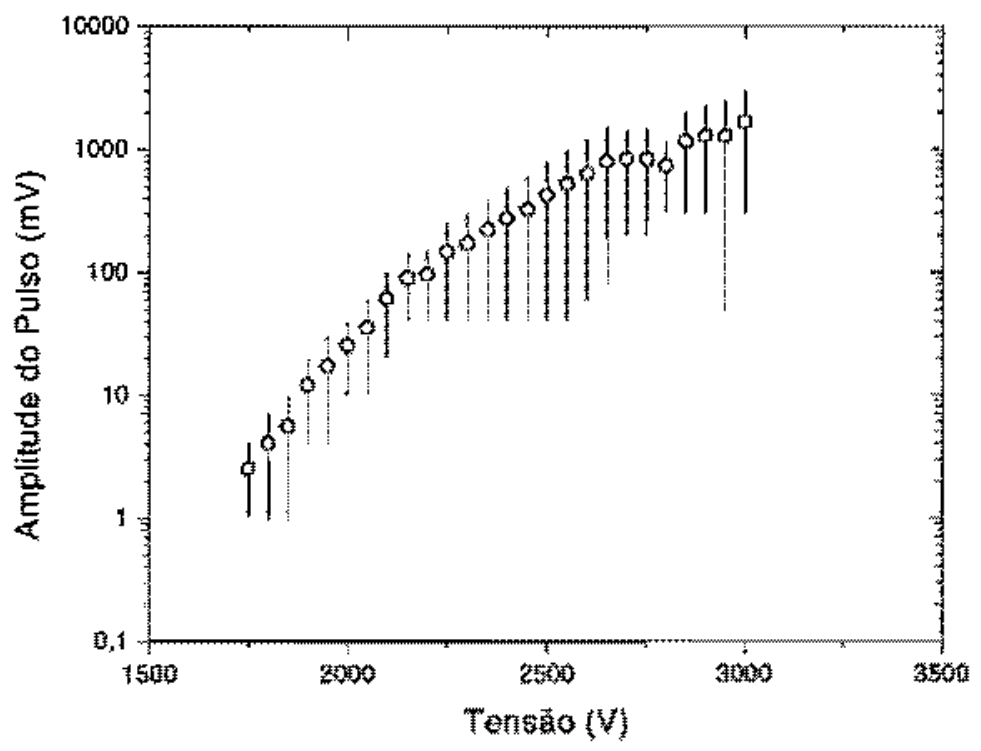

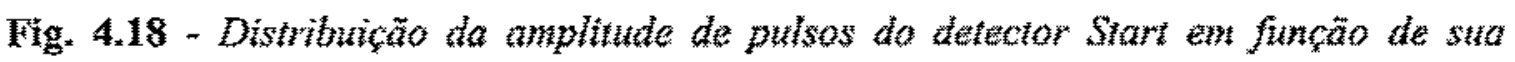

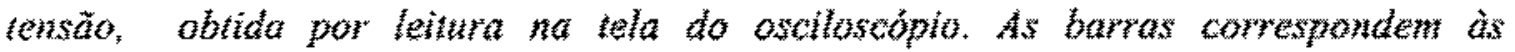
anplindes náximas e minimas observadas. 

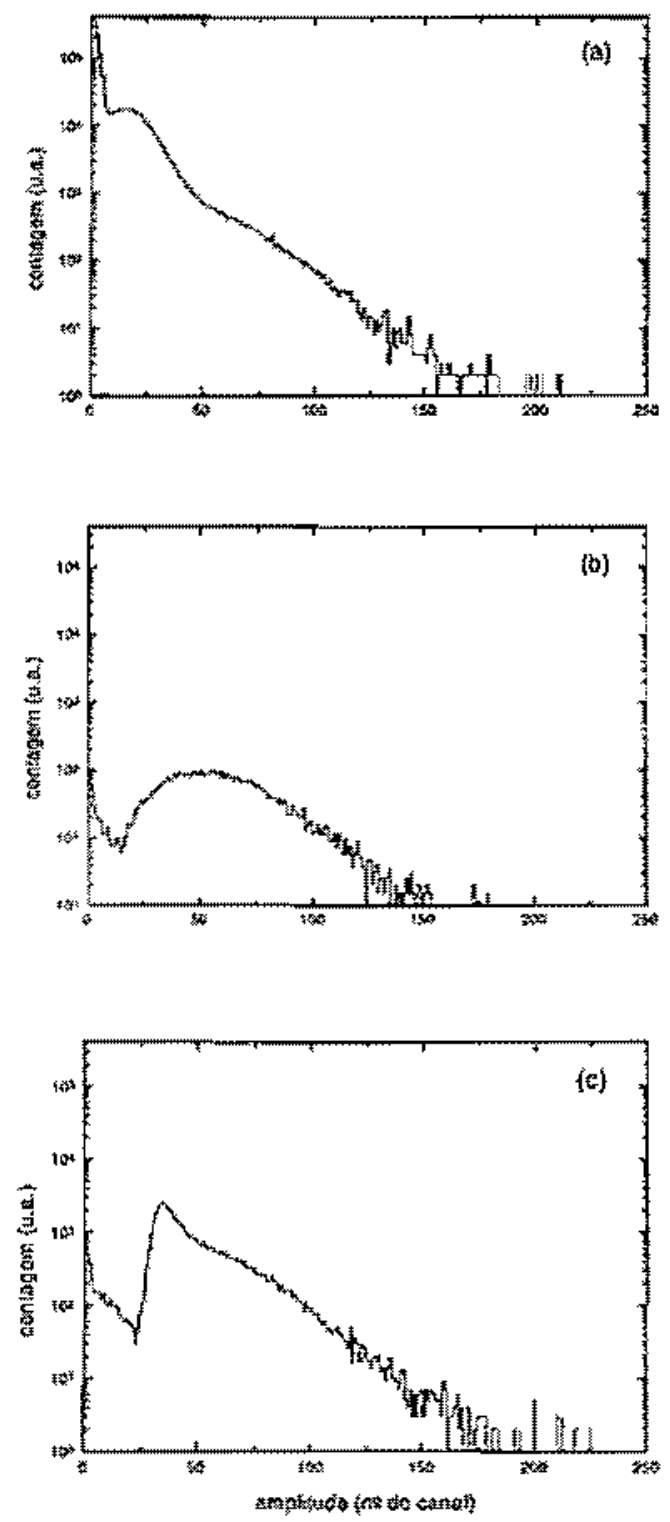

Fig. 4.19 - Distributcăo de amplitude de pulsos do detector Statt, operando a $2700 \mathrm{~V}$, com a incidencia de partículas alfa e produtos de fissâo do ${ }^{252}$ Cf. (a) Contributção do ruido eletronico, particulas alfa e produtos de fissão; (b) em coincidência com elétrons amilidos de una amostra de Csl, resultando apenas na contribuiçăo dos produtos de

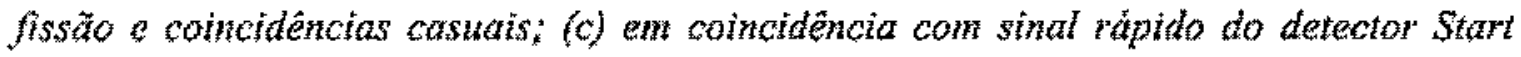
com nivel de discrininaça a atustado $a-200 \mathrm{mV}$. 


\section{Caracterização do Espectrômetro}

\subsection{Influência da Distribuição Bimodal de Velocidades do ${ }^{252} \mathrm{Cf}$}

Aproximadamente $10^{3}$ produtos de fissão por segundo incidem sobre a amostra e sobre o detector Start, devido à geometria adotada na montagem do sistema de suporte de amostras e da fonte de ${ }^{252} \mathrm{Cf}$.

Os produtos de fissão perdem energia ao atravessarem as camadas de $\mathrm{Ni}$ e de $\mathrm{Au}$ usadas como suporte da fonte. Essas perdas foram calculadas usando o programa TRIM (Transport Ions on Matter) de Ziegler e Biersack [Zie88], que simula as interações de ions com um meio material e calcula as taxas de perdas de energia por unidade de comprimento $(d E / d x)$, fomecendo como resultado suas energias finais após a passagem pelo meio. Estimativas dessas perdas foram feitas para o grupo leve e o pesado, representados pelos núcleos do ${ }^{106} \mathrm{Tc}_{43}$ e do ${ }^{142} \mathrm{Ba}_{56}$, respectivamente, atravessando camadas de $\mathrm{Ni}$ de $(1,1 \pm 0,1) \mu \mathrm{m}$ e de Au de $(500 \pm 50) \AA$. A tabela 5.1 apresenta os resultados para as energias finais e velocidades de saída dos íons. Os desvios das energias finais foram determinados analisando-se os valores obtidos em simulações com variações nas espessuras das camadas de Ni e Au, de acordo com suas incertezas.

\begin{tabular}{cccc}
\hline Produto de Fissão & $\begin{array}{c}\text { Energia Inicial } \\
(\mathrm{MeV})\end{array}$ & $\begin{array}{c}\text { Energia Final } \\
(\mathrm{MeV})\end{array}$ & $\begin{array}{c}\text { Velocidade Final } \\
(\mathrm{cm} / \mathrm{ns})\end{array}$ \\
\hline${ }^{106} \mathrm{Tc}$ & 100 & $72 \pm 4$ & $1,15 \pm 0,03$ \\
${ }^{142} \mathrm{Ba}$ & 80 & $52 \pm 3$ & $0,84 \pm 0,02$ \\
\hline
\end{tabular}

Tabela 5.1 - Valores obtidos com o programa TRIM para as energias finais dos ions de ${ }^{106} \mathrm{Tc} e{ }^{1+2} \mathrm{Ba}$, após passagem por folhas de Ni e Au de $(1,1 \pm 0,1)$ un e $(500 \pm 50) \AA$ de espessura, respectivamente. Também são apresentadas suas velocidades ao saírem do material. 
A caracteristica bimodal da distribuiçāo de energia dos protutos de fissăo do ${ }^{252} \mathrm{Cf}$ afeta a distribuição temporal das moléculas ionizadas provenientes da amostrat Devido ao procedimento usado para as medidas de tempo de vô, onde a referência temporal é dada pelo fragmento de fissão que incide sobre o detector Sian, complementar ao que provoca a dessorçăa, ora a deteminaçäo do intervalo de tempo pode ser iniciada por um produto de fissã̃o leve ora por um pesado. Deste modo, o tempo nedido para um mesmo tipo de ton sofre pequenos deslocamentos temporais a cada evento. . partir das veloctdades dos fons de ${ }^{106} \mathrm{To}$ e ${ }^{142} \mathrm{Ba}$ uma estimativa desses deslocamentos temporais pote ser obtida, levando-5e em conta a geometria utilizada, apresentada na Fig. 5.1 , considerando a fonte

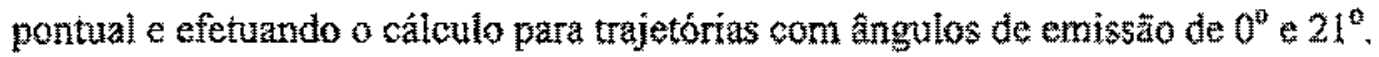

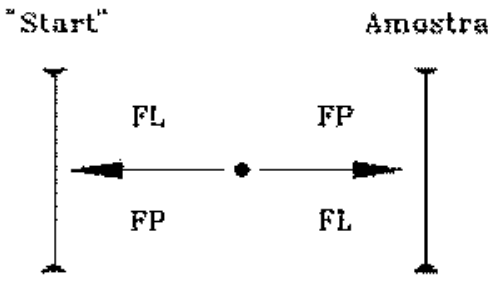

(a)

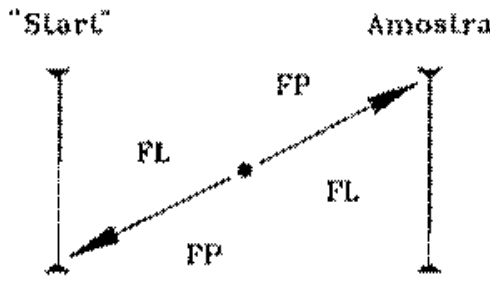

(b)

Fig. 5.1- Esquema da região da fonte de ${ }^{252}$ Cf ilustrando os possivers eventos após a fissão, sendo FL ofragmento leve e FP ofragmento pesado. Em (a) os produtos de fissão incidem perpendiculamente sobre a amostra e o detector Start, em (b) ma região mais distante possivel de sets centros. Em ambos os casos a fonte está colocada a mesma distancia da amostra do detector.

Estando a fonte posicionada à mesma distância $d$ do detector stave da amostra, a diferença temporal $\Delta T$ é dada pela expressŏo: 


$$
\Delta T=2 d\left(\frac{1}{v_{p}}-\frac{1}{v_{l}}\right)
$$

onde $v_{p}$ e $v_{1}$ säo as yelocidades dos fragmentos de fissăto pesado leve, respectivamente.

A tabela 5.2 apresenta as estimativas obtidas para $\triangle T$. As distribuições temporais dos íns molectulares provenjentes da amostra sofrem um deslocamento da ordem de 800 ps para a incidência normal e 900 ps para a incidência na regiäo mais afastada do centro da amostra e do detector Siart.

i (mm)- (ângulo)

(

(a) $\left[3,0-\left(0^{6}\right)\right.$

$800 \pm 100$

(b) $13,9 \cdots\left(21^{\circ}\right)$

$900 \pm 100$

Tabela 5.2 - Cálculo das diferenças temporais devido à incidência dos produtos de fîsä́o leve ou pesado do ${ }^{252} \mathrm{Cf}$ sobre o detector Start, com angulos de $0^{\prime 2}$ e $21^{\circ}$.

A Fig. 5.2 apresenta a distribuição temporal medida com 0 espectrômetro de massa por tempo de vớ para eletrons emitidos devido à incidêncía de produtos de fissāo em uma amostra de Csl. As medidas foram realizadas estando a amostra numa tensão de $-18 \mathrm{kV}$ e fazendo uso do sistema de aquisição descrito no item 4.2. Dois picos separados por $(870 \pm 50)$ ps podem ser observados, sendo o pico a esquerda devido a eventos onde produtos de fissáo pesados incidiram sobre o detector Start e outro pico proveniente da incidencia de fragmentos leves. para verificar o comportamento desta diferença temporal com a tensão da amostra varias medidas, como a descrita acima, foram feitas e os resultados sâo apresentados na Fig. 5.3. Foi encontrado um valor médio de (840 30$)$ ps, estando de acordo com as estimativas. 


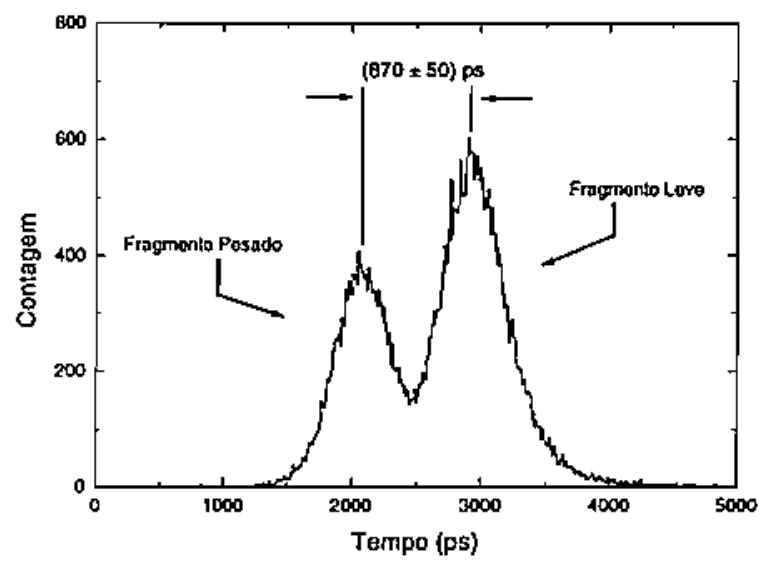

Fig. 5.2 - Influência da distribuição de velocidades dos produtos de fissão do ${ }^{252} \mathrm{Cf}$ na distribuição temporal de elétrons de $18 \mathrm{keV}$ provenientes de uma amostra de CsI. O pico à esquerda corresponde a eventos onde ofragmento pesado incide sobre o detector Start e o da direita ofragmento leve. A origem do tempo é arbitrária.

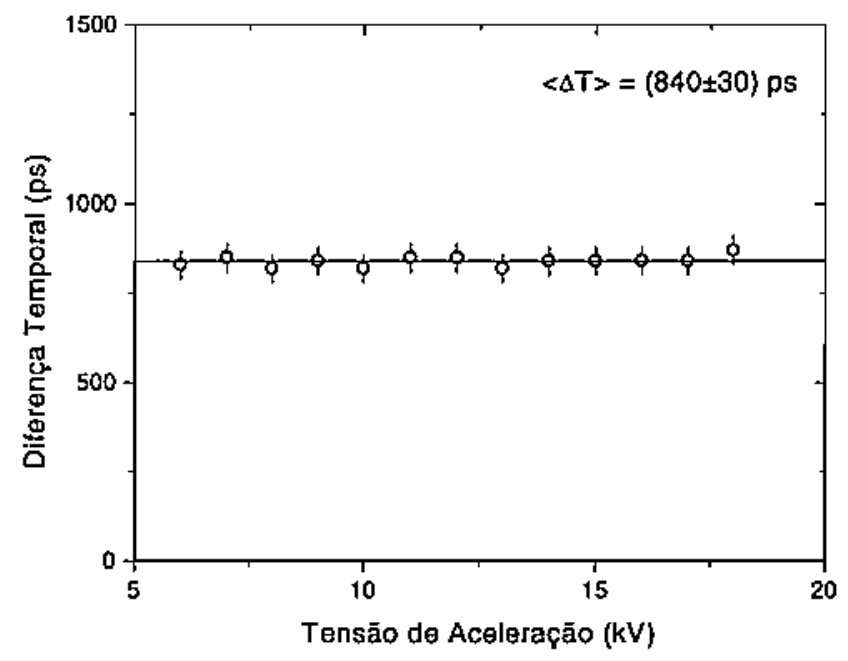

Fig. 5.3 - Diferença de tempo de vôo de elétrons emitidos de uma amostra de CsI pela passagem do produtos de fissão do ${ }^{252} \mathrm{Cf}$. em função da tensão da amostra. 


\subsection{Equaçâo de Tempo de Vôo dos Ions}

A Fig. $\$ 4$ apresenta o esquema do espectrômetro de massa, $\mathrm{O}^{252} \mathrm{Cf}$, ao sofrer a fissäo, emite dois fragmentos colineares em sentidos opostos. Um dos fragmentos, ao atravessar a amostra, provoca a dessorçã̃o eventual ionizaçäo das molếculas. $O$ outro fragmento, correlacionado ao anterior, vai en direçäo do detector Start, provocando a formaçấ de um pulso usado no disparo do sistema de aquisiçăo le dados Os fons secundărios dessorvidos sâo acelerados por uma diferença de potencial $V$ existente entre a amostra e grade de aceleraçäo, que se encontram separados por uma distância $z_{\text {; }}$. Após a aceleraçã os tons penetram no tubo de vô de comprimento za live de campos elétricos que possarn afetar as suas trajetórias. Os ions, chegando ao final do lubo, encontram o detector Stop provocando a formação de um pulso usado para interromper a medida de tempo. Considerando que a aceleração dos ions é provocada por um campo elétrico uniforme, o tempo de vốo para a geometria do espectrômetro de massa pode ser calculado pela expressầ:

$$
T=A \sqrt{\frac{m}{q}}+B
$$

onde m/a a a razấo da massa pela carga do ín e

$$
\begin{aligned}
A= & =\left(\frac{2}{V}\right)^{V / 2}\left[\left[1+\frac{m\left(v_{0} \cos \Theta\right)^{2}}{2 q V}\right)^{/ / 3}-\left(\frac{m\left(v_{0} \cos \theta\right)^{2}}{2 q V}\right)^{y / 2}\right]+ \\
& z_{2}\left(\frac{1}{2 V}\right)^{V / 2}\left(1+\frac{m\left(v_{0} \cos \Theta\right)^{2}}{2 q V}\right)^{-1 / 2}
\end{aligned}
$$

$O$ termo $m(v a c o s \Theta)^{2} / 2$ é algumas vezes referido como "energia inicial axial" $E_{c r}$ do fon secundário, sendo $y_{p} \cos \theta$ a componente da sua velociklade na direçăo perpendicular à superficie da amostra, paralela ao eixo do tubo de vô (Fig.5.5). Medidas realizadas 
mostram que o valor médio de $E_{a j}$ da ordem de $\mathrm{eV}$, sendo maximo para lons $\mathrm{H}^{*}$ [Mac87, Bet94].

O coeficiente $B$ está relacionato com os acréscimos no intervalo de tempo medido devido, por exemplo, ao tempo de processamento dos sinais nos nódulos eletrônicos ou ao tipo de referência usada no disparo do ctonômetro cletrônico (produtos de fissäo ou elétrons damostra).

Como pode ser observado, a equaçǚ 5.2 depende dos parâmetros do espectrômetro. Introduzindo-se os valores efetivos desses parâmetros, sería possivel calcular a massa de um ion a partir do valor medido de seu tempo de voo. Entretanto, irregularidades nas superficies da amostra e dos detectores, nẫo-uniformidades do campo elétrico entre a anostra e a grade, bem como fatores ligados ao tipo de amostra utilizada dificultam a obtenção dos valores exatos desses parâmetros. A maneira mais adequada para a determinação de massas é calibrar o espectro de cada amostra analisada, como será visto na próxima seçăo. 


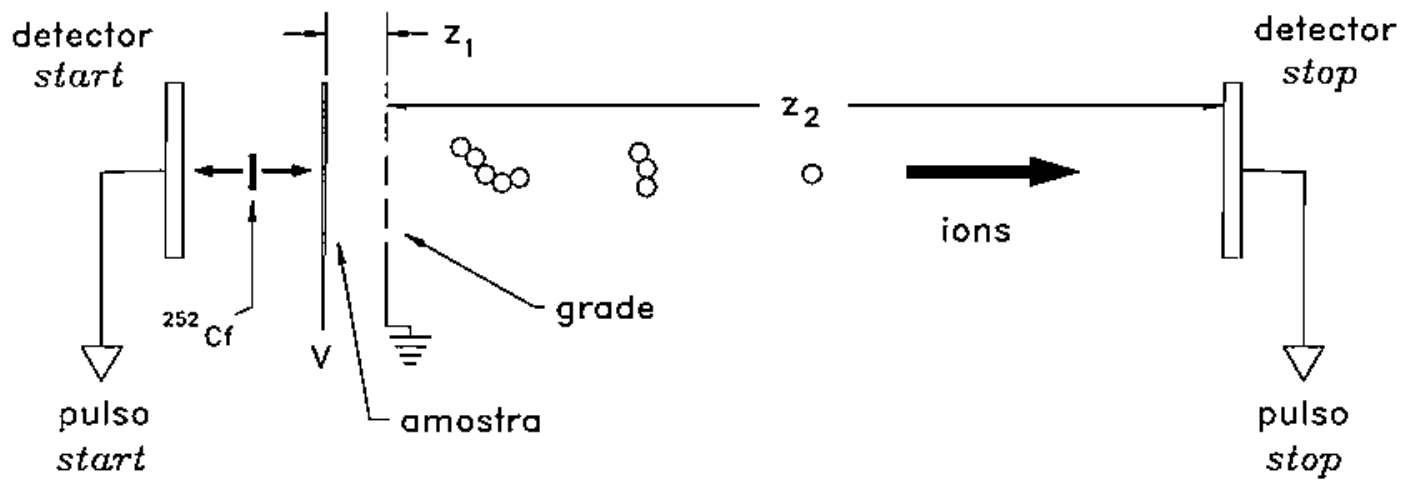

Fig. 5.4 - Esquema da geometria do espectrômeto de massa por tempo de vôo. A fonte de ${ }^{252} \mathrm{Cf}$ encontra-se entre o detector Start e a amostra. Os ions dessorvidos pelos fragmentos de fissão são acelerados na região $z_{l}$ por un campo elétrico, devido à diferença de potencial $V$ aplicada entre a amostra e a grade. Os ions atravessam a região de comprimento $z_{2}$ livre de campos até alcançarem o detector Stop.

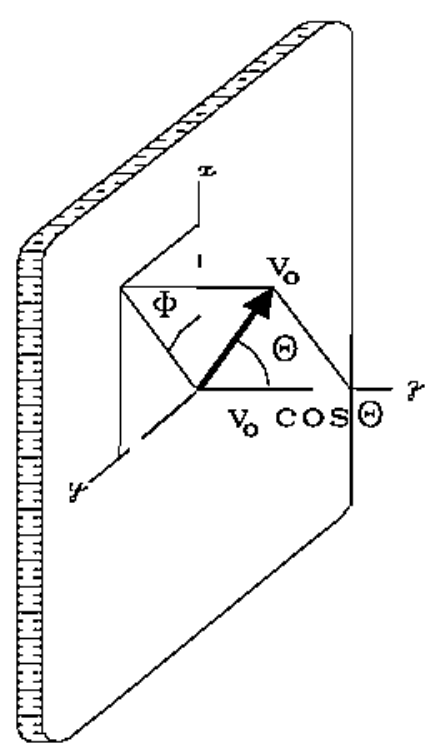

Fig. 5.5 - Representação da velocidade inicial de emissão vo do ion; $\Theta \dot{e}$ o ângulo entre a normal da superficie da amostra e a direção da velocidade do ion. 


\subsection{Calibração em Massa}

Na espectrometria de massa por tempo de vôo a calibraça de um espectro felta a partir da relação 5.2 entre o tempo de vôo dos ions secundários a raiz quadrada da massa do lon. Apesar da equaçăo levar em consideração a velocidade inicial de cada íon, para que uma relaçầ geral possa ser obtida para um determinado espectro de massa esta velocidade E suposta ser a mesma para todos os íons. No caso da operaçăo do equipamento em altas tensões de aceleraçăo tal suposição é aceitável, uma vez que os termos dependentes da velocidade inicial tomam-se desprezíveis.

Genericamente, para se efetuar a calibração de um espectro é necessário apenas a escolha le dois picos de ions cujas massas säo conlectdats. Entretanto, para melhorar a precisão da calibraçâ, um maior numero de ions identificados devem ser utilizados.

A calibraç̃o deve ferta para cada espectro analisado, pois assim é garantido que os ions selecionados para a calibraçăo estão sujeitos as mexmas condições experimentais que os demais ions presentes no espectro.

Os ions utilizados para a calibração podem ser provenientes da própria amostra, do material do substrato, da matriz usada para adsorção e de padrớcs adicionados á amostra para esta finalidade [Bea89, Bea90]. No caso do uso de padrôtes, estes não devem interferir na formação dos lons secundănios da amostra [Mc191].

Os ions $\mathrm{H}^{+}{ }_{3} \mathrm{H}_{2}^{+}$e $\mathrm{H}_{3}^{*}$ esta freqüentemente presentes am um espectro de tempo de

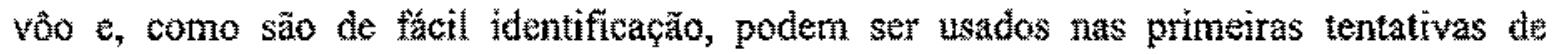
calibração do espectro. Entretanto, por estes ions possưirem uma velocidade de emissăo maior que os demais ions formados na amostra, sua utilização pode fornecer um ajuste inadequado para os íons situados em regiǒes de maior massa, provocando grandes desvios nas massas calculadas. Em alguns casos, após uma calibnaçăo preliminar do espectro, íons de maior massa såo identifucados e usados para uma nova caltbraçăo. Uma outra forma de corrigir o efeito das variaçöes das energias iniciais é associar a cses lons massas empiricas, porem este procedimento nem sempre apresenta resultados satisfatónios [Mcl91, Man90]. 
Também podem ser usados para calibração de espectros ions formados de sais alcalinos, como o CsI. Tanto o Cs como o I sã̃o monoisotópicos e esșe sal tem a caracteristica de formar aglomerados iônicos do tipo $\left(\mathrm{CsI}_{n} \mathrm{Cs}^{+}\right.$e $(\mathrm{CsI})_{n} \mathrm{~T}^{-}$.

Entretanto, os sais alcalinos, quando presentes em grande concentraçäo, prejudicam a formaçẫo de ions de molếculas orgânicas, nẫo sendo adequado assoctáming a essas amostras no propósito de formar lons para auxiliar a calibração do espectro. Quando em pequena quantidade, a contaminaça com material alcalino pode formar tons positivos com as moleculas orgânicas, sendo observado, no caso do $\mathrm{Na}$, lons to tipo $(\mathrm{M}+\mathrm{Na})^{*}$, $(\mathrm{M}+2 \mathrm{Na}+\mathrm{H})^{*}$, atc. Esses lons säo úteis para a identificą̧⿸厃㔾 do material analisado, podendo ser usados na calbraçă do espectro. Porém, caso o espectrómetro possua baixa resolução em massa, picos formados pelos lons da molécula associada ao atomo alcalino podem se sobrepor a picos dos tons quasi-moleculares $(\mathrm{M}+\mathrm{H})^{\dagger}$, prejudicando a sua adequada determinaçầ [Bea90].

Na regiäo de ions leves podem ser ușados na calibraçâo ions formados por fragmentos de moléculas organicas. No caso de fons positivos são usados $\mathrm{CH}_{3}{ }^{+}$e $\mathrm{C}_{2} \mathrm{H}_{3}{ }^{+}$, para os negativos $\mathrm{C}^{\prime \prime}$ e $\mathrm{C}_{2} \mathrm{H}^{-}$. Outros fragmentos podem ser observados, mas isso depende do tipo de amostra orgânica analisada.

Na regiäo de massas grandes os fragmentos iônicos do material analisado săo, na maioria dos casos, os únicos candidatos para uso na calibraçăo, desde que estes sejam devidamente identificicados e não reste duvida quanto à sua composiçăo química.

Para que a curva de calibração de massa forneça boa precista a alguns cuidados devem ser tomados na seleç⿰彳 dos picos usados. A forma e intensidate dos pieos devem

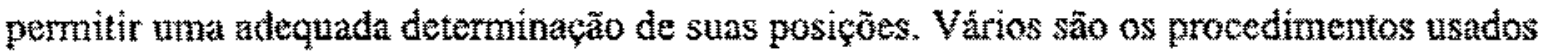
nessa determinažă, aplicados a Mcl91].

Neste trabalho é usado o ajuste de uma distribuiçã̃o nomal para a determinaçẵo da posiça do pico. As distribuiços temporais dos fons apresentam uma porçăo estreita situada sobre uma base bastante larga. Esta base ocorre devido ao decaimento em vố de ions metaestáveis, sendo a porçăo estreita formada pelos ions que säo detectados intactos 
[Cha81]. Nesse caso, o ajuste é feito apenas na porção mais estreita da distribuição temporal, preferencialmente usando-se apenas alguns canais ao redor do pico [Bea90].

Após a determinação das posiçōes dos picos é feito um ajuste pelo método dos minimos quadrados para o conjunto de pontos formados pelas posiçöes dos picos as raizes quadradas das massas dos lons [Hels1]. Nem sempre o uso de vânos picos é garantia da determinação de uma boa curva de calibração, sendo necessário estudar-se qual conjunto de lons produz os menores desvios entre os valores das massas calculadas em relação às provăveis massas dos ions. $O$ conjunto que apresenta os menores desvios é utilizado para a calibração do espectro como um todo [Hil87, Man90].

A correta identificação dos ions inflư na precisão da calibração, uma vez que é a partir de sua fórmula molecular que as suas massas săo calculadas. Na regiăo de pequena massa, caso a resoluçäo do equipamento seja capaz de resolver moléculas isobáricas, deve-se ter o cuidado de identiftcar corretamente os picos, levando-se em conta os isótopos mais abundantes para o catculo da massa, acrescentando-se ou subtraindo-se um elétron no caso de ions negativos ou positivos.

Em um espectrômetro de massa cuja resolução está abaixo da resolução necessária para separar jons originados de uma mesma molécula orgânica, mas com diferentes massas devido à distribuição isotópica de átomos de $\mathrm{C}, \mathrm{H}, \mathrm{N}, \mathrm{O}$ e S, o valor da massa associado ao pico resultante é calculado pela métia ponderada das massas dos fons, com pesos dados pela probabilidade de ocorrencia de cada isótopo [Cha82]. Esta probabilidade é calculada usando-se uma distribuiçăo binomial $\left.\right|^{27}$.

Neste trabalho, o procedimento empregado para a calibraçăo em massa de um espectro inicia-se com a determinação da posição dos picos de alguns íons de pequena massa que, como mencionado anteriormente, estão presentes na maioria dos espectros. Após uma primeira calibração outros ions são identificados e usados para melhorar a precisăo do ajuste na regiäo de maiores massas. As massas e abundânctas usadas nos cálcuIos efetuados neste trabalho são extraidas da tabela de isotopos do C R C Handbook of Chemistry and Physies [Wetal].

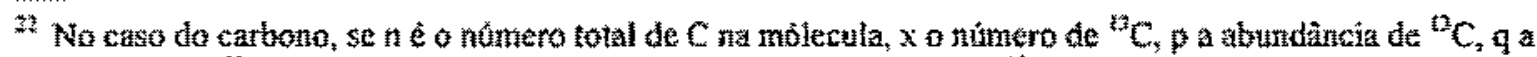

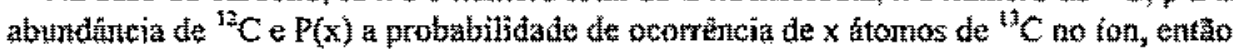
$P(x)=[n] U(x !(n-x)])]\left.p^{x}\right|^{n \cdot x}$.
} 
A seguir são apresentados os resultados obtidos na análise de uma amostra imorgânica, o sal de Csi, e algumas amostras biológicas como aminoácido fenilalalina os peptideos Angiotensin I e LHRH.

\subsubsection{Amostra de CsI}

A amostra de CsI encontra-se depositada sobre um substrato de Kimfol ${ }^{23}$ de 1 um de espessura recoberto por uma fina camada de $\mathrm{Au}$ de $500 \mathrm{~A}$ para garantia do contato elétrico. Este material é depositado pelo processo de evaporação a vácto sendo sua espessura da ordem de $500 \mathrm{~A}$. As Fig. 5.6 (a) (b) apresentam as distributcoto de massa obtidas com a amostra sujeita a tensôes de acelaraçäo de $\pm 18 \mathrm{kV}$. Para calibraçäo do espectro positivo são usados os lons de $\mathrm{Cs}^{*}$ e $\mathrm{Cs}_{2} \mathrm{l}^{*}$, sendo este úlimo pertencente a conjunto de aglomerados fomados por esta amostra do tipo $(\mathrm{Csl})_{n} \mathrm{Cs}^{*}, \mathrm{O}$ aglomerado de maior massa observado é o $\mathrm{Cs}_{5} \mathrm{I}_{4}{ }^{*}$, porém com intensidade muito baixa. No caso dos íons negativos, o ajuste é realizado com os ions $\mathrm{I}^{-}$e $\mathrm{Cs}_{2} \mathrm{I}_{3}{ }^{-}$. Neste caso são observados

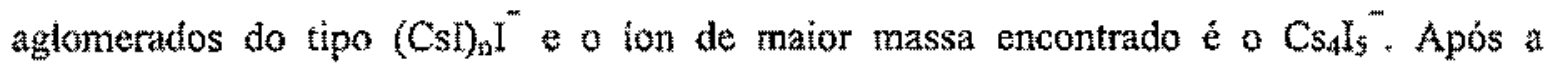
calibraçăo é possivel identifucar a presença de outros aglomerados devido a contaminaçăto da amostra por átomos de Cl e Br. Estes atomos também formam familias de aglomerados

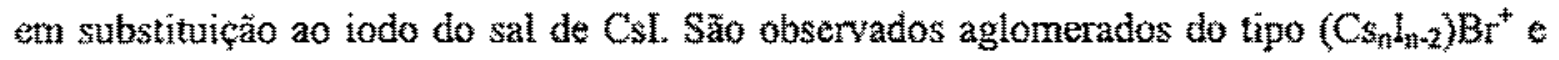
$\left(\mathrm{Cs}_{n} h_{\mathrm{n}-2}\right) \mathrm{Cl}^{+}$para tensōes positivas do bipo $\left(\mathrm{Cs}_{n} \mathrm{Cl}^{-}\right.$e $\left(\mathrm{CsD}_{\mathrm{n}} \mathrm{Br}^{-}\right.$para tensöes negativas. Nestes casos estes aglomerados sotrem a influência da distribuição isotópica dos átomos de $\mathrm{Cl}\left({ }^{35} \mathrm{Cl} \mathrm{e}{ }^{37} \mathrm{Cl}\right)$ e $\mathrm{Br}\left({ }^{79} \mathrm{Br} \mathrm{e}^{81} \mathrm{Br}\right)$, apresentando picos cujas intensidades relativas seguem a distribuiçầo binomial.

Nas tabelas 5.3 e 5.4 são apresentados os valores das massas obtidas pela calibração dos espectros juntamente com as massas calculadas pela fórmula molecular associada ao ton. Na quarta coluna são apresentadas as incertezas das massas medidas, calculadas pela

23 None comercial do polimero $-\mathrm{I}_{17} \mathrm{H}_{25} \mathrm{O}_{4}$. 
propagação de emos dos parâmetros da reta de calîbraçẫo, e na quinta coluna sã̃o apresentadas as diferenças entre as massas calculadas medidas $\Delta \mathrm{m}$. Como pode ser observado para este conjunto de dados as diferenças $A m$ sẫo da ordem de milésimos a centésimos da u.m.a. Na Fig. 5.7 (a) e (b) estäo os gráficos de $\Delta m$ em função de $m / q$ relativos as duas tabelas anteriorts, permitindo uma melhor visualizaçăo da tendencia de maior diffouldade na identificaçăo de lons de maior massa.
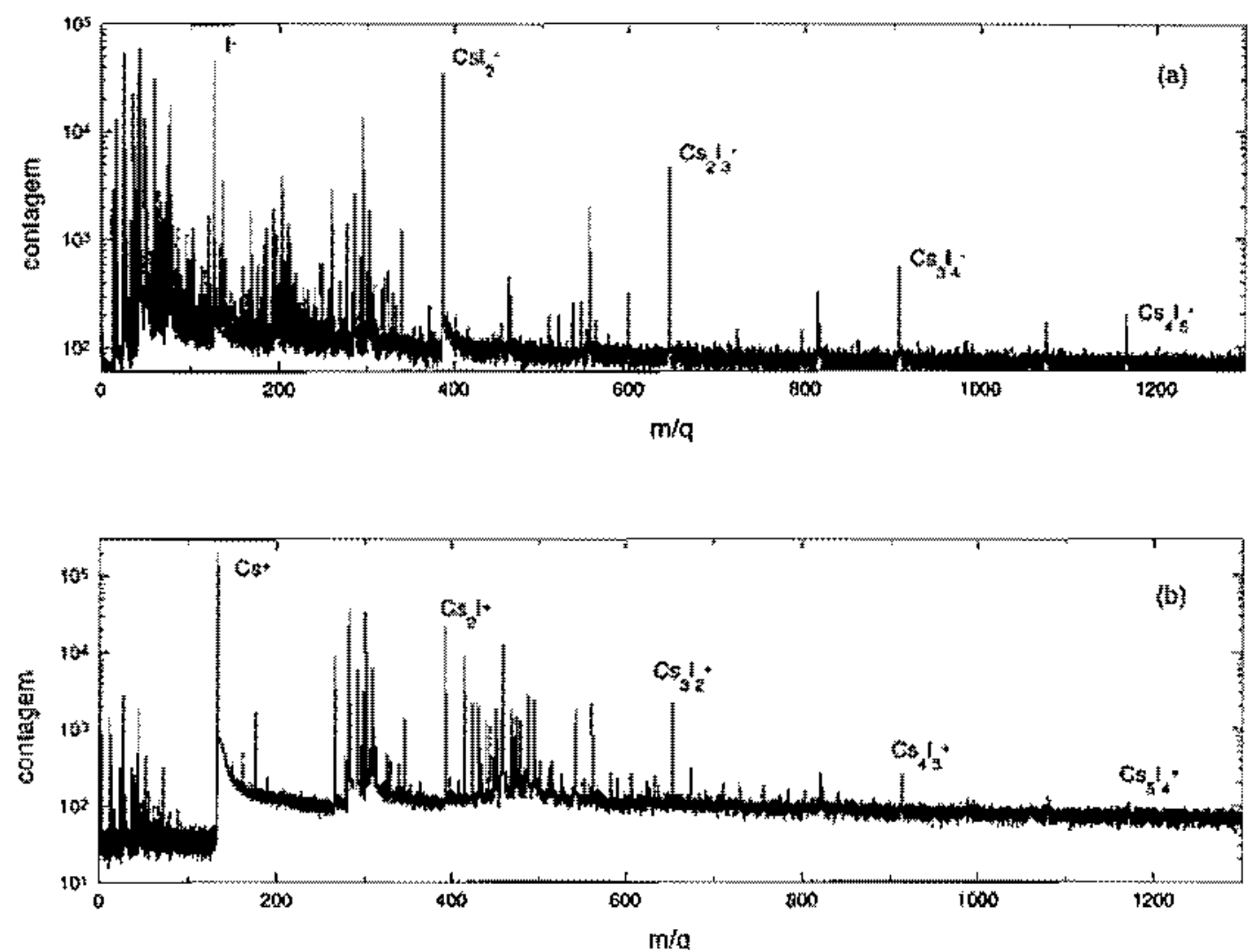

Fig. 5.6 - Espectros de massa de mma amostra de CsI depostada a vácto sobu um substrato de Kimfol racoberto por 500 A de aum, parta tensöes de aceleraçäo da amostra ke $-18 k \mathrm{~V}(a) e+18 k V(b)$ 


\begin{tabular}{|c|c|c|c|c|}
\hline fon Provavel & Massa Calculada & Massa Medida & Erro da Medida & $\Delta \mathrm{m}$ \\
\hline$H^{\circ}$ & 1,00837 & 1,0077 & $0,000 \overline{2}$ & $-0,0007$ \\
\hline $\mathrm{C}^{*}$ & 11,99945 & 11,996 & 0,001 & $-0,000$ \\
\hline $\mathrm{C}_{2} \mathrm{H}^{*}$ & 25,60728 & 25,006 & 0,001 & $.0,001$ \\
\hline $\mathrm{C}_{3} \mathrm{HO}^{*}$ & $4 \simeq, 00329$ & 41,002 & 0,001 & $-0,001$ \\
\hline$r$ & 126,90502 & - & - & (calibr) \\
\hline $\mathrm{Cs}^{2} \mathrm{Cl}^{\mathrm{3}}\left({ }^{3} \mathrm{Cl}\right)$ & 24,7793 & 294,77 & 0,006 & $-0,00 \%$ \\
\hline $\mathrm{CatCl}\left({ }^{3} \mathrm{Cl}\right)$ & 296,77635 & 296,769 & 0,000 & $-0,007$ \\
\hline $\mathrm{Cs} B \mathrm{Bt}^{*}(\mathrm{Br})$ & 338,72879 & 338,723 & 0,006 & 0,006 \\
\hline $\mathrm{CsIBr}^{*}\left({ }^{\mathrm{B}} \mathrm{Br}\right)$ & 340,72674 & 340,723 & 0,007 & $-0,004$ \\
\hline $\mathrm{Cs}_{2}^{\circ}$ & 386,71495 & 386,713 & 0,008 & $-0,002$ \\
\hline $\mathrm{Cs}_{7} \mathrm{ICH}_{2}\left({ }^{3 s_{\mathrm{Cl}}}\right)$ & 462,65358 & 462,651 & 0,009 & $-0,003$ \\
\hline $\mathrm{C}_{\mathrm{S}_{2}} \mathrm{ICl}_{2}\left({ }^{3 /} \mathrm{C}\right)$ & 464,65063 & 464,657 & 0,009 & 0,006 \\
\hline$(\mathrm{Cs})_{2} \mathrm{Cl}^{*}\left({ }^{34} \mathrm{Cl}\right)$ & $554, \$ 892$ & 554,59 & 0,01 & $-0,001$ \\
\hline$(\mathrm{Csl})_{2} \mathrm{Cl}^{*}\left({ }^{37} \mathrm{Cl}\right)$ & 556,58626 & 556,58 & 0,01 & $-0,006$ \\
\hline$(\mathrm{Csl})_{2} \mathrm{Br} \cdot\left({ }^{79} \mathrm{Br}\right)$ & 598,53869 & 598,53 & 0,01 & $-0,009$ \\
\hline$(\mathrm{CsI})_{2} \mathrm{Br}{ }^{-1}\left({ }^{8 t} \mathrm{Br}\right)$ & 600,53664 & 600,53 & 0,01 & $-0,007$ \\
\hline $\mathrm{Cs}_{2} \mathrm{I}_{3}$ & 646,52483 & $\cdots$ & -- & (calibr.) \\
\hline$\left.\left(\mathrm{Cul}_{3}\right)_{3} \mathrm{Cl}^{35} \mathrm{Cl}\right)$ & 814,39911 & $\$ 14,47$ & 0,02 & 0,07 \\
\hline$(\mathrm{CsI})_{3} \mathrm{Cl}^{-}\left({ }^{*} \mathrm{Cl}\right)$ & 816,39616 & 816,47 & 0,04 & 0,07 \\
\hline $\mathrm{C}_{3} \mathrm{l}_{4}{ }^{\circ}$ & 906,334773 & 906,38 & 0,02 & 0,04 \\
\hline$\left(\mathrm{CsL}_{4}\right) \mathrm{Cl}\left({ }^{3} \mathrm{Cl}\right)$ & 1074,20901 & 1074,33 & 0,02 & 0,12 \\
\hline $\mathrm{C}_{3} \mathrm{l}_{2}$ & $1166,1466^{2}$ & 1166,24 & 0,03 & 0,10 \\
\hline
\end{tabular}

Tabela 5.3 - Massas dos provavels lons (uma. provenienes de uma amostra de Cot a

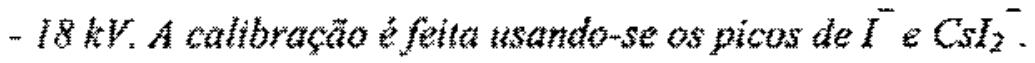




\begin{tabular}{|c|c|c|c|c|}
\hline Ion Provavel & Massa Calculada & Massa Medida & Erro da Medida & $\Delta \mathrm{m}$ \\
\hline $\mathrm{H}^{+}$ & 1,00742 & 1,0101 & 0,0003 & 0,003 \\
\hline $\mathrm{H}_{2}^{+}$ & 2,01510 & 2,0190 & 0,0005 & 0,004 \\
\hline $\mathrm{H}_{3}{ }^{+}$ & 3,02293 & 3,0274 & 0,0004 & 0,004 \\
\hline $\mathrm{CH}_{3}^{+}$ & 15,02293 & 15,032 & 0,001 & 0,009 \\
\hline $\mathrm{Na} a^{+}$ & 22,98977 & 23,001 & 0,001 & 0,01 \\
\hline $\mathrm{C}_{2} \mathrm{H}_{2}{ }^{*}$ & 27,02293 & 27,034 & 0,001 & 0,01 \\
\hline $\mathrm{NO}^{+}$ & 29,99744 & 29,989 & 0,002 & $-0,008$ \\
\hline $\mathrm{Cs}^{*}$ & 132,90488 & $\ldots$ & $\ldots$ & (calibr.) \\
\hline $\mathrm{Cs}_{2}{ }^{*}$ & 263,81031 & 265,761 & 0,007 & $-0,05$ \\
\hline $\mathrm{Cs}_{3} \mathrm{H}^{+}$ & 266,81813 & 266,805 & 0,007 & $-0,01$ \\
\hline $\mathrm{Cos}_{2} \mathrm{O}^{+}$ & 281,80522 & 281,788 & 0,007 & $-0,02$ \\
\hline $\mathrm{Cs}_{2} \mathrm{OH}^{+}$ & 282,81305 & 282,314 & 0,007 & 0,001 \\
\hline $\mathrm{Cs}_{2} \mathrm{CH}\left({ }^{*} \mathrm{Cl}\right)$ & 300,77916 & 300,777 & 0,007 & $-0,002$ \\
\hline $\csc _{3} \mathrm{Cl}^{3}\left(\mathrm{x}^{+2} \mathrm{C}\right)$ & 302,77620 & 302,776 & 0,007 & $-0,0002$ \\
\hline 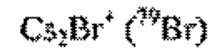 & 344,72865 & 344,726 & 0,008 & $-0,003$ \\
\hline $\mathrm{Cs}_{2} \mathrm{Br}^{*}\left({ }^{*} \mathrm{Hr}\right)$ & $34 b_{*}=2660$ & 346,728 & 0,008 & 0,001 \\
\hline $\mathrm{Cs}_{2}{ }^{*}$ & 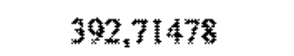 & $=$ & $\ldots$ & (calibr.) \\
\hline $\mathrm{Cs}_{3} \mathrm{IC}^{+} \mathrm{w}^{*} \mathrm{Cl}$ & 560,58906 & 560,59 & 0,01 & 0,001 \\
\hline $\mathrm{Cs} y \mathrm{Cl}^{4} \mathrm{f}^{37} \mathrm{Cl}$ & 562,54611 & 562,58 & 0,01 & $-0,006$ \\
\hline $\mathrm{Cs}_{3} \mathrm{BBr}^{*} \mathrm{f}^{70} \mathrm{Br}$ & 604,53855 & 604,53 & 0,01 & $-0,008$ \\
\hline 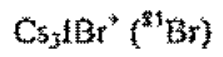 & 606,53650 & 606,54 & 0,02 & 0,003 \\
\hline $\mathrm{Cs}_{3} \mathrm{I}_{2}{ }^{4}$ & 652,52468 & 652,51 & 0,01 & $-0,01$ \\
\hline $\mathrm{Cs}_{4} \mathrm{l}_{2} \mathrm{Cl}^{+}\left({ }^{35} \mathrm{Cl}\right)$ & 820,39897 & 820,43 & 0,03 & 0,03 \\
\hline $\mathrm{CS}_{4} \mathrm{H}_{3}{ }^{*}$ & 912,33459 & 912,32 & 0,02 & $-0,01$ \\
\hline
\end{tabular}

Tabela 5.4 - Massas dos provávess ions (um.a.) provenientes de wma amostra de CsI a $\div$ 18 kV. A calibracăo é fetia usandowe os picos de $\mathrm{Cs}^{*}$ e $\mathrm{Cs}_{2} \mathrm{r}^{+}$. 

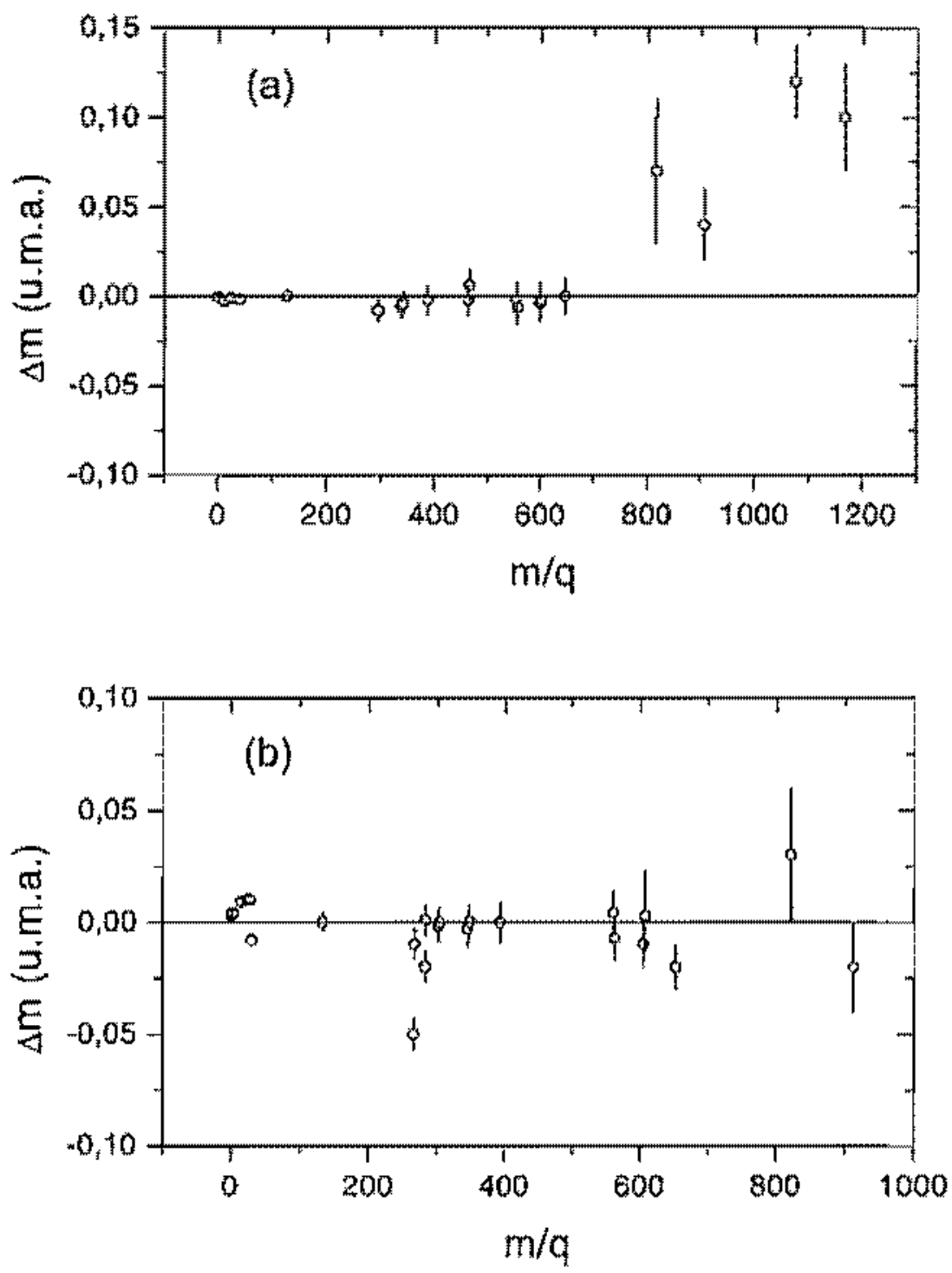

Fig. 5.7 - Diferencas entre as massas medidas e calculadas An para os posstueis ions provenientes de uma amostra de CrI a $-18 \mathrm{kl}(a) \mathrm{e}+18 \mathrm{kV}(\mathrm{b})$. 


\subsubsection{Amostra de Fenilalanina}

A amostra de fenilalanina $\left(\mathrm{C}_{9} \mathrm{H}_{11} \mathrm{NO}_{2}, m=165,08\right.$ um.a.) é preparada com a diluição de $5 \mathrm{mg}$ do material em $10 \mathrm{ml}$ de uma solução de TFA $(0,1 \%)$ gotejada sobre um substrato de mylar aluminizado, de $1,5 \mu \mathrm{m}$ de espessura, e recoberto com uma camada de nitrocelulose usada para melhor adesão do material sobre a sua superficte. Depois de seca go ar livre amostra introduzida no interior do espectrômetro para análise.

Os resulutos de cluas medidas feitas a tensoes de $+12 \mathrm{kV}-12 \mathrm{kV}$ são apresentudos na Fig. 5.8 (a) e (b), respectivamente. Nas distribuiçồ de massa sầo observados os ions quast-moleculares $(\mathrm{M}+\mathrm{H})^{+}$e $(\mathrm{M}+\mathrm{H})^{-}$, sendo ainda identificado no

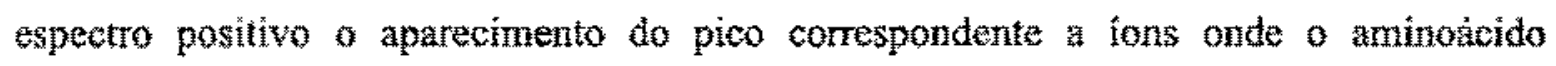
encontramse ligado a um atomo de sodio (M+Na), bem como o pico relativo aos lons bimoteculares $(2 \mathrm{M}+\mathrm{H})^{+}$. Picos observatos no espectro com valores de massa menores que a do pico quasi-molecular săo devidos à fragmentaçâo da molecula de fenilalanina e contribuiçöes do substrato e impurezas. Por exemplo, o fragmento identificado como $(\mathrm{M}-\mathrm{COOH})^{+}$ocorre pela perda do terminal carboxila da fenilalanina.

A utilizaçăo de um substrato de nitrocelulose e própria amostra causam no espectro de massa o aparecimento de picos que podem conter ions isóbaros näo resolvidos pelo espectrômetro, formados pela combinação de atomos de $\mathrm{C}, \mathrm{H}, \mathrm{O}$ e $\mathrm{N}$. Como exemplo, na regiăo de massa de 39 u.m. formado um pico pela provável contribuiçắn de íns do tipo $\mathrm{C}_{3} \mathrm{H}_{3}^{*}$ e $\mathrm{C}_{2} \mathrm{HN}^{+}$. Dessa forma, a escolha de picos para calibraçấo deve ser feita com catela, evitando-se aqueles onde mais de uma espécie de molécula possa estar presente.

As tabelas 5.5 e 5.6 apresentam as formulas moleculares dos prováveis lons observados nos espectros de massa da fenilalanina $a+12 \mathrm{kV}+-12 \mathrm{kV}$, sendo posável comparar as maxsas calculadas pela formula (coluna 2) com as massas medidas, obtitas pata calibraçăo dos espectros (coluna 3). Na coluna 4 são apresentadas as incertezas das nassas medidas e na coluna 5 são apresentadas as dif́crença entre as massas calculadas a medidas An. Nesta tabela tamberm estão presentes as massas de picos isobaros, cujos valores säo os mais proximos do valor obtido pela calibração. Nas Fig. 5.9 (a) e (b) säo apresentados os graficos relativos aos desvios $\Delta m$ e suas respectivas incertezas. Os pontos 
relacionados com os ions isóbaros formados por moléculas possuindo átomos de nitrogênio são representados pelo símbolo $(\Delta)$. Nestas medidas a precisão na determinação das massas encontra-se novamente entre 0,001 u.m.a. e 0,01 u.m.a.
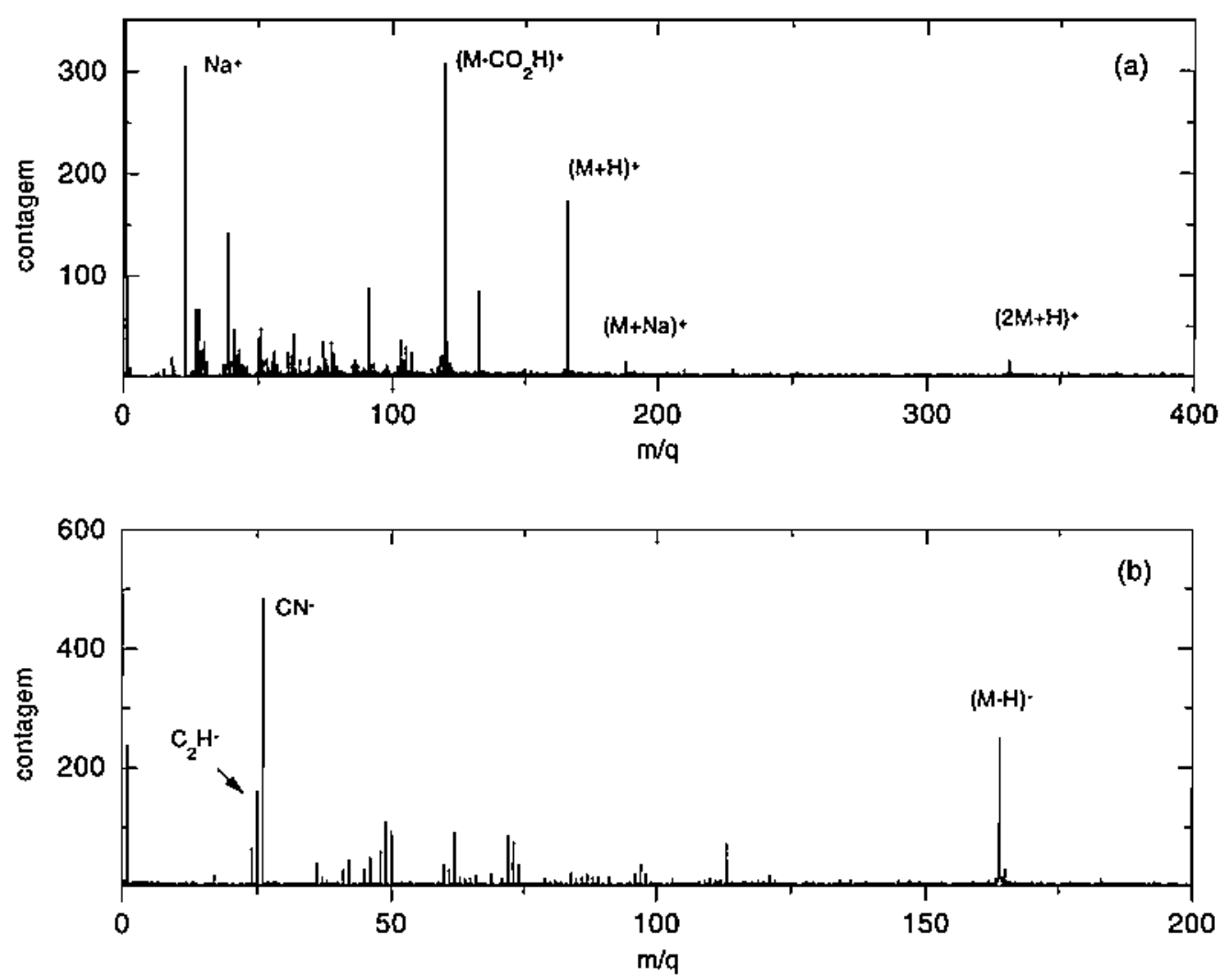

Fig. 5.8 - Distribuições de massa de uma amostra de fenilalanila ( $m=165$ u.m.a.), nas tensões de aceleração de $+12 k V(a) e-12 k V(b)$. 


\begin{tabular}{|c|c|c|c|c|}
\hline Ion Provatel & Massa Calculata & Massa Medida & Erro da Medida & $\Delta m$ \\
\hline $\mathrm{H}^{2}$ & 1,00728 & 1,007 & 0,001 & $-0,0003$ \\
\hline $\mathrm{H}_{2}^{*}$ & 2,01510 & -...- & $+\cdots$ & (calibr.) \\
\hline $\mathrm{CH}_{3}{ }^{+}$ & 15,02293 & 15,026 & 0,006 & 0,003 \\
\hline $\mathrm{Na}^{+}$ & 22,98922 & 22,991 & 0,007 & 0,002 \\
\hline $\mathbf{K}^{+}$ & 38,96316 & 38,965 & 0,01 & 0,002 \\
\hline $\mathrm{C}_{3} \mathrm{H}_{3}$ & 39,02293 & 39,02 & 0,01 & $-0,003$ \\
\hline $\mathrm{C}_{2} \mathrm{HN}^{*}$ & 39,01035 & 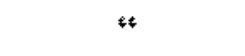 & $*$ & 0.01 \\
\hline $\mathrm{C}_{4} \mathrm{H}_{5}$ & 77,03858 & 77,04 & 0.01 & 0.001 \\
\hline $\mathrm{C}_{3} \mathrm{H}_{3} \mathrm{~N}^{+}$ & 77,02600 & w & $*$ & 0.01 \\
\hline $\mathrm{C}_{4} \mathrm{H}_{2}$ & 91,05423 & 91,04 & 0,02 & $-0,01$ \\
\hline $\mathrm{C}_{6} \mathrm{H}_{5} \mathrm{~N}^{*}$ & 91,04165 & * & “ & -0.002 \\
\hline $\mathrm{C}_{\mathrm{y}} \mathrm{H}_{7}{ }^{+}$ & 103,05423 & 103,05 & 0,02 & $-0,004$ \\
\hline $\mathrm{C}_{3} \mathrm{H}_{3} \mathrm{~N}^{+}$ & 103,04165 & ؛ & $*$ & 0.008 \\
\hline$\left(\mathrm{MCO}_{2} \mathrm{H}\right)^{+}$ & 120,08132 & 120,07 & 0,02 & $-0,01$ \\
\hline$\left.\left.(M+1+)^{*}\right)^{(2} C\right)$ & 166,08626 & 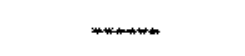 & 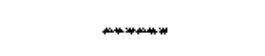 & (calibr.) \\
\hline$(M+H)^{+}\left({ }^{13} \mathrm{C}\right)$ & 167,08961 & 167,09 & 0,03 & 0,0004 \\
\hline$(\mathrm{M}+\mathrm{Na})^{4}$ & 185,06820 & 188,07 & $0,0,3$ & 0,002 \\
\hline$(2 M+1 I)^{*}$ & 331,16523 & 331,20 & 0,05 & 0,03 \\
\hline
\end{tabular}

Tabela 5.5 - Massas dos prováveis ions (u.ma.) observados na amostra de fenilalanina sujeitos a tensão de aceleraçäo de $+12 k V$. A calibração em massa é feita usandomse os picos de $\mathrm{H}_{3}^{+}$e $(\mathrm{M}+\mathrm{H})^{+}$. 


\begin{tabular}{|c|c|c|c|c|}
\hline Ion Provável & Massa Calculada & Massa Medida & Erro da Medida & $\Delta \mathrm{m}$ \\
\hline $\mathrm{H}^{*}$ & 1,00837 & 1,0093 & 0,0006 & 0,0009 \\
\hline $\mathrm{C}_{2} \mathrm{H}^{*}$ & 25,00837 & 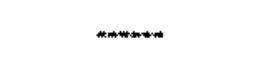 & …… & (calibr) \\
\hline $\mathrm{CN}$ & 26,00362 & 26,007 & 0,003 & 0,003 \\
\hline $\mathrm{C}_{2} \mathrm{HO}^{\circ}$ & 41,00329 & 41,000 & 0,005 & $-0,003$ \\
\hline $\mathrm{CHN}_{7}{ }^{*}$ & 41,01452 & 4. & 0,005 & $-0,015$ \\
\hline $\mathrm{C}_{2} \mathrm{H}_{3} \mathrm{O}^{\prime}$ & 42,01111 & 41,996 & 0,005 & -0.015 \\
\hline CNO & 41,99854 & " & 0,005 & $-0,002$ \\
\hline $\mathrm{HCOO}^{\circ}$ & 44,99820 & 44,998 & 0,006 & 0,0002 \\
\hline $\mathrm{HN}_{2} \mathrm{O}^{\prime}$ & 45,00944 & “ & 0,005 & $0.0 \mathrm{I}$ \\
\hline $\mathrm{C}_{3} \mathrm{~N}^{-}$ & 50,00362 & 50,002 & 0,005 & $-0,002$ \\
\hline$(\mathrm{M}-\mathrm{H})^{-12} \mathrm{C}$ & 164,07170 & ............ & $\ldots$ & (calibr) \\
\hline$(\mathrm{M}-\mathrm{H})^{+13} \mathrm{C}$ & 165,07506 & 165,06 & 0,01 & $-0,015$ \\
\hline
\end{tabular}

Tabela 5.6 - Massas dos prováveis ions (tu.m.a.) observados na amostra de fenilalanina sujetios a tensão de acelertçäo de - $12 \mathrm{kV}$. A caltbraçäo em massa é feita usando-se os picos de $C_{2} H^{m}$ e $(M+H)^{\prime \prime}$. 

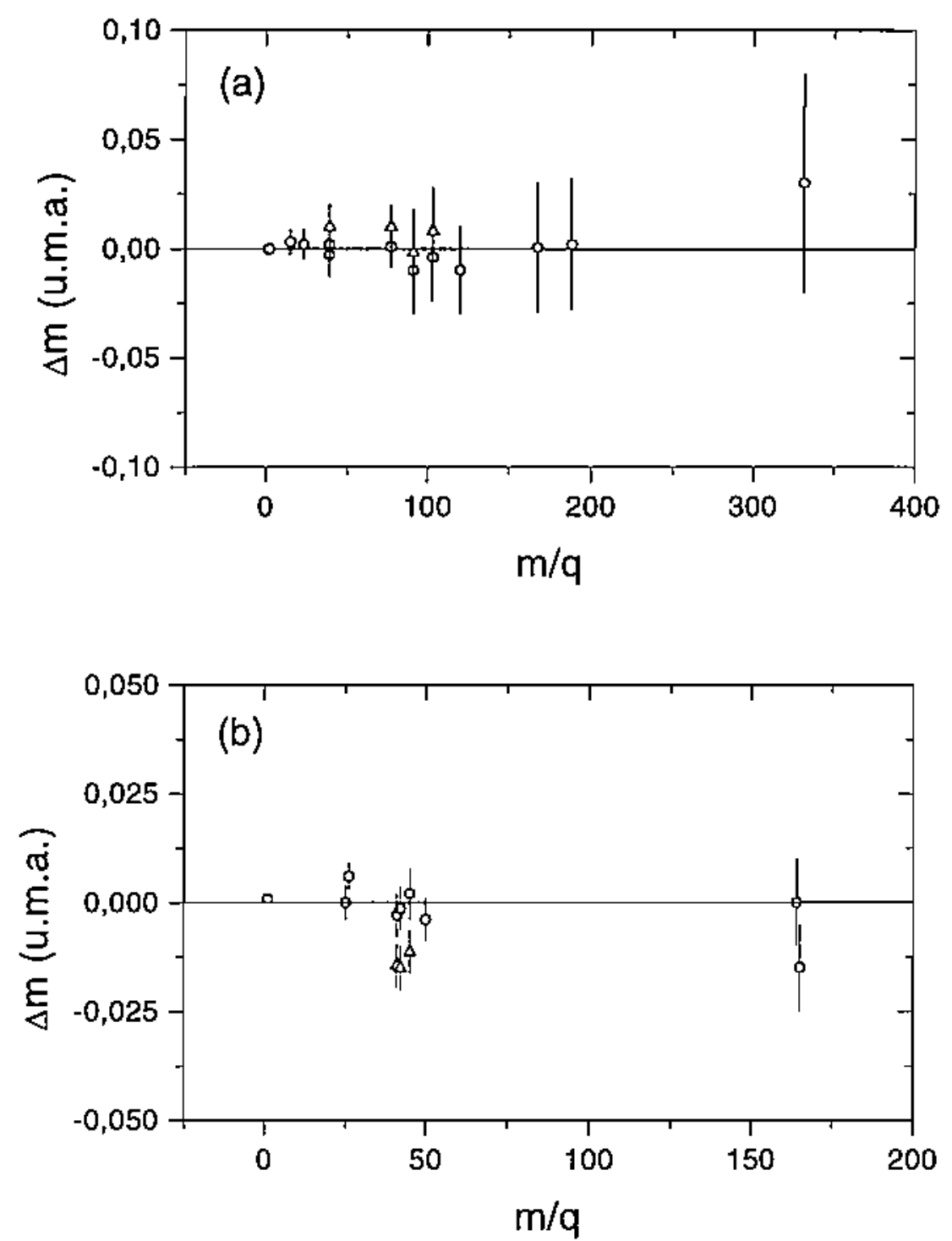

Fig. 5.9 - Diferenças entre as massas medidas e calculadas ( $\Delta \mathrm{m}$ ) para os possiveis íns provenientes de uma amostra de fenilalanina a $+12 \mathrm{kV}$ (a) e $-12 \mathrm{kV}$ (b). Os pontos experimentais $(\Delta)$ representam os ions cuja fórmula molecular possui átomos de nitrogênio e são isóbaros a ions formados por $\mathrm{C}, \mathrm{He} \mathrm{O}$. 


\subsubsection{Amostras de Angiotesin I e LHRH}

Dois peptideos analisados são apresentados como exemplos da análise de biomoléculas com massas na faixa de 1000 um.a. $O$ primeiro $b$ Angitensin $I_{\text {, }}$ $m=1296,7$ u.m.a.; formado por 10 aminoúcidos, e o outro uma amostra de LHRH (Luteinizing Homone Releasing formone), $n=1,82,3$ um, a. tambêm possuinto 10 aminoácidos.

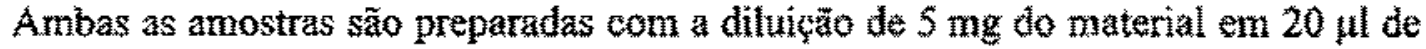
TFA - acido nifluoractico $(0,1 \%)$. O substrato usado nestas medidas $b$ teito por uma folla de Kimfol de 1 um de espessura e $10 \mathrm{~mm}$ de diàmetro, recoluerta por uma camada de ouro de $500 \mathrm{~A}$, sobre a qual é gotejada uma soluçấo de nitrocelulose, feita pela dissolução de uma folha de nitrocelulose de $10 \mathrm{mg}$ em $20 \mathrm{ml}$ de acetona. Durante o processo de secagem da nitrocelulose o suporte é colocado em rotaçẵo para espalhar a soluçẫo de foma tuniforme sobre o substrato de Kimfol. Após esta etapa, uma gota da soluçẵo da amostra é colocada sobre a nitrocelulose, sendo o conjunto deixado secar ao ar livre e posteriormente colocado no interior do espectrômetro para as medidas.

A nitrocelulose é usada como uma matriz que facilita a adesâo da amostra sobre o substrato, permitindo uma distribuiçăo uniforme do material sobre sua superficie. A nitrocelulose também possibilita o aumento da emissäo de ions moleculares da amostra. $\mathrm{O}$ uso da nitrocelulose para este fim iniciou-se em trabalhos realizados pelo grupo de Upsalla, em meados da década de 80 [Jon86], O mecanismo pelo qual matrizes como a nitrocelulose pemitem o aumento na produçấo de ions nấo bem compreendido, sendo este anda motivo de estudos e tentativas de encontrar outros materiais com caracteristicas similares ou superiores às da nitrocelulose [McN86, Nic87, Zub97].

Na Fig. 5.10 (a), (b) e (c) süo apresentados os espectros to Angiotensin $I_{3}$ adquiridos nas tensões de $+12 \mathrm{kV}$ (a) $\mathrm{e}-12 \mathrm{kV}(\mathrm{b})$, a do LHRH (c) na tensà̃o de $+12 \mathrm{kV}$. Cada medida foi realizada durante um periodo de 4 horas, sendo gue para o LHRH näo foi observado o pico $(\mathrm{M}-\mathrm{H})^{-}$para a tensão de $-12 \mathrm{kV}$. O Angiotensin 1 mostrou-se com maior taxa de produçäo do ion $\left(\mathrm{M}+\mathrm{H}^{+} \mathrm{a}+12 \mathrm{kV}\right.$ em ralaçăo ao ion $(\mathrm{M}-\mathrm{H})^{*}$ a $-12 \mathrm{kV}$. 
Para calibraçăo desses espectros foram ntilizados os ions identificados como $\mathrm{H}^{+}$, $\mathrm{H}_{2}{ }^{*}, \mathrm{H}_{3}{ }^{+}, \mathrm{Na}^{*}$ e $\mathrm{CH}_{3}{ }^{*}$, para tensões positivas, e $\mathrm{H}^{*}, \mathrm{C}^{-}$e $\mathrm{C}_{2} \mathrm{H}^{-}$, para as negativas. Os valores obtidos pelas calibraçöes para os fons quasi-moleculares säo apresentados na tabela 5.7. A.s massas usadas para comparaçấ com as enpíricas săo calculadas pela média ponderada das distribuchọes isotópicas dessas moléculas como mencionado no tiem 5.3 .

Os resultados mostram que a precisäo obtida é menor que 1 u.m.a. Tal precisza e suficiente para a deferminaçăo da massa de biomoleculas nessa regiào de massa, permitindo, por exemplo, verificar se o proessso de sintese do materita ocorreu de forma esperada. Nesse sentido, o espectrometro de massa pode servir como torramenta para o controle de qualidade na sintese de peptídeos, verificande posaiveis contaminaços, ausência ou adiçâa acidental de aminoácidos, bem como evidenciando possiveis reaçoes colaterais [Cho89, Bie92].

Picos de baixa intensidade podem ser vistos nos espectros apresentados na regiäo de massas abaixo do pico molecular. Tais picos são formados por lons pertencentes a fragmentos das moléculas analisadas e podem, eventualmente, ser usados em estudos de seqüenciamento de peptideos e proteinas para a identificaçăo de seus aminoácidos [Tsa89, Bie92].

\begin{tabular}{ccccc}
\hline & \multicolumn{2}{c}{$(\mathrm{M} \div \mathrm{H})^{+}$} & \multicolumn{2}{c}{$\left(\mathrm{M} \times \mathrm{H}^{\mathrm{m}}\right.$} \\
& Massa Medida & Massa Calculada & Massa Medida & Massa Calculata \\
\hline Angiotensin I & $1297,1 \neq 0,9$ & 1297,4 & $1295,3=0,8$ & 1295,4 \\
LHRH & $1182,8 \pm 0,8$ & 1187,2 & & $\ldots$ \\
\hline
\end{tabular}

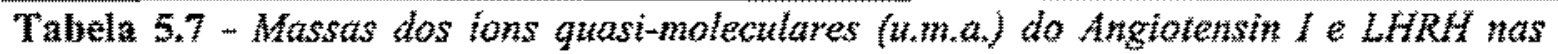

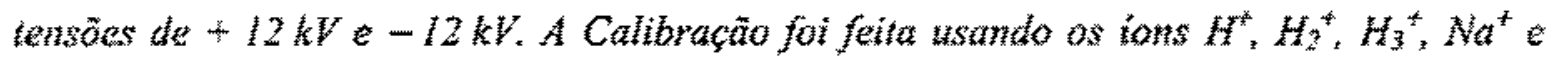

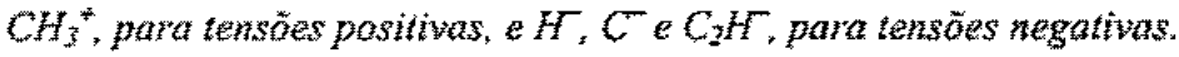



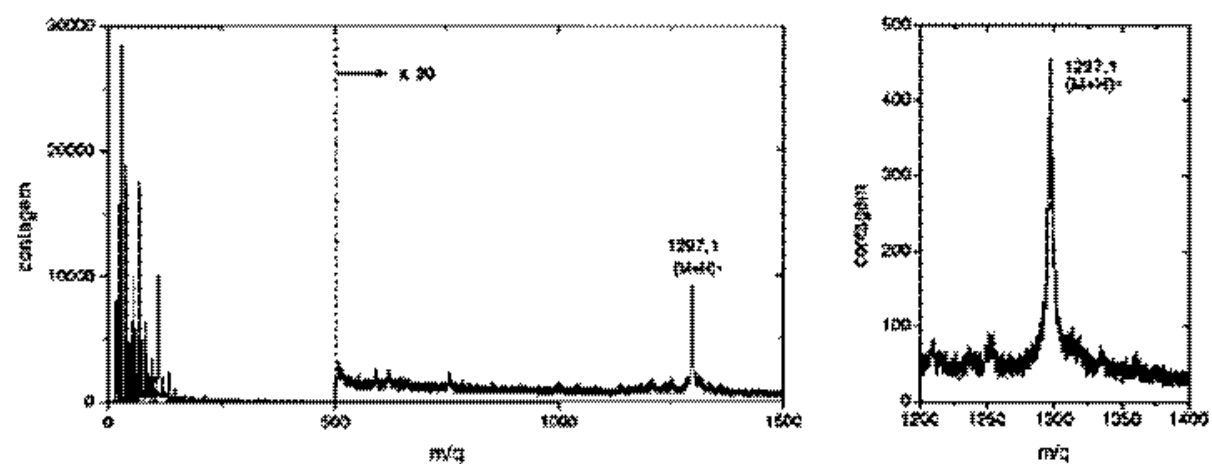

(a)
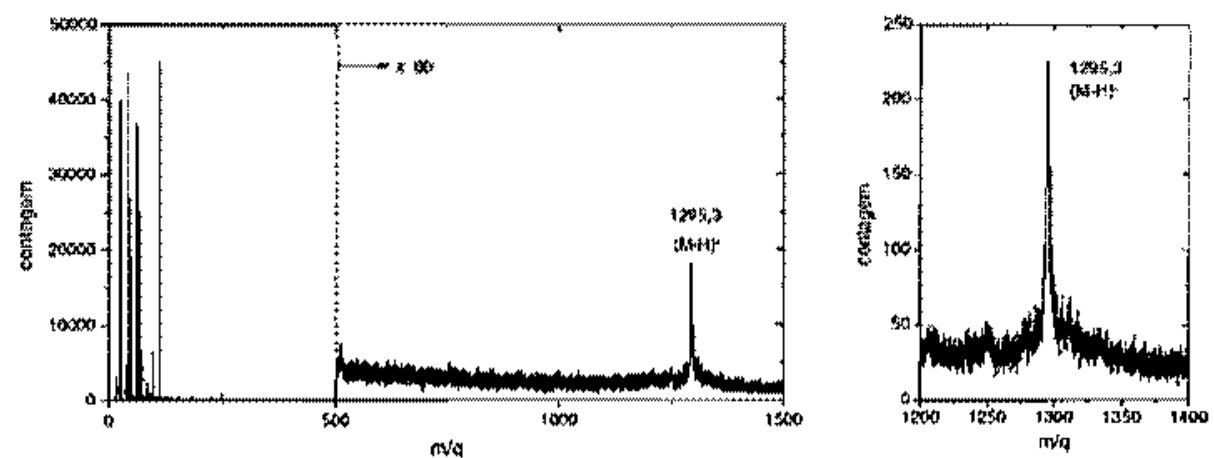

(b)
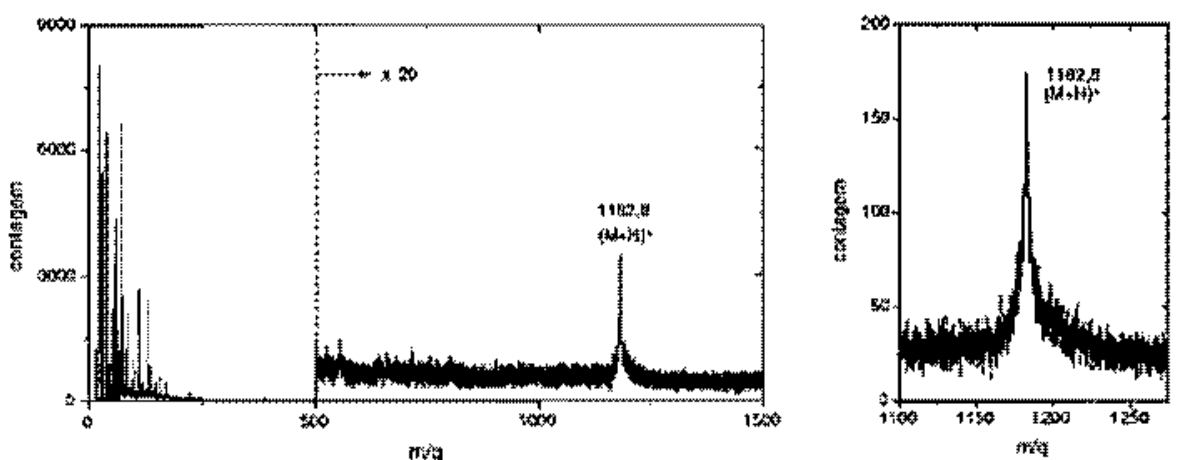

$(\$)$

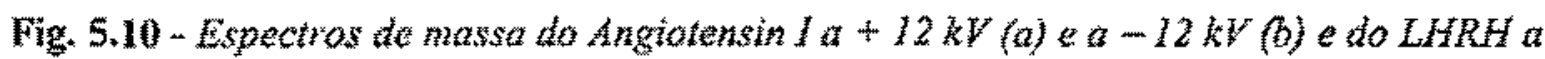
$\div 12 \mathrm{kV}$ (c). Ao lado sto mostrados detahes dos picos dos ions quasimoleculares. 


\subsection{Resoluçäo do Espectrômetro de Massa}

O espectrômetro de massa por tempo de vôo sofre limitaçỏes em sua resoluçắo decorrentes de fatores intrínsecos aos equipamentos de medida e de caracteristicas estatisticas presentes no processo de produção dos lons secundários da amostra [Sta92].

Em relaçã̃o ao sistema de aquisição, a eletrơnica rápida empregada teve seu desenvolvimento em experimentos de física nuclear, que exigem resoluçōes temporais abaixo de $1 \mathrm{~ns}$. Tal característica mais que satisfatória para o uso em espectrometria de massa por tempo de vôo de biomoléculas, porém os módulos eletrônicos utílizados devem ser adequadamente ajustudos para operação neste tipo de aplicaçâo (ver item 4.2) [Ens92].

Outros fatores que podem limitar a resoluçüo do instrumento são os possiveis desvios mecàtitos dos componentes do espectrometro que podem provocar desalinhamentos cntre as superficies da amostra, da grade de aceleraçăo e dos sistemas de detecçã̃o [Rigg 7 .

No desenvolvimento da equą̧ã̃o de tempo de vôo, no item 5.2, o campo elétrico foi considerado uniforme na regiäo de aceleração. Entretanto, o emprego da grade da aceleração provoca inomogeneidades no campo elétrico, causando desvios nas trajetórias dos íns, limitando a resoluçăo do instrumento [Sun85]. Fara minimizar estes efeitos, grades construldas com tramas largas e pouco espaçadas devem ser utilizadas, desde que não haja o comprometimento na transmissão dos lons secundários [Ber89, Owe92].

No aspectrơmetro de massa construido, a energia inicial dos fons secundátios apresenta-se como outro fator de limitaçẫo da resoluçẫo do sistema. Porém. como mencionado no item 5.2, estas distribuições possuem valores da ordem de alguns $\mathrm{eV}$ e, caso o apareiho seja operado em tensōes de aceleração altas, esta contribuição toma-se de pouca importância. Quanto à distribuição espacial dos lons secundários, como o material da amostra é dessorvido de maneira praticamente pontual de uma superficie plana, exte tipo de contribuicầ provoca pequetra influência na resoluçấo do sistema [Sta92].

A equaç⿰彳亍o 5.2 para o calculo do tempo de vôo dos hons secundários é dependente

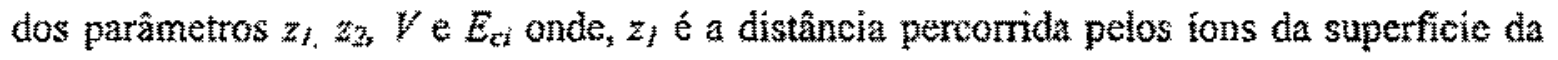
amostra até a grade de aceleraçẫo, $z_{2}$ e a distancia percorrida pelos lons ao longo do tubo de 
vôo, $V$ a tensão de acaleração e $E_{\text {e }}$ a "energita inicial axial" dos lons. A resolução temporal do equipamento sofre limitaçoes devido às posaíveis futuaçöes desses parâmetros durante 0 processo de medida. Supondo que suas contribuiçồ sejam independentes, a resoluçẫo temporal $4 T$ pode ser calculada pela raíz guadrada da sona quadratica das contribuiçoes de cada termo [Hel81], Ainda devem ser acrescentadas a esta soma contribuiçöes referentes às thutuações temporais dos produtos de fissäo no processo de disparo do sistema de aquisiçäo Apf e da resoluçẫo eletrônica $\Delta a l$. Dessa forma, $\Delta T$ pode ser escrita como:

$$
\begin{aligned}
\Delta T=\left[\left(\frac{\partial T}{\partial V}\right)^{2} \Delta^{2} V+\left(\frac{\partial T}{\partial z_{1}}\right)^{2} \Delta^{2} z_{1}+\left(\frac{\partial T}{\partial z_{2}}\right)^{2} \Delta^{2} z_{2}+\right. \\
\left.\left(\frac{\partial T}{\partial E_{c i}}\right)^{2} \Delta^{2} E_{k^{2} t}+\Delta^{2} p f+\Delta^{2} a t\right]^{1 / 2}
\end{aligned}
$$

Após os cálculos das derivadas parciais, a expressấo acima toma-sé:

$$
\begin{aligned}
\Delta T= & \left\{( \frac { 2 m } { q V } ) \left[A(X)\left(\frac{\Delta V}{V}\right)^{2}+B(X)\left(\Delta z_{1}\right)^{2}+\frac{C(X)}{4}\left(\Delta z_{2}\right)^{2}+\right.\right. \\
& \left.\left.D(X)\left(\frac{\Delta E_{c i}}{2 q V}\right)^{2}\right]+\Delta^{2} p f+\Delta^{2} e l\right\}^{1 / 2}
\end{aligned}
$$

sendo

$$
\begin{gathered}
A(X)=\left\{z_{1}\left[X^{1 / 2}-(1+X)^{1 / 2}-\frac{1}{2}(1+X)^{-1 / 2}\right]-\frac{z_{2}}{4}(1+X)^{-3 / 2}\right\}^{3} \\
B(X)=\left[(1-X)^{1 / 2}-X^{1 / 2}\right]^{2} \\
C(X)=(1-X)^{-1}
\end{gathered}
$$




$$
D(X)=\left\{z_{1}\left[(1+X)^{1 / 2}-X^{1 / 2}\right]+\frac{z_{2}}{2}(1+X)^{-3 / 2}\right\}^{2}
$$

$\operatorname{com}$

$$
x=\frac{E_{c i}}{a^{V}}
$$

0 temo referente a contribuị̂̃o dos produtos de fissầ deve ser eliminado do călculo caso as medida sejam feitas com o disparo do sistema de aquisiçâo pelos elêtrons.

A resoluçăo em masşa do equipamento, definida como $m / \Delta m$, onde $\Delta m$ é a largura à meia altura da distribuiçầ de massa, pode ser calculada pela relação:

$$
\frac{m}{\Delta n}=\frac{T}{2 \Delta T}
$$

Substituindo as equaçöes 5.2 e 5.5 na equaça acima e seguindo a análise feita por Davis et al. [Dav88], é verificado que no lïmite de baixas tensóes a resolução é fortemente influenciada pela "energia axial inicial" dos ions. E observado ainda que nesse limite a sua dependência com a massa tende a ser menos importante, uma vez que tanto $T$ quanto $A T$ dependem de $(m)^{-1 / 2}$. No limite de altas tensöes a resolução em massa sofre maior influência dos termos relativos a distribuiçâto temporal dos produtos de fissăo e da resolução do sistema detrönico.

\subsubsection{Comportamento da Resoluçäo com a Tensäo de Aceleração}

Utilizando uma amostra de Csí, o comportamento da resoluçäo em massa do espectrometro fol estudado em funçăo da tensāo de ackleraçân dos hons secundários. Para

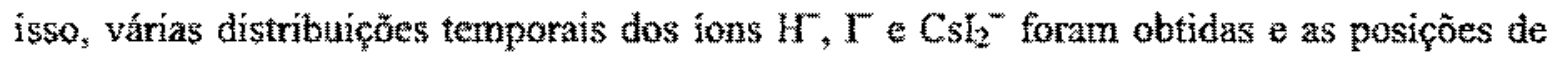
seus picos e larguras à meita altura determinudas. 
A Fig. 5.11 apresenta os resultados para os ions $\mathrm{H}^{-}$, mostrando uma variação da resolução em massa de 600 a 1250 , para tensões de aceleração entre $-2 \mathrm{kV}$ e $-18 \mathrm{kV}$. As incertezas dos pontos experimentais foram obtidas pela propagação dos erros das posições dos picos e das larguras à meia altura das distribuições. Nessas medidas o sistema de aquisição foi disparado com elétrons emitidos da amostra, sendo eliminada a contribuição da distribuição bimodal de velocidades dos produtos de fissão $\Delta p f$ na distribuição temporal dos íons $\mathrm{H}^{-}$. As curvas apresentadas com os pontos experimentais foram calculadas a partir da equação 5.11, com $T$ e $\Delta T$ calculados pelas equações 5.2 e 5.5 , respectivamente. $\mathrm{Na}$ Fig. 5.11 (a) as curvas foram calculadas variando-se os parâmetros $E_{c i}$ e $\Delta E_{c i}$ e fixando-se as demais contribuições e na Fig. $\mathbf{5 . 1 1}$ (b) as curvas foram calculadas variando-se a contribuição do sistema eletrônico $\Delta e l$ e fixando-se as demais contribuições.

$\mathrm{O}$ mesmo estudo foi feito para os íons $\Gamma^{-}$e $\mathrm{Cs}_{2} \Gamma^{-}$mas, nesses casos, o sistema eletrônico foi disparado por produtos de fissão. Para o íon $\Gamma^{-}$a resolução em massa obtida apresentou uma variação entre 990 e 1540 e para o íon ${C s_{2}} \Gamma$, entre 1060 e 1730 , para tensões de aceleração entre $-3 \mathrm{kV}$ a $-18 \mathrm{kV}$. A Fig. 5.12 (a) e a Fig 5.13 (a) mostram os resultados experimentais obtidos juntamente com as curvas calculadas, mostrando o comportamento da resolução com variações de $E_{c i}$ e $\Delta E_{c i}$, fixadas as demais contribuições. Na Fig. 5.12 (b) e na Fig 5.13 (b) os mesmos conjuntos de pontos são apresentados com as curvas calculadas variando-se a contribuição $\left(\Delta p f^{2}+\Delta e l^{2}\right)^{1 / 2}$.

Nos cálculos das curvas apresentadas foram utilizados valores para as variações das trajetórias dos íons na região de aceleração e no tubo de vôo $\Delta z_{l}$ e $\Delta z_{2}$ de $0,1 \mathrm{~mm}$ e $0,2 \mathrm{~mm}$, respectivamente, e para o desvio da tensão de aceleração foi usada a relação $\Delta V=0,005 \% V$, segundo informações do fabricante ${ }^{24}$. Para simplificação dos cálculos foi assumido $E_{c i}=\Delta E_{c i}$, estando a ordem de grandeza de seus valores em acordo com dados encontrados na literatura [Bet94].

\footnotetext{
${ }^{24}$ Fonte de Alta tensāo modelo RHSR30R60 -Speliman High Voltage Corporation, New York, USA.
} 

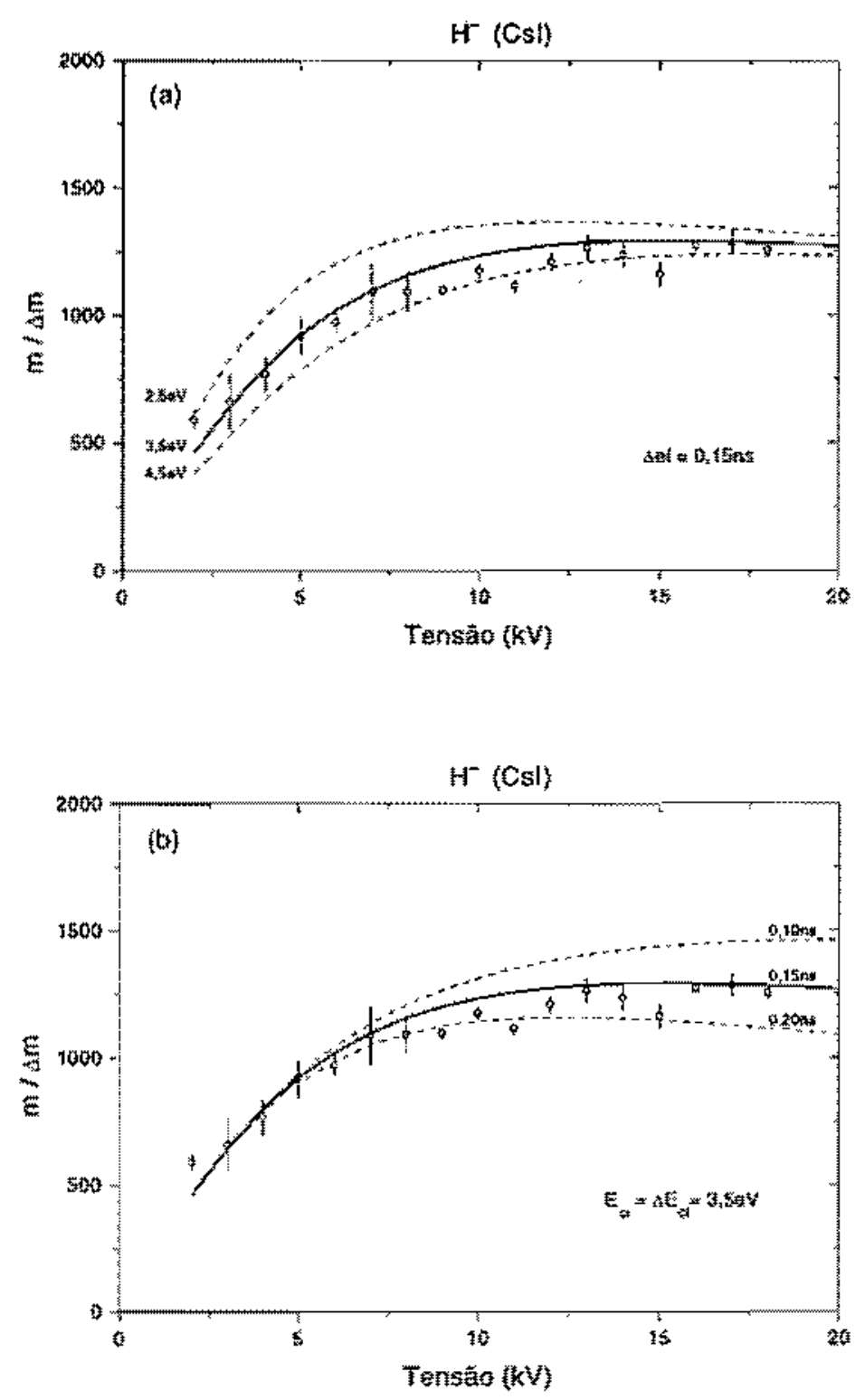

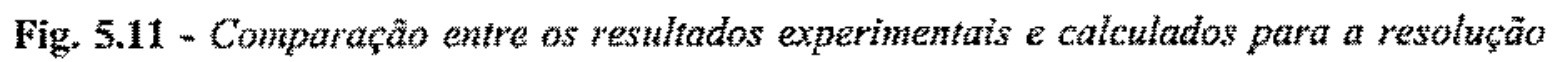

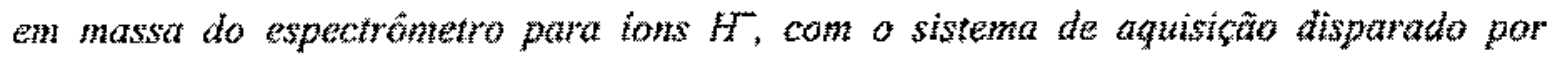
eletrons. (a) Curvas atewladas para diferentes valores de $E_{c \mid} \in A E_{c b}$ fixadas as demais contribuchöex: (b) cumas calculadas para diferentes valores de del, fixadas as demais contribuiçöes. 

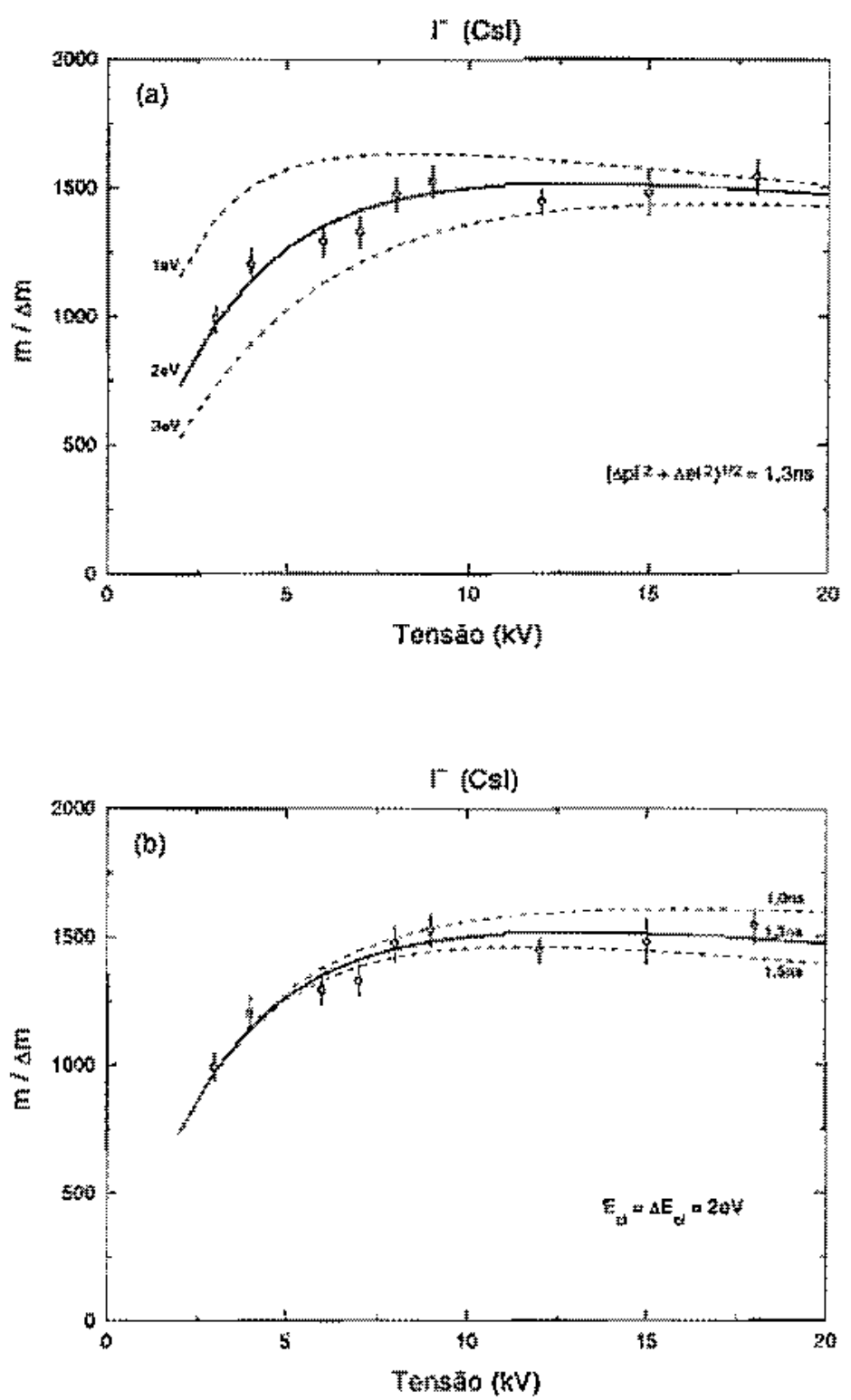

Fig 5.12-Comparação entre os mesultados experintentats e calculatos para a resoluçäo en massa do espectrónetro para ions $r$, com o sistema de aquisiçäo disparato por

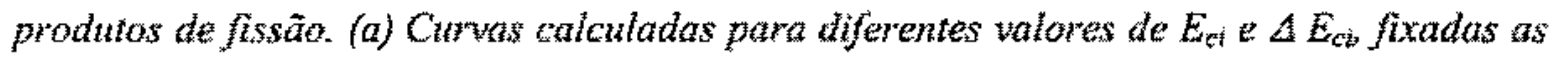
demais contribuiços; (b) curvas calculadas para diferentes valores de $\left(\Delta p f^{2}+\Delta e f^{3}\right)^{\text {, }}$, fixathas as demais contribuicóes. 

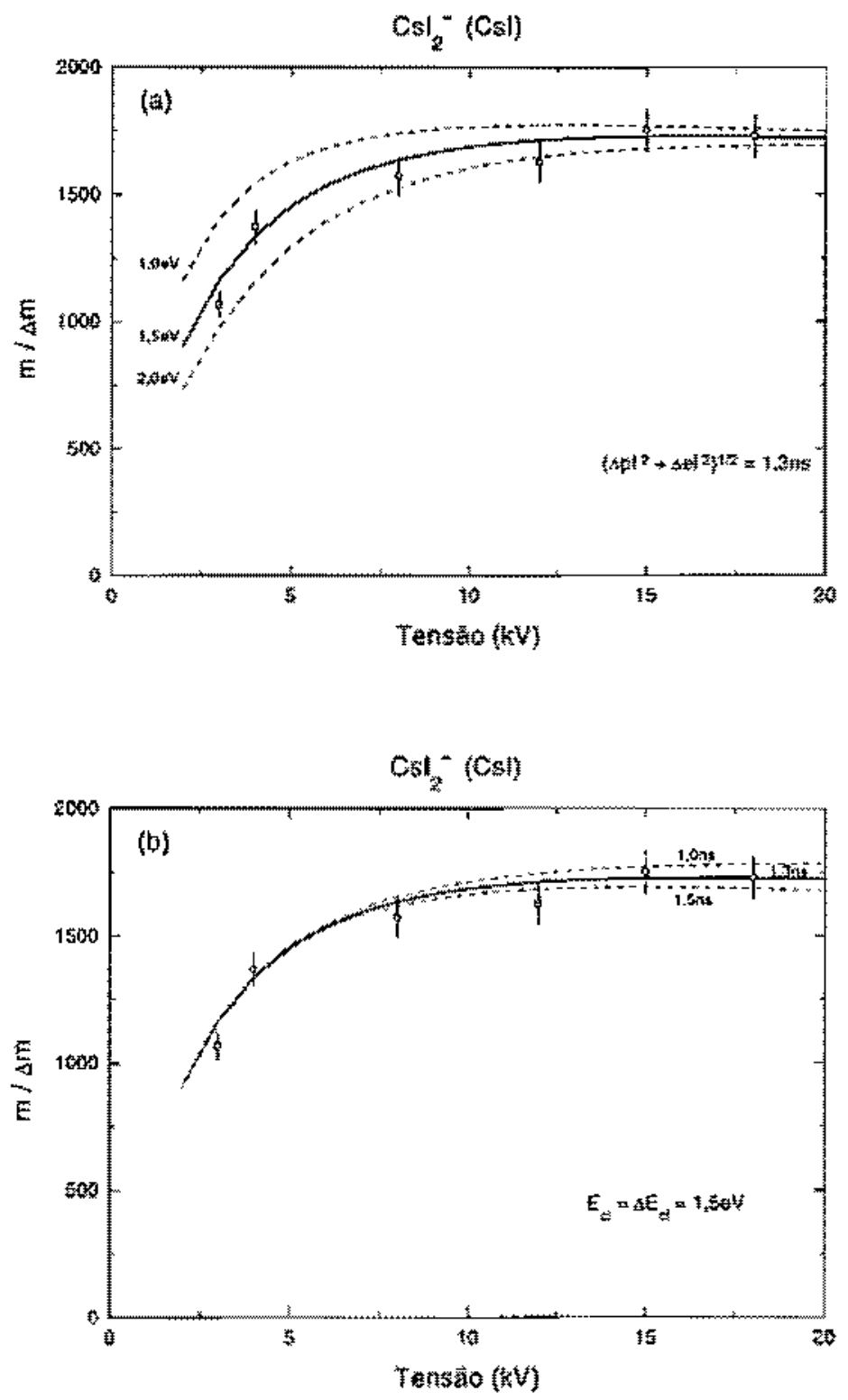

Fig. 5.13 - Comparação entre as resultados experimentais e calculados para a resoltçâo en massa do espectrometro para Lons $\mathrm{Cs}_{2}{ }^{-}$, com o sistema de aquistäa disparato por produtos de fissão. (a) Curvas calculadas para diferentes valores de $E_{i,}$ e $\Delta E_{c i}$, fixadas as

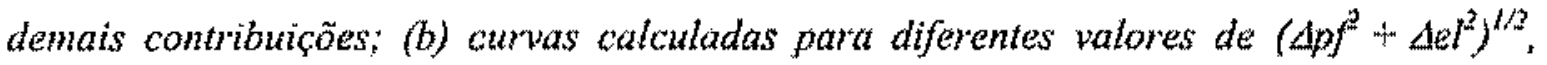
fixadas as denais contribuiçöes. 


\subsubsection{Resolução para regiẫo de massas baixas e altas}

Cono exemplo da capacidade do equipamento em resolver picos na região de massas baixas, uma amostra constituída por uma tolha de mylar aluminizada foi analisada. A Fig. 5.14 (a) mostra a regiato dos picos isobáricos de massa 27 u.m.a., sendo possível a distinçăo entre as picos formados pelos íns $\mathrm{Al}^{+}$e $\mathrm{C}_{2} \mathrm{H}_{3}{ }^{+}$, cujas massas medidas são respectivamente $(26,982 \pm 0,001)$ u.m.a. e $(27,023 \pm 0,001)$ u.m.a., sendo a diferença entre as massas $A m=0,041$ u.m.a. Os ions de $\mathrm{C}_{2} \mathrm{H}_{3}{ }^{+}$possivelmente foram formados pela contaminação com produtos orgânicos provenientes do sistema de bombeamento. Para verificar a correta identificação do pico com esse ín, a amostra foi recoberta por uma camada de sacarose ( $\mathrm{C}_{12} \mathrm{H}_{22} \mathrm{O}_{11}$ ), espessa o suficiente para encobrir totalmente a superficie de alumínio, impedindo a emissăo de lons de $\mathrm{Al}^{+}$e favorecendo a formaçăo de ions $\mathrm{C}_{2} \mathrm{H}_{3}{ }^{+}$ pela fragmentação da sacarose [Cha81]. O resultado desse estudo está apresentado na Fig. $\$ .14$ (b), onde o pico de Al foi completamente eliminado.

Como outro exemplo, na Fig 5.15 (a) é apresentada a regiăo dos picos isobáricos de massa 39 u.m.a de uma amostra de valina depositada sobre um substrato de nitrocelulose. Neste caso, o primeiro pico foi associado ao ion $\mathrm{K}^{4}$ e o segundo à contribuição dos íons $\mathrm{C}_{3} \mathrm{H}_{3}{ }^{+}$e $\mathrm{C}_{2} \mathrm{HN}^{+}$, sendo as massas medidas para esses picos de $(38,965 \pm 0,004)$ u.m.a. e $(39,014 \pm 0,004)$ u.m.a., respectivamente, com $\Delta m=0,05$ u.m.a. $O$ equipamento não possui capacidade de resolver os picos de $\mathrm{C}_{3} \mathrm{H}_{3}{ }^{+}$e $\mathrm{C}_{2} \mathrm{HN}^{+}$, cuja diferença em massa é da ordem de 0,013 u.m.a. Nesse caso, seria necessário um equipamento com uma resolução de $m / \Delta m=3000$. A hipótese da contribuiçăo de ions de $\mathrm{C}_{2} \mathrm{HN}^{+}$ná formação de um dos picos se deve ao uso da matriz de nitrocelulose, como mencionado no item 5.3.2. A amostra foi lavada com água destilada e novamente analisada no espectrômetro de massa. A Fig. 5.15 (b) apresenta o resultado dessa medida, mostrando a perda de intensidade do pico de $\mathrm{K}^{+}$. Um outro pico, associado a ton $\mathrm{Ca}^{+}$, também sofreu perda de intensidade com esse procedimento, como pode ser visto pela comparaçăo com o espectro da Fig. 5.15 (a). Após esta etapa, uma solução de KI foi depositada sobre a superficie da amostra. Um novo espectro foi adquirido, apresentando, mais uma vez, o pico de $\mathrm{K}^{+}$, como pode ser observado na Fig. 5.15 (c). 
Medidas feitas com uma amostra de CsI possibilitaram a avaliação da resoluçẫo espectrômetro na região de massas da orden de centenas de u.m.a. Na Fig. 5.16 (a) e (b) sfio apresentados os picos correspondentes aos aglomerados $\mathrm{Cs}_{4} \mathrm{I}_{3}{ }^{+}(912,3240,02) \mathrm{u}, \mathrm{m}, \mathrm{a}$. e $\mathrm{Cs}_{3} \mathrm{H}^{-}(906.38 \pm 0,02)$ u,m.a., sujeitos a tensões de aceleração de $\pm 18 \mathrm{kV}$, As medidas das larguras à meia ultura obtidas para estes picos, 0,50 u.m.a. e 0,56 u.m.a., mostram que a resoluçất $m / \Delta m$ para estes aglomerados é de 1800 e 1600 , respectivamente. 

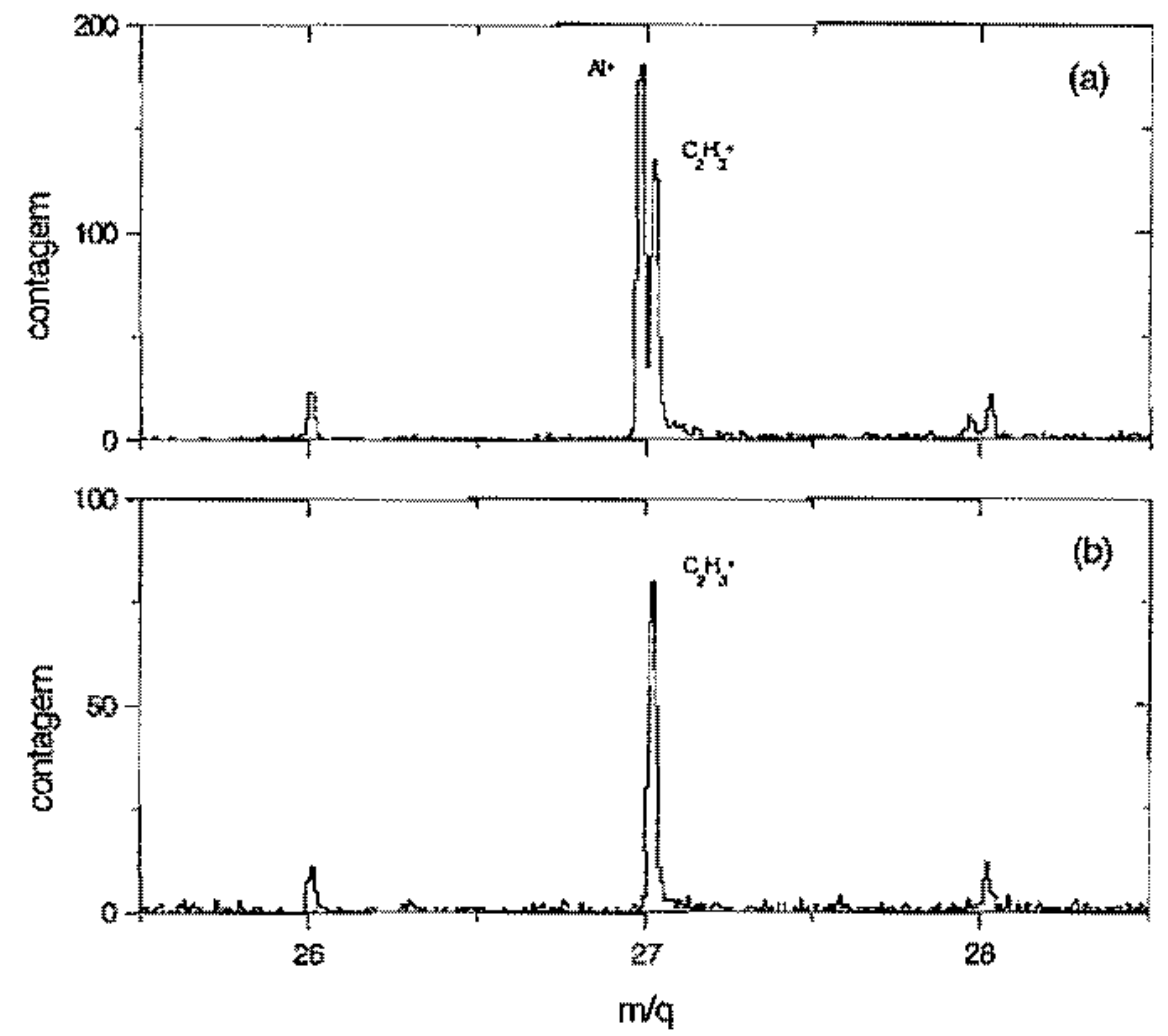

Fig. 5.14 - Resoluçäo do espectrometro ma regiäo de pequenas massas. bn (a) picos

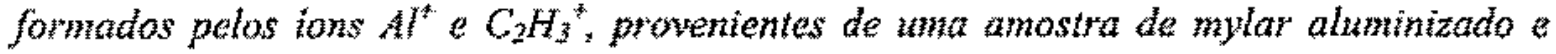
saparados po* $\mathrm{Am}=0,04 \mathrm{~J}$ uma.; $\mathrm{em}$ (b) a amostra, recoberta por sacaroze $\left(\mathrm{C}_{12} \mathrm{H}_{22} \mathrm{O}_{\mathrm{H}}\right.$ ), teve o pico de $\mathrm{Al}^{+}$eliminado. 

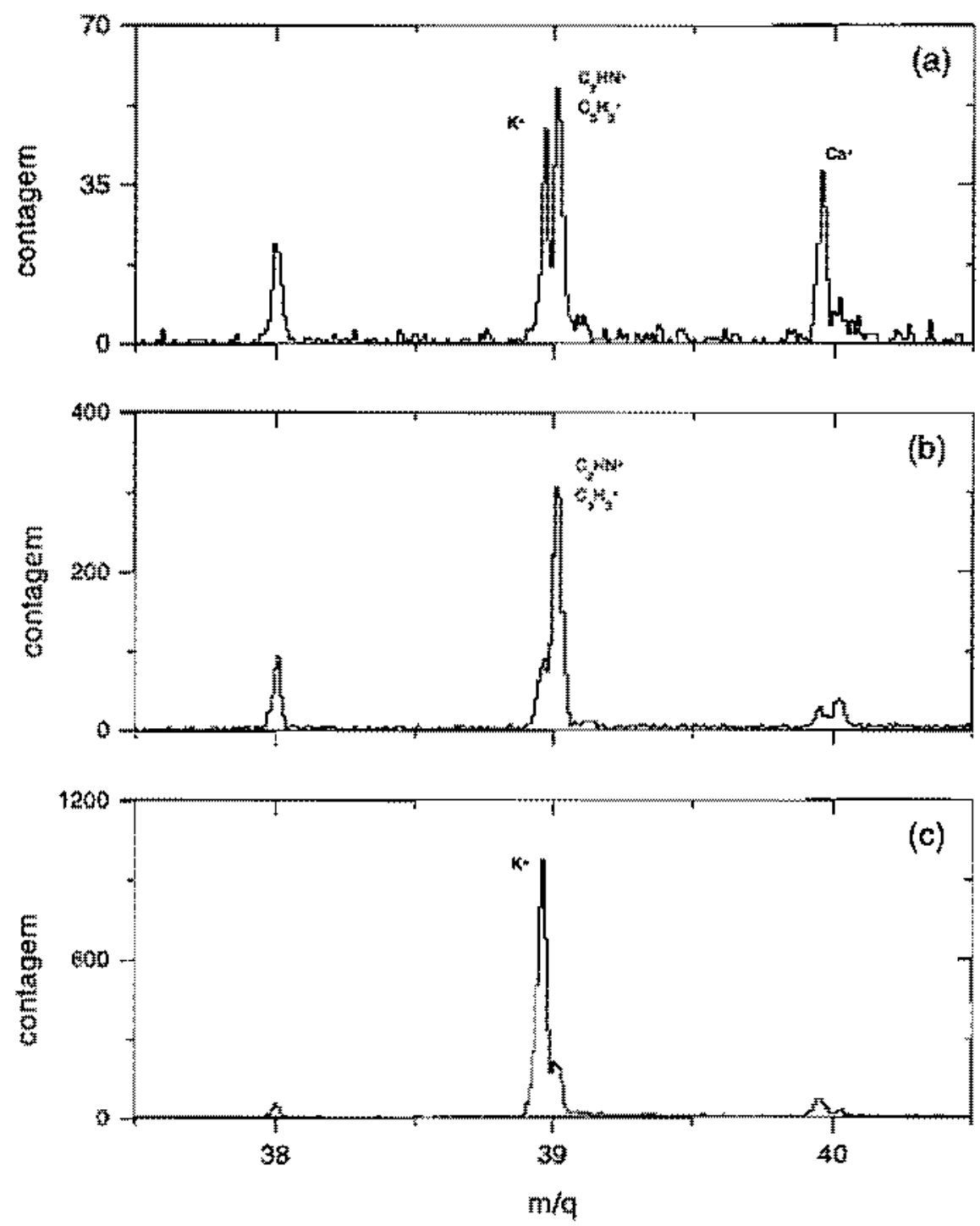

Fìg. 5.15 - Resolução do espectrôneiro na regiăo de pequenas massas. Em (a) picos formados por ions $\mathrm{K}^{+}$e por ions $\mathrm{C}_{2} \mathrm{HN}^{+}$e $\mathrm{C}_{3} \mathrm{H}_{3}{ }^{*}$, provententes de uma amostra de valina sobre nitrocelulose, estäo separados por $\mathrm{Am}$ …0,0.5 u.m.a.; em (b) a amostra lavada com agua destiada, teve o pico de $K^{+}$praticamente elminado em (c) a amosma, após a depostça de uma soluçấo de Kl, apresenta novamentu o pico de $K^{*}$. 

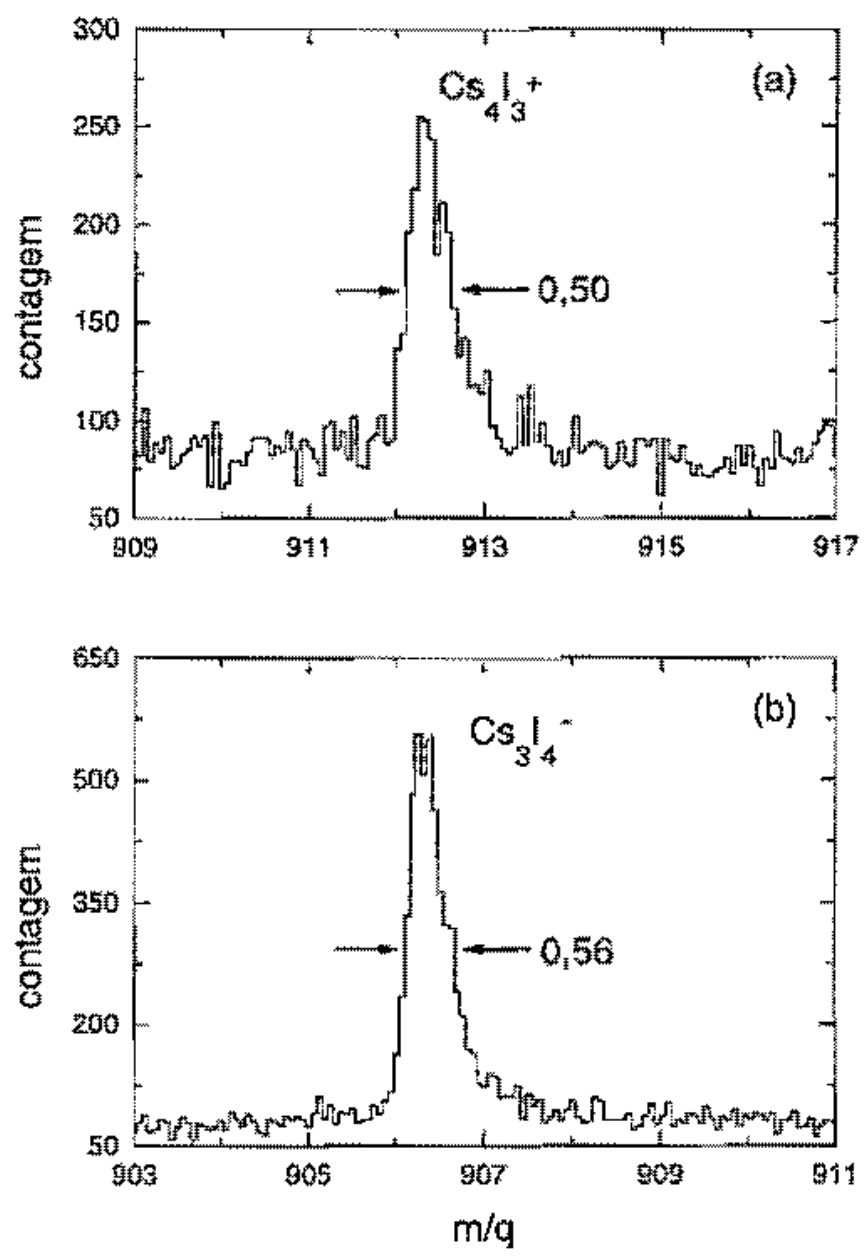

Fig. 5.16 - Picos correspondentes aos aglomeratos fontcos de tha amostra te Csl para tensôes de acelenaçăo de $\pm 18 \mathrm{kV}$, la) $\mathrm{Cs}_{4} \mathrm{I}_{3}^{+}$com $\mathrm{m} / \mathrm{mm}=1600$ e (b) $\mathrm{Cs}_{3} \mathrm{I}_{4}$ com $m / \Delta n=1800$. 


\subsection{Transmissẫo e Cuia Eletrostático de Particulas}

\subsubsection{Transmissão dos lons Secumdazios}

Para estudar o comportamento da transmissão dos lons secundários através do espectrômetro de massa foram feitas medidas das intensidades de alguns lons, normalizadas em relação ao número total de eventos que dispararam o sistema de aquisição de dados. Foram analisados os íons $\mathrm{H}^{-}, \mathrm{T}, \mathrm{CsI}_{2}{ }^{-}$e $\mathrm{Cs}_{2} \mathrm{I}_{3}{ }^{-}$provenientes de uma amostra de $\mathrm{CsI}$ evaporada sobre um substrato de Kimfol recoberto por 500 A de ouro. Nestas medidas a tensão de aceleraçäo foi variada de $-1,5 \mathrm{kV}$ a $-18 \mathrm{kV}$, sendo una espectro de massa obtido para cada tensầo. A mig. 5.17 apresenta os resultados obtidos para os quatro fons,

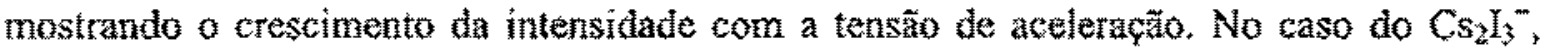

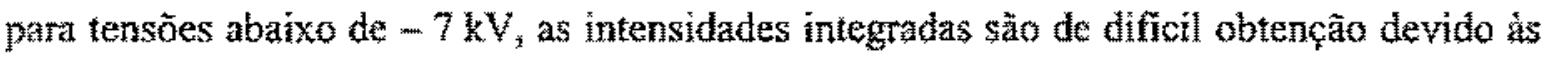
baixas razões sinal-ruido para este ion, o mesmo ocorrendo para o I' e o $\mathrm{CsI}_{2}{ }^{-}$em tensōes abaixo de $-2,5 \mathrm{kV}$.

O feixe de íons provenientes da amostra possui um formato cônico, cuja abertura angular depende das componentes radial e axial da velocidade dos lons secundários. Sendo

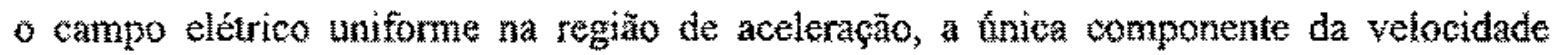

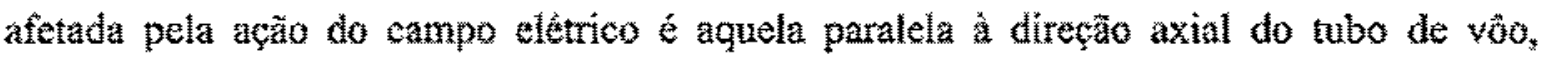
ficando a velocidade radial inalterada durante todo o pereurso do ion. Dessa forma, quando a intensidade do campo elétrico bumentada, a velocidade axial aumenta, provocando a diminuição da abertura angular do cone. Isto faz com que uma maior quantidade de fons seja transmitida e colida com a superficie do detector, explicando o comportamento observado na Fig. 5.17. Quando a área da secção transversal do cone é menor que a área do detector, todos os ions podem ser detectados, não sendo mais observados acréscimos na intensidade dos lons com o aumonto da tensão de aceletação. Tal condiçăo aparentemente nầo fol alcançada para o conjunto de ions estudados, uma vez que năo é observada uma tendência de saturaça nas intensidades integradas dos lons.

A condição que deve ser satisfeita para que os íns tmitidos da amostra possam ser transmitidos até o detector é dada pela relação: 


$$
v_{0} \operatorname{sen} \theta_{0} \leq \frac{R_{3}}{T}
$$

onde $v_{n}$ e a velocidade inicial do ín, $\theta_{\hat{f}}$ o seu ângulo de emissão em relação à normal da superficie da amostra, $T$ o seu tempo de vôo e $R_{d}$ o raio do detector.

Utilizando o programa SMION ${ }^{25}$ para modelagem de campos eletrostáticos, símulaçôes de trajetórias de ions de $\mathrm{H}^{*}$ atravessando o espectrômetro de massa desde a região da amostra até a porção final do tubo de vôo foram realizadas. Na Fig $\mathbf{5 . 1 8}$ são apresentados os resultados dessas simulą̧oes, sendo os ions de $\mathrm{H}$ emitidos da regiäo central da superficie da amostra, com energias iniciais de $3,5 \mathrm{eV}$, ângulos de emissão variando de $-80^{\circ} \mathrm{a}+80^{\circ}$, em passos de $20^{\circ}$, e a tensões de aceleraçằo de $-4 \mathrm{kV},-12 \mathrm{kV}$ e $-18 \mathrm{kV}$. Detalhes das porçâes inictal e final do espectrômetro de massa tambẻm sâo mostrados, sendo possivel acompanhar o estreitamento do cone com o aumento da tensão de aceleraçầo dos ions. Em $-4 \mathrm{kV}$ alguns íons näo consegrem alcançar o final do tubo de vôo, colidindo com sua parede. Em $-12 \mathrm{kV} \mathrm{e}-18 \mathrm{kV}$ todos os fons simulados chegam ao final do tubo, sendo a eventual deteç̧ão dependente do raio do detector.

A influência da geometria do sistema e da distribuição de energias iniciais dos ions na transmissão do espectrômetro de massa foi simulada com auxilio de um programa desenvolvido em linguagem FORTRAN77, onde as posições iniciais de emissão dos íns $\left(x_{n}, y_{\theta}\right)$, seus ângulos $\left(\theta_{0}, \phi_{0}\right)$ e suas energias iniciais $E_{\theta}$ são obtidos por sorteios. A distribuição das posiçöes iniciais é suposta uniforme, podendo ocorrer em qualquer ponto da superficie da amostra de raio $R_{a}=5 \mathrm{~mm}$ e os ângulos $\theta_{a} \odot \phi_{n}$ podendo assurnir valores de 0 a $\pi / 2$ e de 0 a $2 \pi$, respectivamente. As energias iniciais são sorteadas adotando-se uma distribuifão normal, com valor médio $\left\langle E_{\theta}\right\rangle$ e desvio padrão $\sigma=\left\langle E_{v}\right\rangle / 2$. Após o sorteio, 0 ion atravessa o sistema segundo trajetórias calculadas por suas equaçōes de movimento. No final do percurso, a posiçăo radial $r$ do ín em relação ao eixo do tubo é comparada com o

25 Idaho National Engineering Laboratory EG\&G Idaho Inc, Idaho Falls, ID 83415 , EUA. 
raio do detector $\left(R_{d}=10 \mathrm{~mm}\right)$, sendo considerada uma transmissâ bem sucedida aquela em que $r<k_{a}$

Várias simulaçōes foram realizadas para lons de diferentes energias médias iniciais e tensôes de aceleraçăo varianto de $1,5 \mathrm{kV}$ a $20 \mathrm{kV}$. Na Fig. 5.19 são apresentadas as razốes dadas pelo número de hons transmitidos em relaçẵo ao número de ions emítidos da amostra $\left(N / N_{0}\right)$. Neste caso, os resultados independem da massa do hon, una vez que a posiçäo radial dos lons no final do tabo de vôo de comprimento 4 é dada peta relação:

$$
y=d \operatorname{sen} \theta\left(\frac{E_{n}}{q^{v}}\right)^{\psi^{z}}
$$

As diferenças entre os vărios tipos de fons devem se tomar aparentes se os modelos usados nas simulaçốcs forem modificados com a introdução das distribuições angulares e de energias iniciaís mais condizentes com as dos próprios ions. Por exemplo, no caso do $\mathrm{H}^{\prime}$ medidas indicam que este ion possui tama distributęo angular do tipo $\cos ^{1 / 2} \theta$, com um ẫngulo médio de emissão $<\theta=36^{\circ}$, e para o lon de $\mathrm{Cs}^{+}$ebservada uma distribuicăo angular do tipo $\cos ^{3} \theta, \operatorname{com}<\theta=27^{\circ}$ [Bat94].

A Fig. 5.19 mostra o gradual aumento do numero de ions que alcançam o detector com o aumento da tensăo de aceleraçĩo, similarmente aos resultados apresentados na Fig. 5.17. Entretanto, uma comparaçäo direta cntre os dois rçultados näo pode ser feita, uma vez que as intensidades integradas obtidas experimentalmentz dependem, além do efetito da tensão de aceleraçăo, das contribuiçổes relativas à eficiência da dessorçăo pelos lons primários, à transmissão da grade de acaleração e à eficiência do detector Stop. Para tensões th ordem de $18 \mathrm{k}$, os resultados das simulaçöes indicam que são transmitidos, artavés do sistema, cerca de $50 \%$ dos fons com energitas médias entra 3 eV e 4 eV $75 \%$ com energias medias entre $1 \mathrm{eV}$ e $2 \mathrm{eV}$, que corresponderiam às transmissoues do $\mathrm{H}^{*} \mathrm{e}$ " que possuem energias dentro destas faixas, segundo dados encontrados na literatura [Bet94]. 

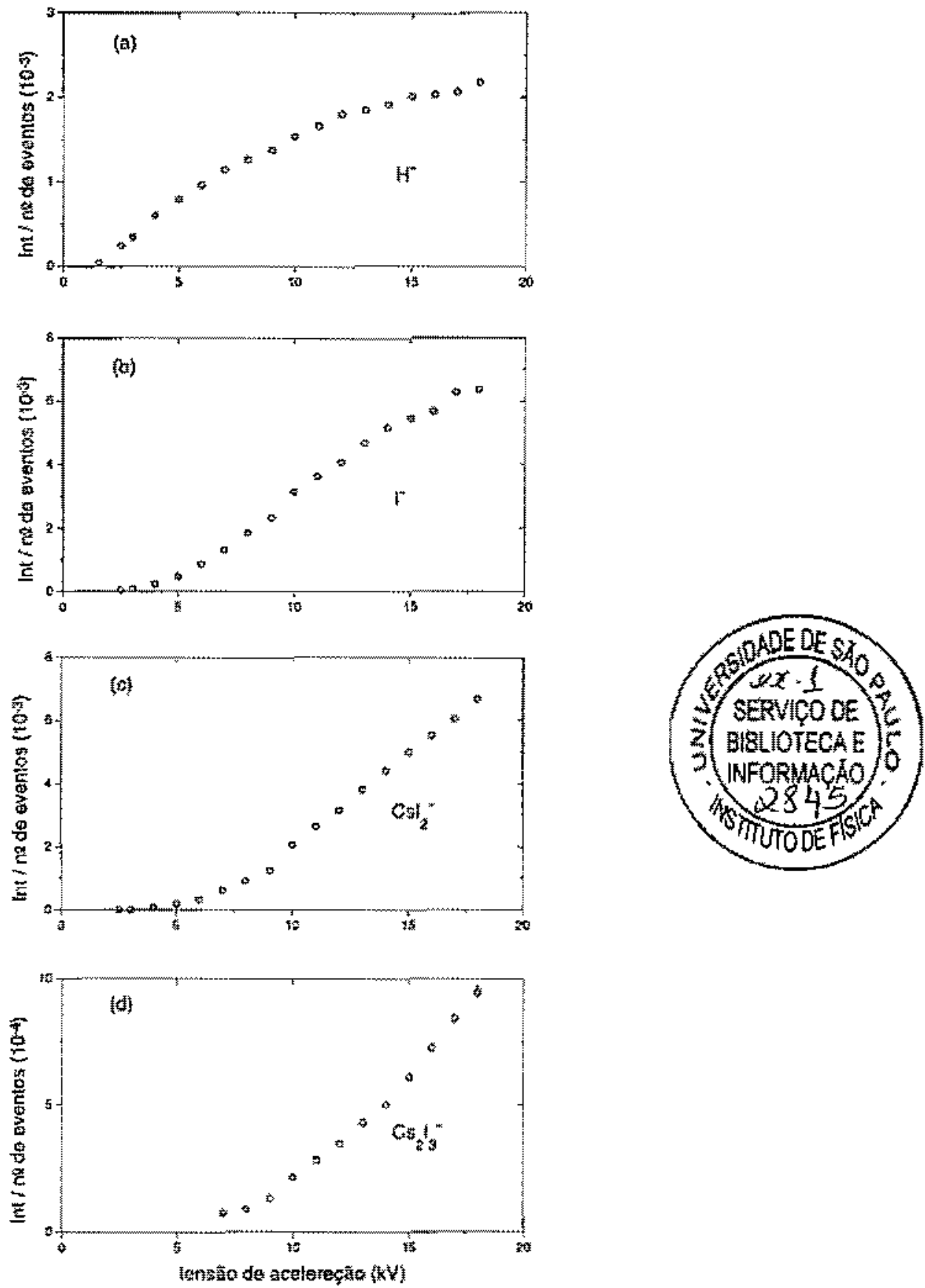

Fig. 5.17 - Comportamento das intensidades integnadas xos ions $H^{-}$(a), $I^{\prime}(b), C s l_{2}^{-}$(c) e

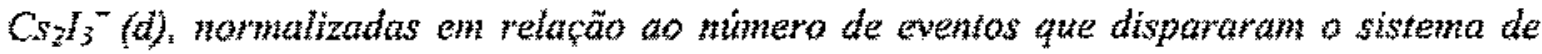

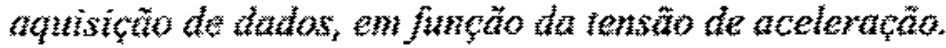


$-4 \mathrm{kV}$

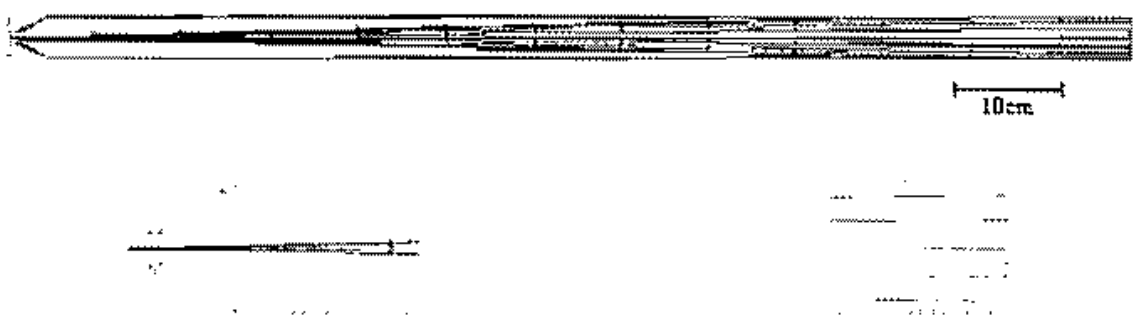

(a)

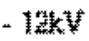

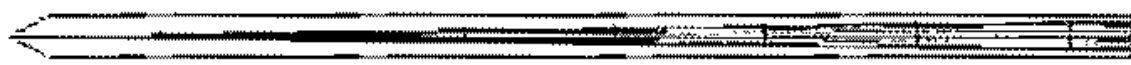

(b)

- I 3 然

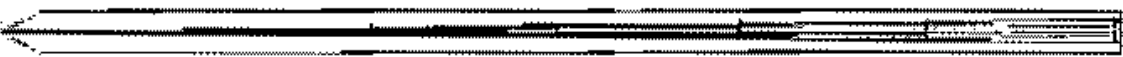

(c)

Fig. 5.18 - Resultados de simulaçös realizadas com o programa SHMON de trajetónas de tons de $H$ emitidos da superficte de uma amosta, com angulos de anissäo de - $80^{\circ}$ a $+80^{\circ}$ e energias inciais de $3,5 \mathrm{~g}$, para tensöes de aceleraça do $-4 \mathrm{kV}(\mathrm{a}),-12 \mathrm{kV}(\mathrm{b}) \mathrm{e}$ $-18 \mathrm{kl}(\mathrm{c})$ 


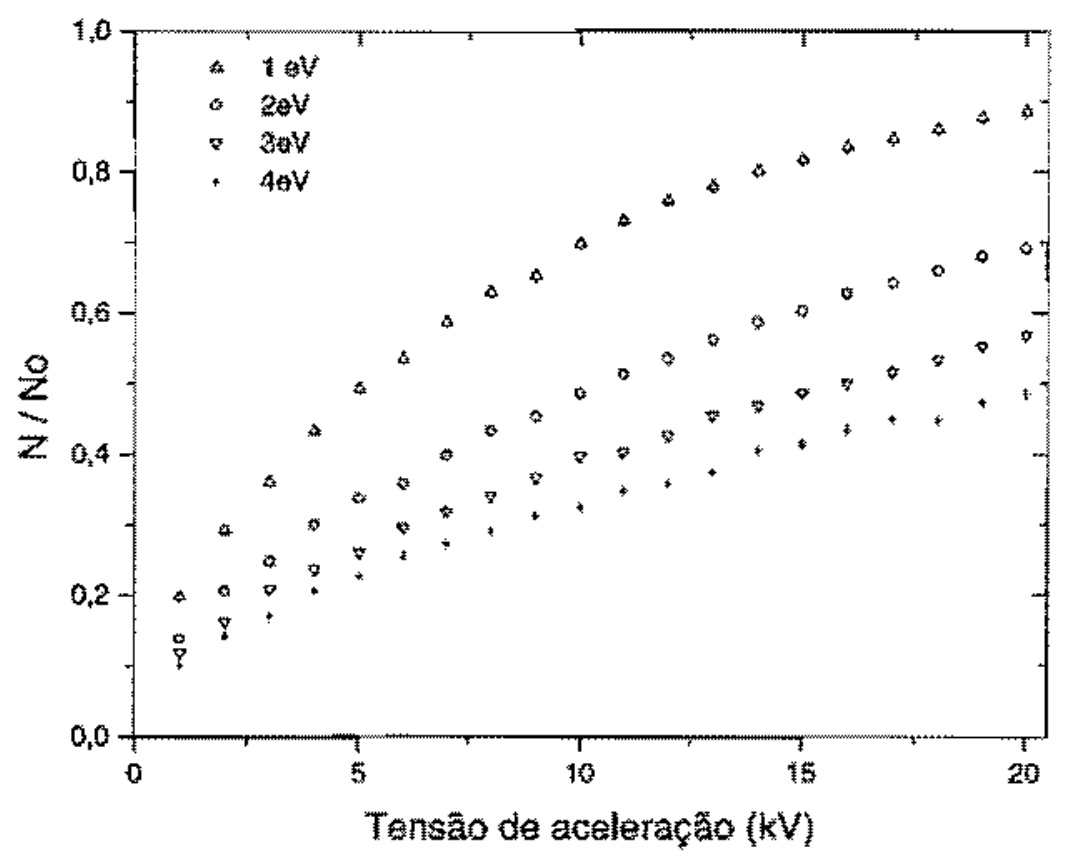

Fig. 5.19 - Fraçâo de hons transmitidos pelo espectrômetro de massa em fthçấo da tensäo de aceleraçăo, sujeitos a influências da geometria do sistema e das energias iniciais, obtidas por simulações computacionats. 


\subsubsection{Guia Eletrostático de Partículas}

O espectrometro de massa utiliza um dispositivo que permitc aumentar a transmissão dos lons secundảrios atraves de seu interior, chamado guia eletrostático de particulas (gep), cuja utilizaça em sistemas de tempo de vô foi introduzida por Oakey e Macfarlane [Oak67]. Conforme a descriçäo mecânica no item 3.3 , gep é constituído por dois cilindros metálicos concêntricos, um deles sendo o tubo de vô e o outro um fio de tungstênio rccoberto com ouro, havendo antre os dois uma diferença de potencial $V_{a}$, cuja polarizaçäo depende da carga los ions que se quer transmitir.

A funçăo do gep é fazer com que os ions presentes no interior do tubo fiquem aprisionados em órbitas espirais, devido to campo elétrico radial ali existente, sejam transmitidos ate a ragiāo de deteçăo. Na Fig. 5.20 é apresentada a geometria do sistema para um ion viajando no interior do gep em um instante de tempo qualquer, com velocidade $\eta$, direcionada segundo os angulos $\theta$, medido am relą̧ăo à normal do plano $x y$, e $\phi$, medido em relação ao plano $y z$. A componente da velocidade paralela a fio $v_{z}$ não é alterada pelo campo clétrico nessa regiäo, sendo responsavel pelo transporte do ín até o final do tubo. A componente peppendicular de velocidade $v_{p}$ cstả relacionada com o movimento espiral do ion ao redor do fis:

$$
y_{p}=v \operatorname{sen} \theta
$$

A "energia orbital efetiva" do ion em coordenadas cillindricas é dada pela relação:

$$
E_{e j}=\frac{m r^{2}}{2}+\frac{L^{2}}{2 m r^{2}} U(r)
$$

onde $L=m m^{2}$ d é o módulo do momento angular do lon em relação ao tixo do tubo de vôo. 


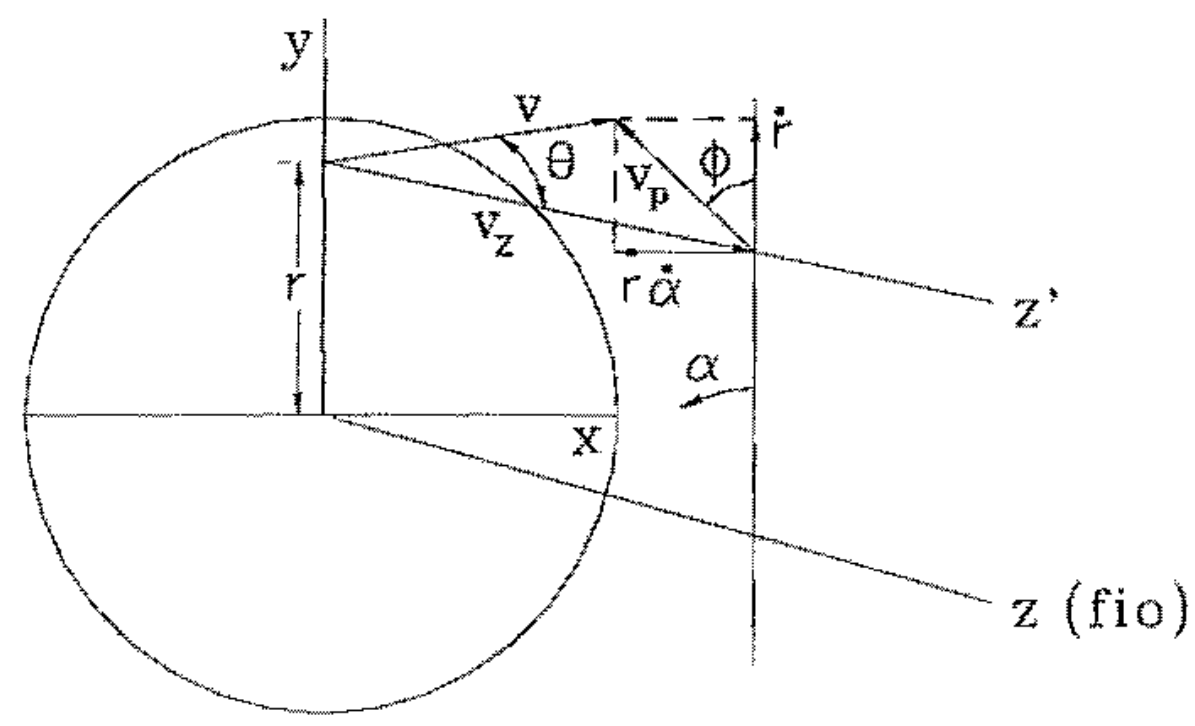

Fig. 5,20 - Ceometria do guma eletrostático de pantculas. Em um instante quataner, a won encontrazze a uma disiancia $r$ do fio, possuindo velocidade v e fazendo um ângulo $\theta$ com a totmal wo plano $x y$ e bcon o plano yz fadaptado de [Oak67]).

Nesta configuraçăo, a energia potencial para um ion posicionado a uma distância do fio no interior de um gep infinito, e dada por [Oak67]:

$$
U(r)=-G\left|V_{0}\right| \frac{\ln (r / R)}{\ln (s / R)}
$$

onde $q$ é a carga do ion, $s$ o rajo do nio e $R$ o rato do tubo.

Uma vez que nầo há torques agindo sobre os lons em relaçẫo ao eixo do tubo na regiâno de aceleração no interior do gep, pela conservaçäo do momento angular o termo dependente de $l^{2}$, na equação 5,15 , pode ser escrito como: 


$$
\frac{L^{2}}{2 m r^{2}}=E_{0} \operatorname{sen}^{2} \theta_{0} \operatorname{sen}^{2} \phi_{0}\left(\frac{r_{0}^{2}}{r^{2}}\right)
$$

onde $E_{a}$ a energia inicial do ion, $\theta_{0}$ e $\phi_{0}$ são os seus ângulos de temissão na superificie da amostra e ria a sua posiçẩo radial.

Para que um ín não colida com as paredes do tubo e com o fio, sua energia inicial Ea deve respeitar a seguinte condiçã̃o [Dav88]:

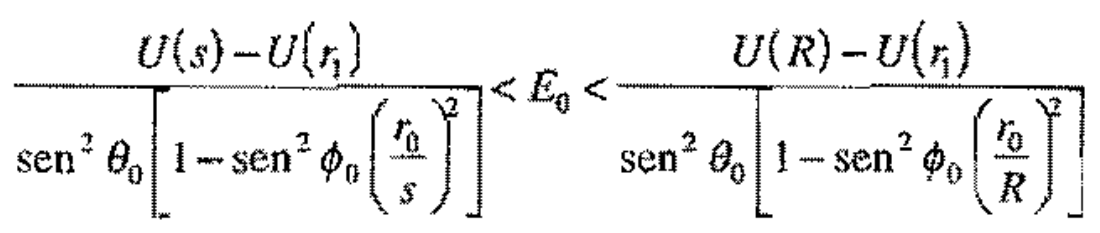

sendo $U(r)$ a energia potencial do ion ato entrar no gep.

Este resultado advém da utilização da conservaçăo de energia e tas condiçồ para a ocorrência, ná órbita do ion, de um apogeza e um perigen $(\dot{t}=0)$, com ratos iguais a $R$ e $s$, respectivamente.

As equaçöes de movimento dos ions podem ser obtidas por meio da Lagrangiana do sistama escrita em termos dos parânetros acima descritos, conforme cálculos feitos por Oakey el al. [Oak67]:

$$
\begin{aligned}
& \ddot{r}=\frac{A_{1}}{r^{3}}+\frac{A_{2}}{r} \\
& \dot{x}=\frac{A_{1}^{1 / 2}}{r^{2}}
\end{aligned}
$$


sendo

$$
\begin{aligned}
& A_{1}=r_{0}^{2} v_{p}^{2} \operatorname{sen}^{2} \phi \\
& A_{2}=\frac{q V_{0}}{m \ln (s / R)}
\end{aligned}
$$

Entretanto, as equaçōes 5.19 e 5.20 nẫo podem ser integradas, näo sendo possivel obter expressões analíticas para $r(t)$ e $\alpha(t)$. Para o cálculo dessas grandezas é necessário utilizar técnicas de cálculo numérico, como realizado por Hooverman [Hoo63] e Oakey [Oak67].

As trajetórias do ions sob a influência do gep foram simuladas com o auxilio do programa SIMION. Os resultados dessas simulaçōes são apresentadas na Fig. 5.21, Nestas simulações dois ions $\mathrm{H}$ partern de posiçōes simétricas em relação ao centro da amostra, con energias iniciais de $3,5 \mathrm{eV}$ e ângulos de emissăo de $\theta_{0}=36^{\circ}$ e $\hat{\phi}_{6}=20^{\circ}$, estando o gep a uma tensão de $\div 15 \mathrm{~V}$ e tensôes de aceleraçằo de $-100 \mathrm{~V},-3 \mathrm{kV} e-8 \mathrm{kV}$, Os valores para $E_{0}$ e $\theta_{0}$ utilizados nestas simulaçoes representam os valores médios dessas grandezas encontrados na literatura [Bet94]. Na figura são tambẻm apresentados detalhes da porção inicial do tubo de vôo e as projeçōes das trajetónias dos ions no final do tubo sobre o plano xy. Nestas projeçôes, é observado que, com o aumento da tensão de aceleração, o ion não consegue executar vários periodos de rotaçăo em torno do fio, ficando pouco a pouco a projeçäo de sua trajetória sem o padrão de pétalas observado no caso da tensão de $-100 \mathrm{~V}$.

Para estudar o comportamento do gep em função de sua tensão de operação e da tensăo de aceleraçăo dos íons secundários, espectros de massa foram obtidos para uma amostra de Csl. A Fig. 5.22 apresenta as intensidades dos picos dos íons $\mathrm{H}, \mathrm{r}$ e $\mathrm{CsI}_{2}{ }^{-}$ nomalizadas em relação à intensidade desses picos sem o gep em operação. Foram utilizadas variações da tensão do gep de $+5 \mathrm{~V} a+50 \mathrm{~V}$ e tensões de aceleração de $-3 \mathrm{kV}$ a $-18 \mathrm{kV}$.

Ao se utilizar o gap em tensões de aceleração elevadas, o efeito do estreitamento radial do feixe de ions provoca a diminuiçäo do número de íns que somente poderiam ser transmitidos com o auxilio do gep. Este efeito pode ser observado na Fig. 5.22, mostrando 
que para uma tensäo do gep fixa, o sel ganho diminui com o aumento da tensầ de aceleraçäo.

Uma maior eficiência do ganho do gep é notada a baixas tensões de aceleração, a $-3 \mathrm{kV}-4 \mathrm{kV}$, para o $\mathrm{H}^{-}$comparativamente aos fons de $\mathrm{I}$ e $\mathrm{Csl}_{2}{ }^{-}$. Tal comportamento pode ser atribuido às energias inicizis dos ions que, sendo maior para o $\mathrm{H}^{m}$, faz com que as suas trajetónas fiquem maił dispersas, possibilitando a açäo do gep sobre uma população mais numerosa de ions.

Part tensões de aceleração maís elevadas o ganho do gep praticamente se iguala para todos os tons, uma vez que a componente axial da velocidade $v_{z}$ extromamente grande, mascarando o efeito da velocidade radial. Nas medidas analisadas, observa-se que para tensỏes de aceleraçăo entre $-12 \mathrm{kV}$ e $-18 \mathrm{kV}$ ogep possibilita um aumento no valor da intensidade da ordem de $50 \%$

Da mesma maneira que no item anterior, ganho do gep foi modelado por meio de simulações dus trajetóntas dos ions emitidos da superficie da amostra, passando pela etapa de aceleração e alcançado o início do gep, que transmite os lons ate a regĩo do detector. Para isso, um novo programa foi desenvolvido, em linguagem FORTRAN77, onde são

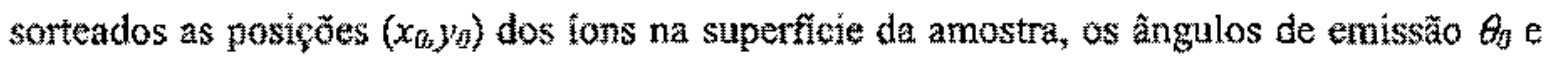
$\phi_{n}$ e a energia inicial $E_{q}$, exta última artir de uma distribuição do tipo normal com valor

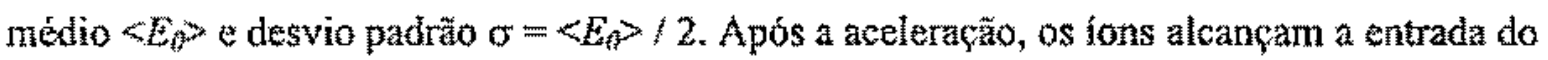

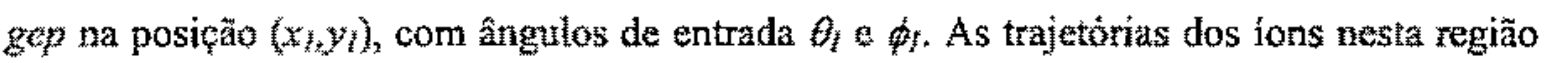
\$ăo calculadas ponto a ponto, por meio de integração mumérica da equação 5.19 , utilizando a técnica desenvolvida por Verlet [Al89], onde a componente radial da trajetória, no instante $(1+8 \mathrm{t})$, e dada por:

$$
n(t+\delta t)=2 n(t)-n(t-\delta t)+t(t) \delta t^{2}
$$

Este resultado é obtido tomando-se as expansões em série de Taylor das posiçoes radáta $r(t+8 t)$ e $r(t-8 t)$, somando-as e considerando apenas os termos até segunda ordem. 
Durante a simulação são testadas as condiç̧es de contomo geométricas do sistema, sendo verificato, em cada instante, se há colisäo do ion com as paredes do tubo ou com o fio do gep. Ao final do trajeto é determinado se o ín alcança o detector.

Na Fig 5.23 sã̃o apresentadas projeçöes no plano xy de duas trajetóriłs para lons de H“ calculadas com o programa desenvolvido, ilustrando a capacidade do gep em transmitir os ions até o detector. Os lons săo acelerados com tensões de $-500 \mathrm{~V} e-3 \mathrm{kV}$ estando o gep a $+20 \mathrm{~V}$. A circunferencia incluida na figura representa o naio do detector $(10 \mathrm{~mm})$ instalado no final do tubo.

Os resultados das simulaçổes para fons de $\mathrm{H}$ - I" são comparados com os dados obtidos experimentalmente na Fig* 5.24. As simulą̧óes reproduzem o comportamento do ganho do gep em funçäo de sua tensão, bem como com a tensăo de aceleraçẵo. Entretanto, as simulaçoes fornecem valores supeñores de $\mathrm{N} / \mathrm{No}$ em telação aos dados experimentais, sendo maiores as discrepâncias para baixas tensợes de aceleraçẫo.

Uma possivel explicaçăo para este resultado é o uso de um nodelo ideal para o potencial do gep, que náa leva em consideraçăo os possiveis desvios das trajetórias dos íns nas partes inicial e final do dispositivo, devido às deformaçoes nas linhas de campo eletrostático. Com auxilio do programa SMION é possivel modelar um gep mais realístico e observar as deformaçồ das equipotanciais nestas regiôes, como no exemplo da Fíg 5.25 , Devito a estas perturbaçôes, um ín é acelerado nas proximidades da entrada do gep, e desacelerado em sua saida.

Para um futuro aperfeiçoamento da simulaçăo, arq̧uivos poderão ser gerados com 0 programa SIMION, contendo uma matriz de pontos com o mapeamento do potencial nas porçöes inicial e final do geg, e usados como arquivos de entrada do programa para o călculo das trajetorias dos fons nestas regiões. 


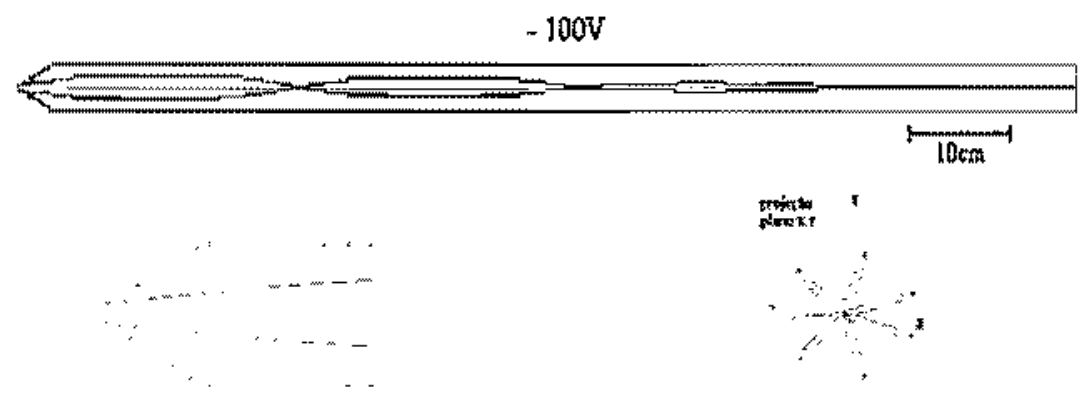

(a)

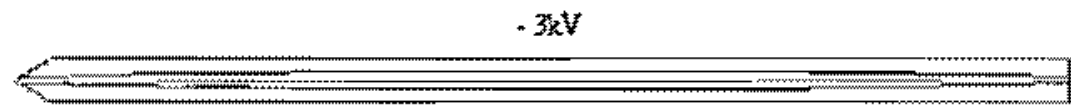

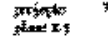

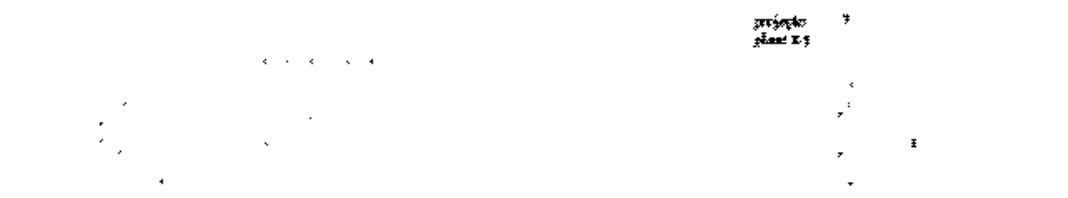

(b)

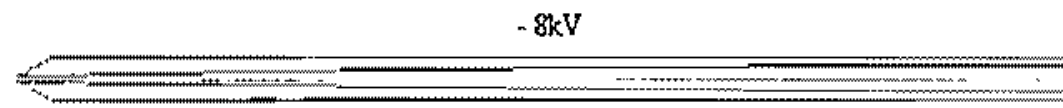

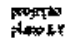

(c)

Fig. 5.21 - Träetotas de lon $H$ simuladas con o programa SMMON Os tons HT säo

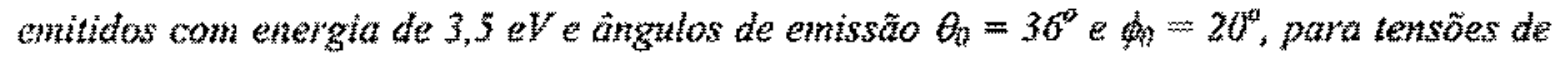
$-100 \mathrm{~V}(a),-3 k \mathrm{~V}$ (b) $-3 k \mathrm{~V}$ (c) Nos detalhes são apresentados, a esquerta, a ponça inicial do tubo de vốo e, à direita a projeçào no plano xy das trajetónias no final do tubo. 

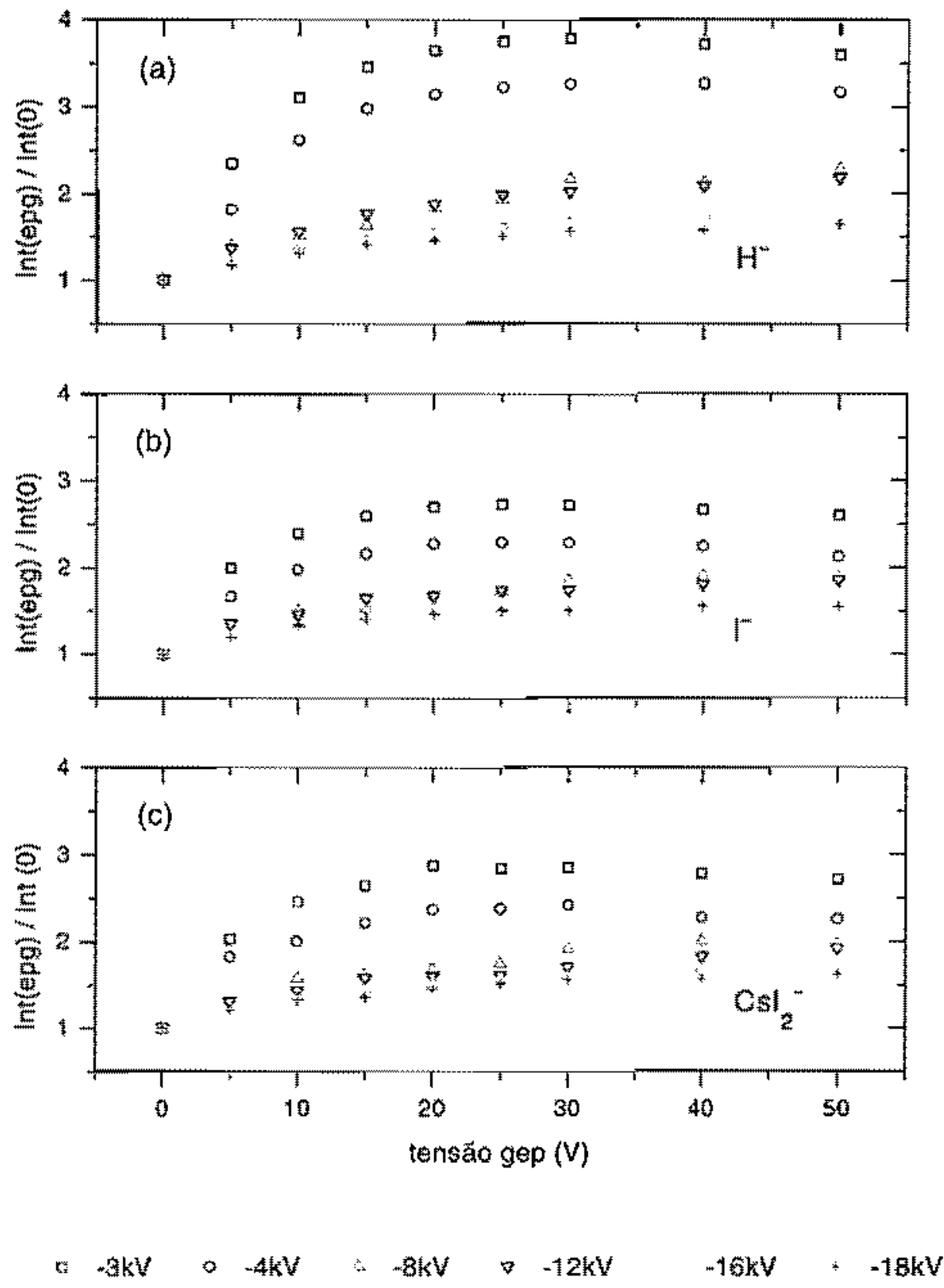

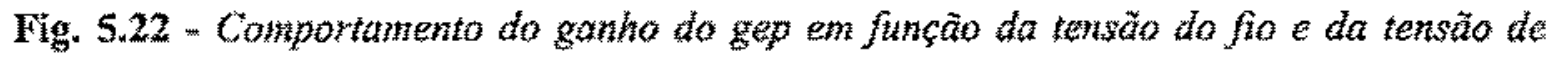

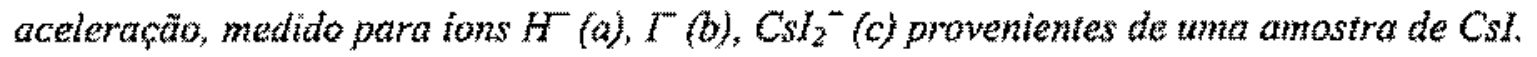




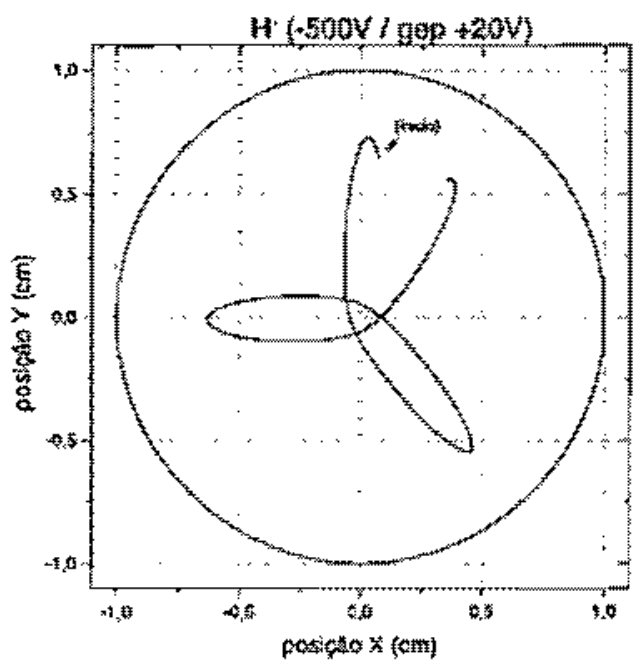

(a)

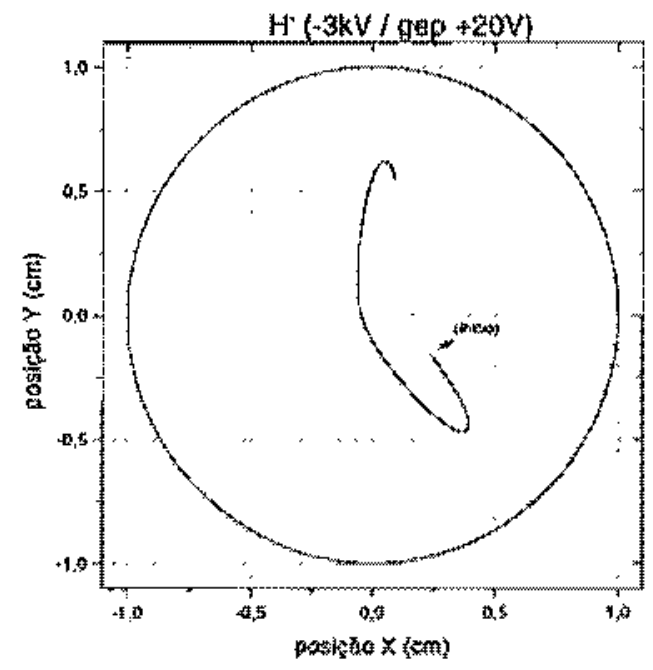

(b)

Fig. 5.23 - Projeçoes das trajetórias no plano xy de lons $y^{2}$ com enengia inicial de 3,5 el.

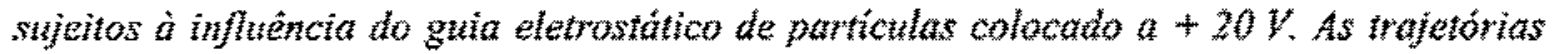
são abtidas por integração numérica das equaçös de movimento. 

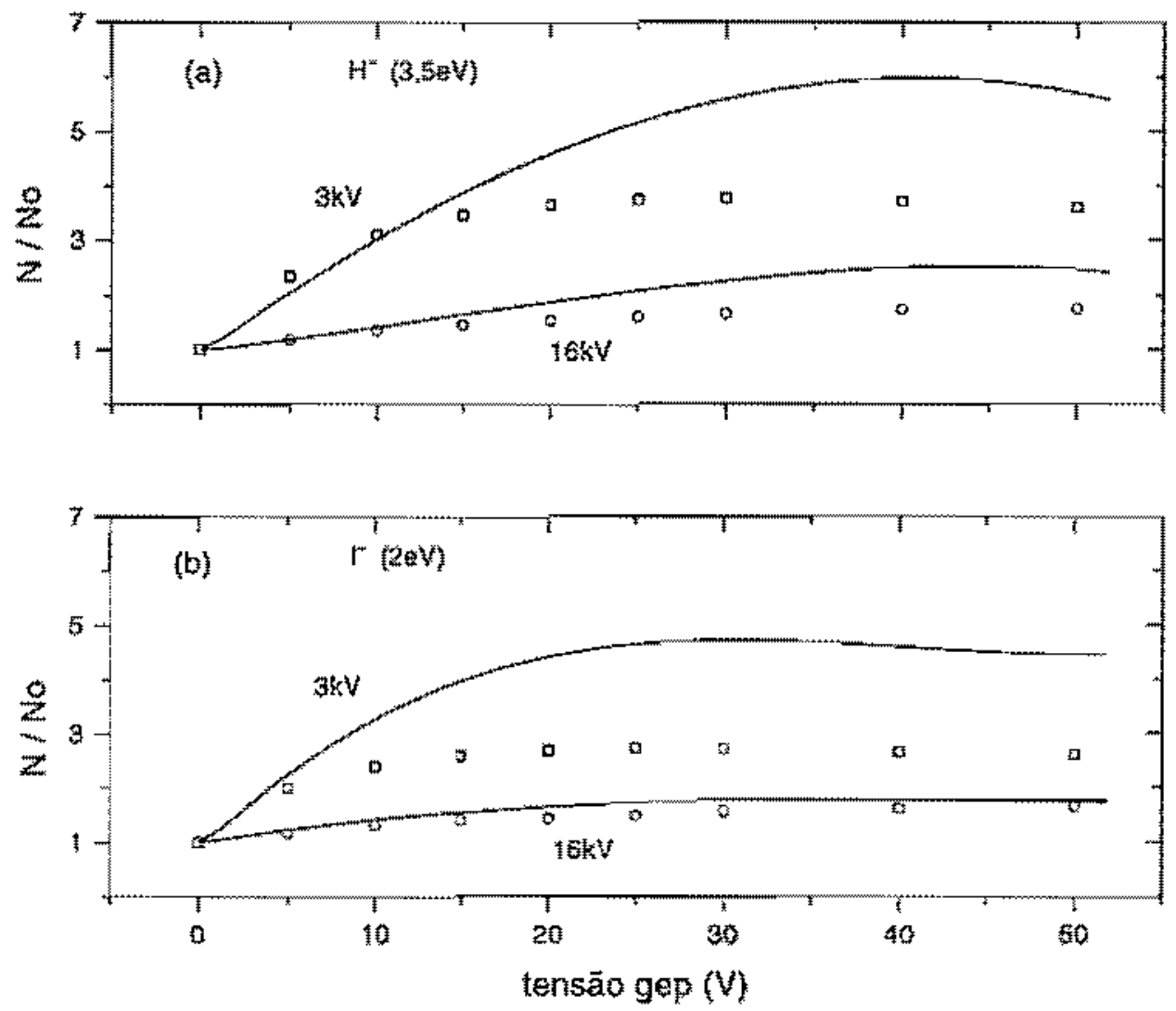

Fig. 5.24 - Comparação dos resultados experimentais do ganho do gep com as obtidos por simulações (curvas continutas), para os ions $H$ (a) e T (b). 


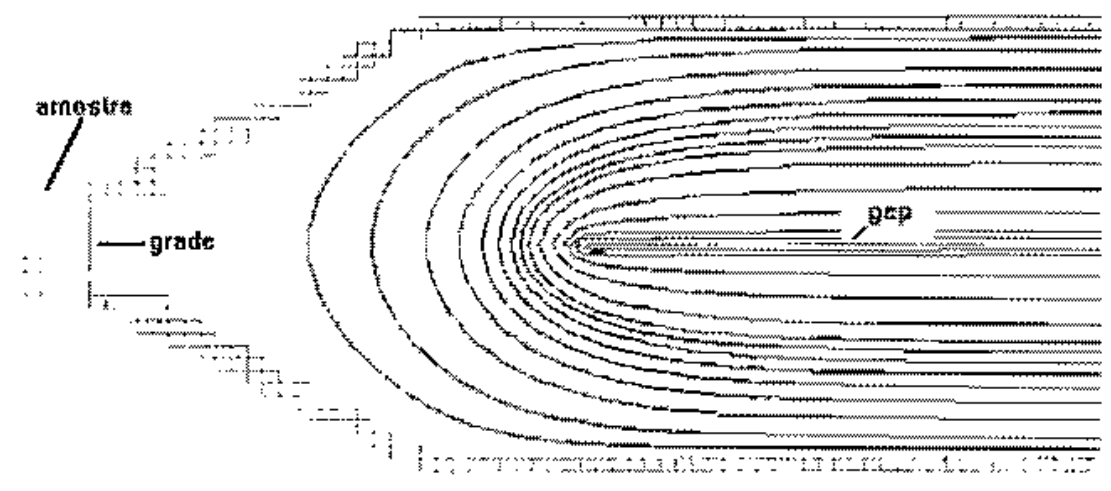

Fig. 5.25 - Detalhe da porcão intcial do tubo de vôo mostrando as deformacóes nas eqüipotenciais devido a efeitos de borda do gep de dimensäo finita. 


\section{Análise do Peptídeo \%-GIutamil-S-Metilcisteina}

Em colaboraçăo com o Departamento de Alimentos e Nutriçẫo Experimental da Faculdade de Ciências Farmacêuticas da USP e com o Departamento de Bioquímica do Instituto de Química da USP foi analisado o peptideo Y-glutamil-S-metilcisteina $\left(\mathrm{CaH}_{16} \mathrm{O}_{3} \mathrm{~N}_{2} \mathrm{~S}\right)$ de massa 264,30 u.m. com o espectrômetro de massa por tempo de vô. $\mathrm{O}$ interesse no asudo desse peptideo sulfurado não-protéco reside no fato de o mesmo estar presente, em quantidade variável, en diversas sementes de leguminosas comestiveis, incluindo o feijăo, e ser suspeito de causar efeitos tóxicos semelhantes aos descritos para a S-metilcisteína [Gia98].

Uma soluça da amostra foi gotejada sobre um substrato de Mylar aluminizado de 1,5 fim de espessura, formando, após a sua secagen, um depásito de 40 nmoles do material. A seguir, amostra foi introduzita no espectrometro de massa analisada por um periodo de 5 horas a uma tensăo de aceleragäo de $+10 \mathrm{kV}$. A Fig. 6.1 (a) apresenta o espectro de massa obtido a Fig.6.1 (b) mostra em detalhe a regiăo de interesse, onde foram indentificados alguns dos prováveis ions formados pela amostra. Na Tabela 6.1 estão listados os ions identificados e suas respectivas massas medidas, tendo sido utilizados para a calibraçio os picos dos ions $\mathrm{H}^{*}, \mathrm{H}_{2}{ }^{*}$ e $\mathrm{Na}^{+}$, não apresentados no spectro, e as massas calculadas pelas formulas associadas aos tons.

Após esta primeira andiliș a amostra foi retirada do espectrômetro e sobre ela foram gotejados 5 all de uma soluçằo de $\mathrm{H}_{2} \mathrm{O}_{2}(30 \%)$, com a intençâ้o de provocar a oxidação do material e mostrar a possibilïdade da técnica na análise de produtos resultantes de reaçoes químicas realizadas "in situ”. A Fig. 6.2 (a) apresenta o espectro de massa obtido apos tum periodo de análise de 2 horas a Fig. 6.2 (b) mostra em detalhe a regiâo de interesse. Na Tabela 6.2 estão listados os tons prováveis e as massa calculadas pela calibraçẫo por suas formulas. Apos o processo de oxidaçă os picos formados pelos lons $(\mathrm{M}+\mathrm{H})^{+},(\mathrm{M}+\mathrm{Na})^{+},(\mathrm{M}+2 \mathrm{Na}-\mathrm{H})^{+}$e $(\mathrm{M}+3 \mathrm{Na}-2 \mathrm{H})^{+}$foram praticamente eliminados, restando apenas as formas oxidadas e aparecendo com maior intensidade o pico de $(\mathrm{M}+\mathrm{Na}+2 \mathrm{O})^{+}$. 


\begin{tabular}{cccc}
\hline Ion Provavel & Massa Calculada & Massa Medida & $\Delta \mathrm{m}$ \\
\hline$(\mathrm{M}+\mathrm{H})^{+}$ & 265,31 & 265,30 & 0,01 \\
$(\mathrm{M}+\mathrm{O}+\mathrm{H})^{+}$ & 281,303 & 281,269 & 0,034 \\
$(\mathrm{M}+\mathrm{Na})^{+}$ & 287,29 & 287,30 & $-0,1$ \\
$(\mathrm{M}+\mathrm{Na}+\mathrm{O})^{+}$ & 303,285 & 303,260 & 0,025 \\
$(\mathrm{M}+2 \mathrm{Na}-\mathrm{H})^{+}$ & 309,272 & 309,277 & $-0,005$ \\
$(\mathrm{M}+\mathrm{O}+2 \mathrm{Na}-\mathrm{H})^{+}$ & 325,267 & 325,266 & $-0,001$ \\
$(\mathrm{M}+3 \mathrm{Na}-2 \mathrm{H})^{+}$ & 331,22 & 331,24 & $-0,02$ \\
$(\mathrm{M}+2 \mathrm{O}+2 \mathrm{Na}-\mathrm{H})^{+}$ & 341,262 & 341,256 & 0,006 \\
$(\mathrm{M}+\mathrm{O}+3 \mathrm{Na}+2 \mathrm{H})^{+}$ & 347,25 & 347,29 & $-0,004$ \\
\hline
\end{tabular}

Tabela 6.1 - Massas tos provaveis long positivos (a.m.a.) provenientes de uma amosta de

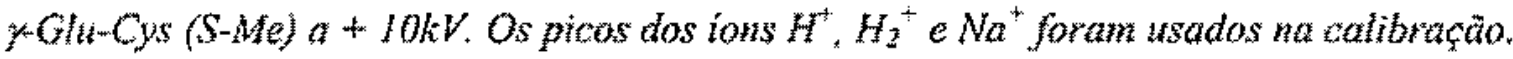

\begin{tabular}{cccc}
\hline Ion Provavel & Massa Calculata & Massa Medida & $\Delta \mathrm{m}$ \\
\hline$(\mathrm{M}+\mathrm{O}+\mathrm{H})^{+}$ & 281,30 & 281,34 & $-0,04$ \\
$(\mathrm{M}+\mathrm{Na}+\mathrm{O})^{+}$ & 303,28 & 303,30 & $-0,02$ \\
$(\mathrm{M}+\mathrm{Na}+2 \mathrm{O})^{+}$ & 319,28 & 319,22 & 0,06 \\
$(\mathrm{M}+\mathrm{O}+2 \mathrm{Na}-\mathrm{H})^{+}$ & 325,27 & 325,28 & $-0,01$ \\
$(\mathrm{M}+2 \mathrm{O}+2 \mathrm{Na}-\mathrm{H})^{+}$ & 341,26 & $341,2 \mathrm{I}$ & 0,05 \\
$(\mathrm{M}+\mathrm{O}+3 \mathrm{Na}-2 \mathrm{H})^{+}$ & 347,25 & 347,30 & $-0,05$ \\
\hline
\end{tabular}

Tabela 6.2 - Massas dos provavets ions posituves (1.m.a.) provenientes de uma amostra de $\gamma-G h-\mathrm{Cys}$ (s-Me), após axidaçäo com $\$$ th de $\mathrm{H}_{2} \mathrm{O}_{2}(30 \%), \mathrm{a}+10 \mathrm{kV}$. Os picos dos tons $\mathrm{H}^{+}$, $H_{2}^{*}$ e Na foram usados na culbraçấo. 

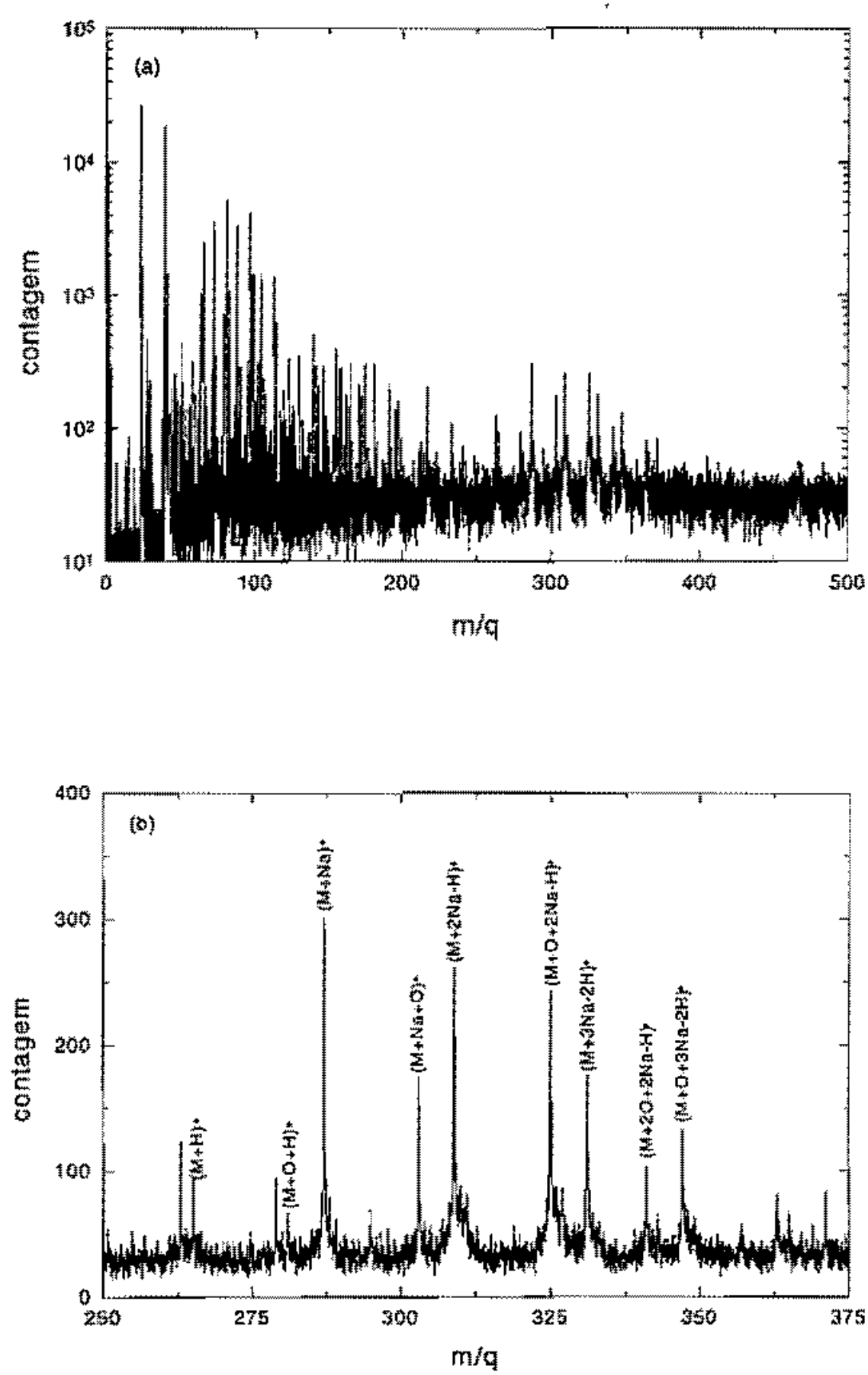

Fig. 6.1- (a) Espectros de masssa de uma amostra de yGitu-Cys (S-Me) depositada sobre um substrato de mylar aluminizado, a uma tensão de $+10 k \mathrm{k}$. Em (o) detalhe da região de interesse. 

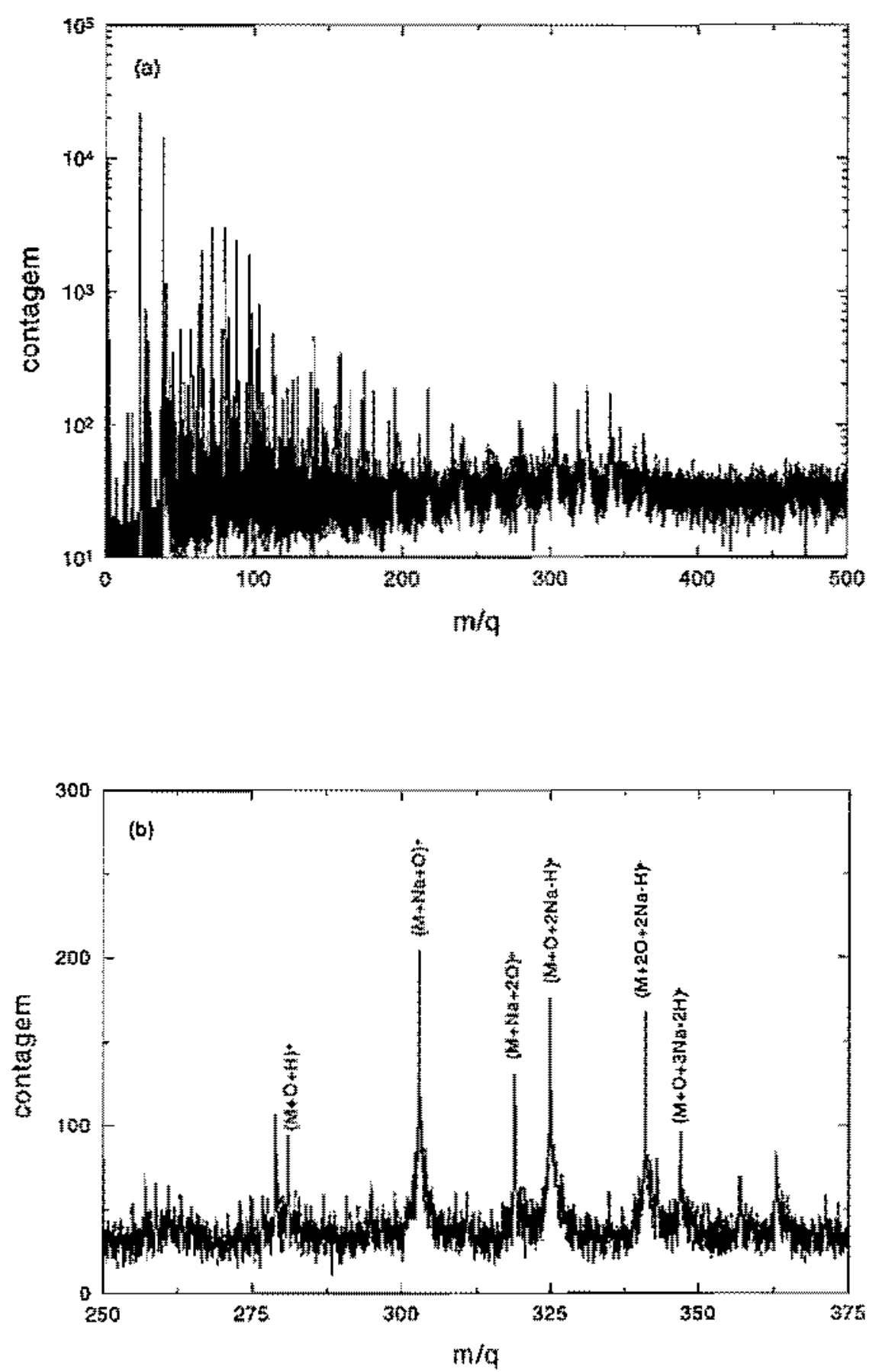

Fig. 6.2- (a) Espectro de masssa de uma amostra de †Glu-Cys (S-Me) após sua oxidaçăo "in situ" com $5 \mathrm{H}$ de $\mathrm{H}_{2} \mathrm{O}$ ( $(30 \%)$, a uma tensăo de $+10 \mathrm{kV}$. Em (b) detalhe da negiäo de interesse. 


\section{Conclusốes}

Este trabalho consistiti no desenvolvimento de um espectrômetro de massa por tempo de vô que utiliza a técnica de dessorção ionização de molteulas por bombardeamento de íons rảpidos. Sua realização possibilitou uma visão geral das vatrias etapas ligadas a um projeto na área de instrumentaçăo, desde a sua concepcão até os testes de caracterizaça do equipamento.

Numa primeira etapa foram feitos a montagem e testes de estanqueidade da câmara de vácuo do sistema, que alcançou uma pressano final de $2 \times 10^{-7}$ tor a $3 \times 10^{-7}$ torr. Em seguida, foram executados as montagens e ajustes das partes mecânicas internas de movimentaça do porta-amostras e da fonte radioativa, como também testes de isolamento elétrico desse conjunto. Finalizadas as montagens, foram instalados o tubo de vô com 0 guta eletrostático de particulas es sistemas de deteção.

Apos esta fase preliminar, seguiu-se uma serie de medidas para o ajuste da eletrônica associada a instrumento, o que permititu um entendimento das capacidades e limitaçòes do sistema de aquisição de dados.

Nos estudos que se seguiram, amostras-padrão foram analisadas para a

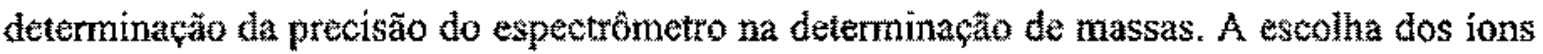
para a calibração dos espectros deve ser feita de maneira criteriosa, sendo esta escolha dependente do tipo de amostra analisada. Entretanto, lons como $\mathrm{H}^{*}, \mathrm{~Hz}^{*}, \mathrm{Na}^{+}, \mathrm{H}^{-}, \mathrm{C}$ e $\mathrm{C}_{2} \mathrm{H}^{-}$, presentes na matoria dos espectros, são normalmente usados no processo inital de calibração, podendo ser realizados refinamentos, com atilização de outros íons identificados no espectro damosta.

No caso da amostra da CSI, as diferenças obtidas entre as massus medidas e as massas cafculadas pelas formulas yuimicas dos ions foram de 0,01 u.m.a., para a regiăo de masas de algumas t.m.a. até centenas de a.m.a, e de 0,1 u.m.a., para massas entre 500 u.m.a. e 1000 u.m.a. Os mesmos valores para as diferenças de massas foram encontrados no caso dos ions cmitidos de uma amostra do aminoácido fenilalanina.

Para os peptídeos Angiotensin 1 LHRH, a precista na determinação de suas massas ficou em tomo de l U.m.a. A distribuiçẩo isotópica dos elementos constituintes 
dessas molecoulas causam dificuldades na determinação de suas massas, devido à sobreposição de vários picos, não resolvidos pelo equipamento. Entretanto, os valores medidos das massas possuem precisão suficiente para o uso do instrumento na verificaçäo de possiveis fallas durante os processos de sintese de peptideos e proteínas.

O uso de amostras-padrão também possibilitou o estudo da resoluçẵo do espectrômetro de massu. No caso da amostra de $\mathrm{CsI}$ fö obtida uma resoluçẵo de $m / \Delta m=1600$ para o ion $\mathrm{Cs}_{4} \mathrm{I}^{+}(m=912,32 \pm 0,02$ u.m.a. $)$ e m/Am $=1800$ para o ion $\mathrm{Cs}_{\mathrm{y}} \mathrm{L}_{4}^{-}(\mathrm{m}=906,3 \mathrm{n} \pm 0,02$ u.m.a.). Tamberm foi estudado o comportamento da rasolução en funçăo da tensäo de aceleração dos ions secundários, tendo sído analisadas as possíveis fontes de sua limitaçăo. Foi visto que, para tensöes entre $2 \mathrm{kV}$ e $10 \mathrm{kV}$, a distribuiçă de velocidades iniciais dos íns uma das principais causas da limitaçăo da resolução do sistema e, para tensỏes acima de $10 \mathrm{kV}$, as perdas da resolugăo são associadas ao sistema eletrônico e a distribuiçă bitmodal de velocidades da fonte de ${ }^{23} \mathrm{Cf}$.

Na regiư de ions com pequena massa o espectrômetro mostrou ser capaz de separar pices com diferenças de massa de $\Delta m=0,041$ u.m.a., no caso de uma amostra constituída por uma folha de mylar aluminizado. Para a verificação da correta icientificação dos picos no espectro de massa da amostra, sacarose foi cepositada sobre o substrato de mylar, acentuando o pico de $\mathrm{C}_{2} \mathrm{H}_{3}{ }^{+}$. Tal procedimento exemplifica a possibilidade tessa técnica, que permite novas análises apos modificaçōes na amostra.

A transmissão do espectrơmetro foi estudada em função da tensẵo de aceleraçã̃o dos ions secundários e modelada com o auxilio de um prograna desenvolvido para simular as trajetórias desses ions, levando-se em conta a geometria do sistema. Das simulaçöes foi possivel concluir que, operando o espectrömetro a tensỏes de aceleraça da ordem de $18 \mathrm{kV}$, a transmissão de tons com energias iniciais métias entre 1 eV e $2 \mathrm{eV}$ é de $75 \%$ c con energias entre $3 \mathrm{eV}$ e $4 \mathrm{eV}$ é de $50 \%$. Nestes resultados não foram consideradas as eficiências de detecção e de produção de tons secundários da amostra pelos produtos de fissão.

Com o objetivo de aumentar a transmissão dos lons secundarios, foi instalado no tubo de vôo do espectrônetro de massa un guia eletrostático de panticulas (gep). 0 ganho da transmissắo também foi modelado com o uso de um programa desenvolvido para 
simular as trajetórias dos íons secundários sujeitos à açâo do gep, reproduzindo parcialmente o comportamento dos resultados experimentais. Nas medidas do ganho deste dispositivo, aumentos de 50 \% foram obtidos na transmissăo dos lons $\mathrm{H}^{-}, \mathrm{I}^{-}$e CsL- a uma tenstio de aceleraçäo de - $18 \mathrm{kV}$.

Como continuidade do trabalho está programada a inclusizo de uma conte de ionizaçăo por fốtons de ultravioleta para uso do espectrômetro de massa com a técnica MALDI [Lim98]. Para isso, uma janela de quartzo será instalada em uma das entradas laterais da câmara de vácuo, que permitirá a passagem de um pulso de laser para o interior do sistema. Deste modo, será possivel estender o limite de anảlise de massas para a faixa de $10^{4}$ u.m.a. Outra modificação necessátia para o uso dessa técnica é a instalação, no analisador de massa por tempo de vô, de um sistema de deflexăo de fons secundários para eliminar a interferência de lons de pequena masssa produztdos em grande quantidade pelo pulso do laser, prejudicando a deteç̧âo de ions de grandes moléculas. Para uso com a técnica MALDI, também seră desenvolvido um sistema de acuisiçắa de dados baseado em un digitalizador de pulsos (Transient Recorder).

Paralelamente a essas implementações, serão realizados estudos para a construção de um novo espectrômetro de massa possuindo um espelho eletrostático que permitirá medidas com resoluçäo em massa superior ầ do atual sistema [Hir98].

Alem dos esforẹos voltados à área de instrumentaç冖̆o, deverăo ser intensificados os intercambios com gnupos ligados à espectrometria de massa para a caracterização de bionolèculas. Nesse sentido, contatos estäo sendo feitos com grupos da Escola Paulista de Medicina (UNIFESP), do Instituto de Química da USP e da Faculdade de Ciências Farmacêtuticas da USP, tendo sido realizado, em colaboração com os dois últimos, um trabalho relacionado á análise do peptideo $\gamma$-glutamil-S-metileisteína. Como continuidade, um programa de estudos relativos à análise de substâncias clorofiladas extraidas da soja será realizado. 


\section{Referencins}

[A189]-M.P. Allen and D. I. Tildesley, "Computer Simulation of Liquids", Claredon Press, Oxford, UK, 1989.

[AN34] - Experiments in Nuclear Science - AN34 Laboratory Manual, EG\&O Ortec, 1984, EUA.

[Bar81] - Michel Barber, Robert S. Bordoli, R. D. Sedgwick and A. N. Tyler, I. C. S. Chem. Comm., (1981)325.

[Bea89] - R. C. Beavis, B. T. Chait, Rapid Commun. Mass Spectrometry, 3(1989)233.

[Bea90] - R. C. Beavis, B. T. Chait, Anal. Chem, 62(1990)1836.

[Bec69] - H. D. Beckey, J. Mass Spectrometry and Ion Physics, 2(1969)500.

[Ben]6]-A. Benninghoven, D. Jaspers and W. Sichtermann, Appl. Phys., 11/97693.

[Ber89] - T. Bergmann, T. P. Martin and H. Schaber, Rev. Sci. Instrum, 60(1989)347.

[Bet94] - Gerhard Betz, Karl Wien, Int. J. of Mass Spectrometry and Ion Process, 140(1994)1-110.

[Beu74]-R, J. Beuhler, E. Flanigan, L. J. Greene and L. Friedman, J, of the American Chemical Society, $96(1974) 3990$.

[Beu77] - R. J. Beuhler; L. Friedman; Int J. Mass Spectr. \& Ion Physics 23(1977)81.

[Bie92] - K Biemann, Annu, Rev. Biochem., 61(1992)977.

[Bit87] - I.s. Bitensky and E.5. Parilis, Nuclear Instr. and Methods in Physics Research B $21(1987) 26$.

[Brus7]-C. Brumée, Intmational Joumal of Masss Spectrometry and lon Process, $76(1987) 125$.

[Cha81] B. T. Chait, W. C. Agosta and F. H. Field, International Journal of Mass Spectrometry and Ion Physics, 39(1981)339.

[Cha82]-B. T. Chait, B. F, Gisin and F. H. Field, J, Am Chem. Soc., 104(1982)5157-5162.

[Chathe] - B. T. Chait and F. H. Field, Biochem. Biophys. Res. Commun, 134(1986)420. 
[Cho89]- Swapan K. Chowthury and Brian T. Chait, Analytical Biochemistry, $180(1989) 387-395$.

[Cle73]-H.G. Clerc, H.]. Gehrhardt, L. Richter \& K.W. Sehmidt; Nuclear Instruments and Methods, $113(1973) 325-331$.

[Cov90] - S. Cova and G. Ripamonti, Rev. Sci. Instrum. 61(1990)1072.

[Cov91]- S. Gova, M. Ghioni and F. Zappa, Rev. Sci. Instrum 62(1991)2596.

[Cov93] - S. Cova, M. Ghioni and F. Zappa and A. Lacaita, Rev. Sci. Instrum 64(1993)118.

[Dav88]-K.V Davis, E.F. da Silveira and E. A. Schweikert, Nuclear Instruments and Methods in Physics Research A273(1988)203.

[Dem9] - P. Demirev, G. Brinkmalm, D. Fonyö, Per Hảkanskon and B.U.R Sundquist, Int 1. Mass Spectrom. Ion Proc. 111 (1991)41.

[Ens89] - W Ens, B.U.R Sundqvist, Per Hảkansson, A. Hedin and G. Jonsson, Phys. Rev, B $39(1989) 763$.

[Ens92] - W. Ens, K. G. Standing and A. Verentchikov, "Digital and Analog Methods for Time of Flight Mass Spectrometry", Proceedings of the Intemational Conference on Instrumentation for Time of Flight Mass Spectrometry, LeCroy Corporation, Chestnut Ridge, New York, November 11-12, 1992, Editors George J. Blanar e Robert J. Cotter, 1992, pag. 137.

[Eri96]-J. Eriksson, P. Demirev, P. Håkansson, R. M. Papaleo, and B.U.R. Sundquist, Phys. Rev. B, 54(1996)15025.

[Fen91] - Catherine Fenselau, Annu. Rev. Biophys. Biophys. Chem. 20(1991)205.

[Gen88]-P. W. Geno, tese de doutorado, Departamento de Química, Texas A\&M Unversity, College Station, Texas, USA, 1988.

[Gen89]-1. W. Geno \& R. D. Macfarlane, Int I of Mass Spectr. \& lon Process $92(1989) 195$.

[Gey76] - C. Geyari, Vacuum, no.7, 26(1976)287.

[Gia98]-M. de L. R. Giada M. T. M. Miranda and U. M. L. Marquez, Food Chemistry $61(1998) 177$.

[Gib94]-D.K Gibson \& I.D. Reid; Joumal of Physics E: Scientific Instruments; $17(1994) 443$. 
[Hak92]-Per Hakansson, "Desorption Experiments on Organic Insulators with High Energy Particle Beams", em Fundamental Process in Sputtering of Atoms and Molecules - SPUT92, Matematisk Fysiske Meddelelser, 43(1992)593.

[Har90]-AIex G. Harrison e Robert J. Cotter, "Mathods of Ionization", Methods in Enzymology: Mass Spectrometry, Editor James A. McCloskey, Academic Press, Inc, New York, $193(1990) 1$.

[Hed87]-A. Hedin, P. Hâkansson e B. U. R. Suntgvist - International Joumal of Mass Spectrometry and Ion Process, 75(1987)275-289.

[Hel81] - O. A. M. Helene e V. R. Vanin, "Tratamento Estatístico de Dados em Física Experimental”, Ed. Edgar Blucher Ltda, São Paulo, Brasil, 1981.

[H1187]- John Chester Hill, Phd Dissertation, "Californim-252 Plasma Desorption Mass Analysis of Proteins Adsorbed on Polymer and Modiffed-Polymer Surfaces", Texas A\&M University, 1987, Texas, USA.

[Hil88]-M. Karas and F. H Hillenkamp, "Photochemical Reaction Pathways and their Relevance to Ultraviolet Laser Desorption Mass Spectra", em lon Formation from Organic Solids IV, editudo por A. Benninghoven, John Wiley 4 Sons, Now York, 1988, p. 103 .

[Hir98] - J. H. Hirata, comunicaçăo interna.

[Hof96] - E. de Hoffmam, J. Charktte V. Stroobant, "Mass Spectrometry - Principles and Applications", John Wley \&ons, New York, 1996.

[Hoo63] - R.H. Hooverman, J of Applied Physics 34(1963)3505.

[Jen90] - Keith R. Jennings and Gregory G. Dolnikowski, "Mass Analyzers", Methods in Enzymology: Mass Spectrometry, Editor Iames A. MoCloskey, Academic Pross, Ino. New York, 193(1990)37.

[Joh87] - R. E. Johnson, Int. Journal of Mass Spect. and Ion Proc., 78(1987)357.

[Joh89]- R. E. Johnson, B. Sunqvist, A. Hedin and D. Fenyo, Phys. Rey. B, 40(1989)49.

[Joh82]-R, E. Johnson and W. L. Brown, Nuclear Instruments and Medhods, $198(1982) 103$.

[Jon86]- G. P. Jonsson, A. B. Hedin, P. L. Hăkansson, B. U. R. Sundqvist, B. G. S. Säve, P. F. Nielsen, P. Roepstorf, K. E. Johansson, I. Kamensky and M. S. L. Lindberg, Anal. Chemistry $58(1986) 1084$ 
[Jom89]- G. D. Jonsson, A. B. Hedin, P. L. Hakansson, B. U. R. Sundquist, H. Bennich, P. Roepstorf, Rapid Commun. Mass Spectrom. $3(1989) 190$.

[Kno89] - F. G. Knoll- Radiation Detection and Measurement, John Wiley \& Sons, New York, second edition (1989).

[Koi91]-K. Koide, E.L.A. Macchione, M.A.L. Leite, J.H. Hirata, V. Stojanoff, A.C. Lanza, I.P. Cavalcante, F.T. Degasperi e O. Dietzsch, caderno de resumos da Escola Latino Americana de Física (ELAF91), Caxambú, Minas Gerais, 1991.

[Lims8] - E. L. Lima, "Desenvolvimento de um Espectrometro de Massa utilizando o Método MALOF", projeto de dissertação de mestrado, Instituto de Fisica, Unversidade de Sâ Paulo, São Paulo, 1998.

[Lan93] - A. C. Lanza, K. Koide, E.L.A, Macchione, J. H, Hirata, S.S. Vasconcelos e O. Dietzsch, XVI Encontro Nacional de Fisica da Matéria Condensada, Programas e Rastinos, p. 185, Caxambu, Minas Gerais, 1993.

[Luc87] - R. R. Lucchese, J. Chem. Phys-, 86(1987)443.

[Mac76]-R, D. Macfarlane and D. F. Torgerson, International Journal of Mass Spectrometry and Ion Physics, 21(1976)81-92.

[Mac83]-R. D. Macfarlane, Anal. Chem., 55(1983)1247A.

[Mac87] - R. D. Macfarlane and D. L. Jacobs, "Influence of Substrate on Kinetic Energy Distributions in ${ }^{252}$ Cf-Plasma Desorption Mass Spectrometry", Proceedings of the Fourth International Conference on Ion Fomation from Organic Solids (IFOS TV) - Mass Spectrometry of Involatile Material, Munster, Federal Republic of Gemany, September 21-23, 1987, Editor A. Benninghoven, pg. 71 .

[Mac94]-E. L. A. Macchione, K. Koide, J.H. Hirata, S.S. Vasconcelos, , C. Lanza, I.P. Cavalcante, F.P. Zandona e Dietzsch. Workshop sobre Métodos Avançados para Antistise Estrutural de Biomoléculas, caderno de resumos, p. 19, \$ăo Carlos, Sấo Paulo, 1994

[Mam73]-B.A. Mamyrin, V.I. Karataev, D.V. Shmikk, and V.A. Zagulin, Sov. Phys.JETP, 37(1973)45.

[Man90]-M. Mann, H. Rahbek-Nielsen and P. Roepstorff, "Practical Aspects of Calibration and Effect of Non-Protein Compounds on Spectrum Quality in Protein Analysis by PDMS", Proceedings of the Fifth Intermational Conference on Ion Formation from Organic Solids (IFOS V), Lövanger, Sweden, June 18-21, 1989, Editor A. Hedin, B. U. R. Sundquist, A. Benninghoven, (1990), p. 47. 
[Mc191]-Thomas Shane Mclntire - Msc. Thesis - High Performance ${ }^{252} \mathrm{Co}$ Plasma Desorption Mass Spectrometry - 1991 - Texas A

[MoN86]-Catherine J. MoNeal e Ronald D. Macfarlane, J. Am. Chem. Soc. $108(1986) 2132-2139$.

[Mos89]-R. Moshammer, R. Matthäus, K. Wien and G. Bolbach, "Energy and Angular Distribuitions of Secondary lons Ejected from Organic Solids by MeV Ions", Proceedings of the 5th International Conference on Ion Formation from Organic Solids (IFOS V), A. Hedin, B.U.R. Sundvist, A. Benninghoven editors, Lövanger, Sweden, 1989, Wiley, Chichester, 1990, p. 17.

[Mun66] - M. S. B. Munson e F. H. Field, Joumal of the Chemical Society, 88(1966)2621.

[Nic87]-P. F. Nielsen e P. Roepstorf, "Sensitivity as Function of Sample Preparation Technique in Plasma Desorption Mass Spectrometry", Proceedings of the fourth International Conference on Ion Fomation from Organic Solids (IFOS WV) - Mass Spectrometry of Involatile Material, Munster, Federal Republic of Gemany, September 21-23, 1987, Editor A. Benninghoven, pg. 87 .

[Oak67]-N.S. Oakey and R. D. Macfarlane, Nuclear Instruments and Methods $49(1967) 220$.

[Ove90] - A. Overberg, M. Karas, U. Bahr, R. Kaufinann e F. Hillenkamp, Rapid Commun. Mass. Spectrom. 5(1990)128.

[Owe92] - K. G. Owens and R. C. King, "Ion Flight Time Calculations and Instrument Design", em Proceedings of the International Conference on Instrumentation for Time-of- Flight Mass Spectrometry, Editores George J. Blanar e Robert J. Cotter, Lecroy Corporation, Chestmut Ridge, New York, 1092, USA.

[Pagl]- Paul D. Mudget - Phd. Dissertation * "Characterization of Ion Desorption and Decay in ${ }^{252}$ Cf Plasma Desorption Mass Spectrometry", 1991 - Texas A\&M University, USA.

[Pin93]- R. R. Pinho, Phł Thesiš "Estudo da Dessorçẫo lốnica Induzida pelo Impacto de lons Rápidos sobre Fenilalanina", Pontificia Universidade Católica do Rio de Janeiro, 1993.

[Pos78] - M.A. Posthumus, P.G. Kistemaker, H. L.C. Meuzelaar e M.C. de Brauw, Anal. Chem., $50(1978) 985$.

[Prigo] - D. Price and G.J. Milnes, Int. Joumal of Mass Spect. and Ion Proc, $99(1990) 1$. 
[Rei92]-C. T. Reirmann, "Theoretical Models for Sputtering and Desorption of BioOrganic Molecules under Collisional and Electronic Excitation by Ion Impact", em Fundamental Process in Sputtering of Atoms and Molecules - SPUT92, Matematisk Fysiske Meddelelser, 43(1992)593.

[Rig87] - F. Riggi, Nuclear Instruments and Methods in Physics Research B22(1987)588.

[Sig1]-E. F, da Silveira E. A. Schweikert, "Desorça de lons Induzida por Feixe de Particulas Carregadas. Mecanismos e Espectrometria de Massa." sumário de aulas ministrada na Escola Latino Americana de Fisica - ELAF91, Caxambu, Brasil, 1991.

[Sta92]-K. G. Standing, W. Ens and X. Tang, "Some Problems in Time-of-Flight Measurements", em Proceedings of the International Conference on Instrumentation for Time-of- Flight Mass Spectrometry, Editores George I. Blanar e Robert J. Cotter, Lecroy Corporation, Chestnut Ridge, New York, 1992, USA.

[Sun85] - B. Sunquist, A. Hedin, P. Hakkansson, L. Kamensky, M. Salehpour and G. Săwe, Int. J. of Mass Spect. and Ion Proc., 65(1985)69.

[Sun91]-B. U. R. Sundqvist, "Eletronic Sputtering of Large Organic Molecules and Its Application in Biomolecular Mass Spectrometry", sumário de aulas ministradas na Escola Latino Americana de Física - ELAF91, Caxambú, Brasil, 1991.

[Tor74]-D. F. Torgerson, R. P. Skowronski and R. D. Macfarlane, Biochemical and Biophisical Research Communications, 60(1974)616.

[Tsa99] - Anthony Tsarbopoulos, Peptide Research, $2(1989) 258$.

[Wai93] - Robin Wait, Methods in Molecular Biology, vol. 17, Spectroscopic Methods and Analyses; NMR, Mass Spectrometry and Metaloprotein Techniq̨ues. Editores C: Jones, B. Mulloy e A. H.. Thomas. 1993 Humana Press Inc., Totowa, NJ, USA.

[Wea91] - CRC Handbook of Chemistry \& Physics - First Student Edition, Robert C. Weast Editor, $3^{\mathrm{E}}$ Ediçẫ, 1991, CRC Preșs, USA.

[Wiz79]- J.L. Wiza, Nud. Instr. Meth. 188(1979)587.

[Yam88]-M. Yamashita I.B. Fenn, Phys. Chem, 88(1988)4451.

[Zie88]-J.F. Ziegler, J.P. Biersack e G. Cuomo, Programa TRIM 88, versão 4.4.

[Zub97]-R. A. Zubarev, P. Håkansson, B. U. R. Sunquist and V. L. Talrose, Rapïd Communication in Mass Spectrometry 11(1997)63-70. 